\title{
Impacto económico del Tren Crucero en las comunidades por las que transita. Caso: Nizag y Palacio Real
}

\section{Economic impact of the Cruise Train on communities, where it goes through. Case Study: Nizag and Palacio Real}

\author{
Katherine Toctaguano ${ }^{1}$ \\ 凶 Autor de correspondencia: katytoc-2689@hotmail.com \\ ${ }^{1}$ Universidad de Buenos Aires, Facultad de Ciencias Económicas. Av. Córdoba 2122. Buenos Aires, Argentina \\ Artículo original de la ponencia presentada en el IV CONGRETUR - "El impacto del turismo en el desarrollo del Ecuador", Universidad \\ Central del Ecuador, 21 al 24 de noviembre de 2018
}

\section{Resumen}

La necesidad que surge de las comunidades por lograr el bienestar a nivel social, económico y cultural, ha impulsado nuevas alternativas para lograr dichos objetivos, que ayuden al desarrollo local en las comunidades de mayor vulnerabilidad para poder ejecutar proyectos que contribuyan a dinamizar la economía local. En consecuencia, surge como alternativa viable el turismo comunitario, como factor que genere poblaciones autónomas en las que los beneficios sean equitativos para sus habitantes, produciendo impactos positivos a largo plazo. En el Ecuador se ejecutan proyectos que vinculan a poblaciones con altos índices de pobreza, para fomentar el desarrollo local de las mismas, tal como lo indica la última Constitución en vigencia que propone un Buen Vivir con la ayuda de los sectores público y privado. Es por eso que esta investigación surge con la finalidad de indagar cuáles son los verdaderos impactos socio-económicos que ha generado el proyecto estatal Tren Crucero como producto turístico en las poblaciones por las que transita con ayuda de datos cualitativos y cuantitativos referentes al objeto de estudio. Para la realización de la investigación se procedió a implementar encuestas y entrevistas a los principales actores involucrados en el estudio, resultados que indicaron falencias marcadas en los beneficios sociales y económicos de las poblaciones implicadas. Se obtuvo como conclusión que el desarrollo local en las comunidades es incipiente puesto que cada población se ha desarrollado de manera diferente y con distintos métodos; además, las instituciones estatales no han generado actividades contundentes que ayuden a las comunidades. Los proyectos estatales pueden y deben generar mejoras en los proyectos que se implementan en zonas vulnerables del país, ya que si la planificación, organización y ejecución son adecuadas puede llegar a ser una alternativa viable para el desarrollo local.

Palabras clave: Desarrollo local, Turismo comunitario, Zonas vulnerables, Economía comunitaria.

\begin{abstract}
New alternatives for local development in order to achieve social, economic, and cultural welfare arises from the need of communities. Consequently, Community Tourism emerged as a viable alternative, as a factor for generating autonomous communities with fair benefits for the population by implementing positive impacts in long-term. In Ecuador, some projects that deal with country town people with high poverty levels are developed for promoting their local development as it is stated by the latest approved Constitution that is currently in use and which proposes the Buen Vivir Plan with the assistance of the public and private sectors. This is why this research arises to focus on the real socio-economic impacts that have been originated by the Cruise Train State project as a tourist product in the country towns where this train goes. This investigation has been aided by qualitative and quantitative data about this topic. To carry out this research, some surveys and interviews were applied to the main stakeholders and the results showed great shortcomings of social and economic benefits in those groups.
\end{abstract}


As a conclusion, the local development of communities is not good enough since each country town has been developed in a different way and with different methods with which the state institutions have not generated significant activities that help those groups. The state projects should produce improvements in the plans that have been implemented in the vulnerable regions of the country, so if the planning, organization, and implementation of these projects are correct, these kinds of projects can be a viable alternative for the local development.

Keywords: Local development, Community tourism, Vulnerable zones, Community economy.

\section{Introducción}

La necesidad que surge de las comunidades a través del tiempo ha sido fundamental para buscar el bienestar a nivel social, económico y cultural, lo cual ha conllevado a que diversas organizaciones mundiales tomen cartas en el asunto y generen nuevas alternativas para lograr dichos objetivos. Estos procesos fueron conceptualizados en el desarrollo local, los cuales comienzan a ser aplicados en las comunidades de mayor vulnerabilidad con la ejecución de proyectos que ayuden a dinamizar la economía local. Razón por la cual surge como alternativa viable el turismo comunitario, como factor que genere poblaciones autónomas en donde los beneficios sean equitativos para sus habitantes, implementando impactos positivos a largo plazo.

En el Ecuador, al ser el primer país que formalizó una red de turismo comunitario conocida como Federación Plurinacional de Turismo Comunitario del Ecuador, y con base en lo dispuesto en la última Constitución que se encuentra en vigencia en la que propone dar un Buen Vivir a la población ecuatoriana, en especial a las más vulnerables, con ayuda de los sectores público y privado, surgen proyectos que vinculan a poblaciones con altos índices de pobreza, para fomentar el desarrollo local de las mismas. Justamente, esta investigación nace con la finalidad de indagar cuáles son los verdaderos impactos socio-económicos que ha generado el proyecto estatal Tren Crucero como producto turístico en las poblaciones por las que transita con ayuda de datos cualitativos y cuantitativos referentes al objeto de estudio.

La investigación tuvo como objetivo general, proponer lineamientos de operación del Tren Crucero que contribuyan al desarrollo local sostenible de las comunidades por las que transita. Y como objetivos específicos, analizar la gestión y operación turística de Ferrocarriles Ecuador; e, investigar el desarrollo del turismo en las poblaciones por las que pasa el Tren Crucero. La hipótesis planteada fue que la vinculación de comunidades a proyectos estatales, en este caso el Tren Crucero, como una alternativa viable, genera desarrollo local a través del involucramiento de distintos actores.

Para iniciar esta investigación se realizó la revisión de la bibliografía referente a conceptos relacionados con desarrollo, turismo sustentable, turismo comunitario y turismo ferroviario. El estudio de estos conceptos a nivel general ha despertado gran interés para su investigación, ya que con el transcurso del tiempo ha ido evolucionando y cambiando conforme las nuevas tendencias. Por ello, el punto de inicio de esta investigación es la comprensión de qué es el desarrollo local, cómo ha evolucionado y cuál es la importancia del mismo.

\subsection{Desarrollo local}

La terminología desarrollo local surge de la combinación de estos dos términos por lo que se abordará los conceptos de desarrollo y desarrollo local, los que se conceptualizan de la siguiente manera. Con respecto a desarrollo, Múnera (2007) afirma que "la definición de desarrollo a pesar de sus posibilidades semánticas, se construye a partir de otras nociones con las cuales se le relaciona y en algunos casos se le identifica; entre ellas se encuentran las nociones de evolución, crecimiento, riqueza, progreso" (p. 14). Es decir, como explica Juárez (2013) “El concepto de desarrollo ha sido utilizado en la mayoría de las ocasiones con una significación cualitativa. En el lenguaje común se emplea como sinónimo de crecimiento, y generalmente, aumento económico" (p. 10). La concepción de la terminología de desarrollo según Varisco (2008), "surge con fuerza en la década de los cuarenta, finalizada la segunda guerra mundial, y se vincula con la noción de progreso a través del crecimiento económico. A partir de entonces diversas teorías y modelos intentaron explicar la forma en que los países subdesarrollados podían acceder a la categoría de desarrollados, considerando en la mayoría de los casos como objetivo central el incremento de los bienes y servicios producidos a nivel nacional" (p. 16).

Con respecto a la categorización de países la autora Múnera (2007) aclara que, "como construc- 
ción teórica, con efectos políticos y semánticos para la población de distintos contextos, es importante destacar los conceptos de subdesarrollo, en vía de desarrollo y Tercer Mundo, que significa básicamente lo mismo y se refiere a los países que no cumplen con los parámetros de desarrollo" (p. 29).

En el ámbito político el desarrollo tomó gran importancia, lo que dio lugar a que se implementaran instituciones especializadas en estas cuestiones, por lo que se indica que: la invención del desarrollo necesariamente implicó la creación de un campo institucional desde el cual los discursos son producidos, registrados, estabilizados, modificados y puestos en circulación. Este campo está íntimamente imbricado con los procesos de profesionalización: estos constituyen un aparato que organiza la producción de las formas de conocimiento y el despliegue de formas de poder, relacionando unas y otras. La institucionalización del desarrollo tiene lugar en todos los niveles, desde las organizaciones internacionales y agencias de planificación nacionales en el Tercer Mundo, a las agencias de desarrollo local, los comités de desarrollo comunitario, las agencias voluntarias privadas y las ONGs (Picas, 1999, p. 48).

Recapitulando las conceptualizaciones, se manifiesta que el desarrollo constituye la evolución de las sociedades en los aspectos económico, social y cultural, es por ello que se crean diversas instituciones para la obtención de este propósito. "El desarrollo es un proceso de cambio estructural global (económico, político, social, cultural y del medio ambiente), tendiente a aumentar la calidad de vida de todos los miembros integrantes de la sociedad, de forma de alcanzar una más completa satisfacción de las necesidades colectivas básicas" (Casanova, 2004, p. 24).

\subsection{Desarrollo económico}

Después de analizar los diferentes conceptos referentes a desarrollo es oportuno también indicar la conceptualización acerca del desarrollo económico para enfocar de mejor manera este estudio. Para Casanova (2004) "el desarrollo económico sería, por tanto, un proceso de crecimiento y cambio estructural, en el que las formas de organización, el sistema de relaciones y la dinámica de aprendizaje juegan un papel estratégico" (p. 20) y asegura que se caracterizaría por la dimensión territorial, sobre todo por el hecho de que cada localidad o región es el resultado de la historia en la que se ha desarrollado el entorno institucional, económico y organizativo.

El Programa de Desarrollo Económico Local de la Organización Internacional de Trabajo (citado por Alburquerque, 2004b), considera al desarrollo económico local como "un proceso de desarrollo participativo que fomenta los acuerdos de colaboración entre los principales actores públicos y privados de un territorio, posibilitando el diseño y puesta en práctica de una estrategia de desarrollo común a base de aprovechar los recursos y ventajas competitivas en el contexto global, con el objetivo final de crear empleo decente y estimular la actividad económica". Para la determinación de las diferentes estrategias se menciona a White \& Gasser (2001), que establecen cuatro rasgos básicos que deben ser realizados y gestionados a nivel local y estas se recogen en la figura

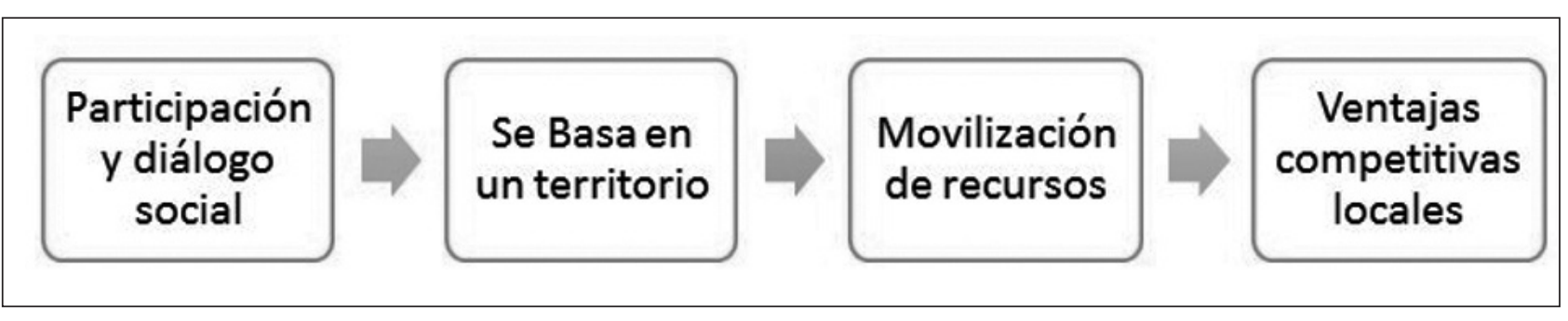

Figura 1. Estrategias para el desarrollo local según White \& Gasser (2001).

Así también, asegura Alburquerque (2004a) que "los niveles de exigencia mayores en los mercados internacionales y las mejores prácticas son referencias para la introducción de mayores niveles de competitividad tanto en el mercado interno como internacional", el cual indica que es importante atender a la articulación interna de los diferentes siste- mas productivos locales, y que solo de esta manera se puede conseguir el máximo aprovechamiento de los recursos, manteniendo el éxito competitivo a largo plazo. En este sentido, la adaptación flexible que deben poseer los sistemas dan paso a la incorporación de la innovación para el desarrollo de las economías locales, es decir, "la introducción de in- 
novaciones productivas puede desplegarse a través de innovaciones de productos o de procesos productivos, mediante innovaciones en métodos de gestión o a través de innovaciones sociales o institucionales" (Alburquerque, 2004b, p. 21).

Otro autor que confirma la importancia de la innovación es Pérez (2008) quien dice que "la innovación ha sido y continúa siendo la piedra angular no sólo del desarrollo económico, sino de la evolución del conjunto de la sociedad. La historia de la humanidad está guiada por las continuas innovaciones, que han ido marcando las transformaciones necesarias para facilitar el desarrollo de los pueblos y la mejora de su nivel de vida". Definiendo así que en el desarrollo de la economía local es fundamental la participación pública y privada como también el constante desarrollo de innovación en los procesos productivos, como lo argumenta Varisco (2008) el cual expresa que "el desarrollo económico local por otra parte, surge de tres temas comunes: la importancia de la innovación, las aglomeraciones productivas y la asociación. Por lo que esta teoría del desarrollo se ajusta a la visión del turismo, ya que permite integrar a la planificación a nivel de centros turísticos, con el objetivo de lograr el desarrollo regional y mejorar la calidad de vida de las comunidades receptoras".

\subsection{Desarrollo local}

En referencia al desarrollo local, Varisco (2008) explica que "el concepto de desarrollo local surge en la década del 80 en el contexto de crisis del sistema de producción fordista, y se consolida en la década del 90 con la plena vigencia de la globalización" (p. 33). El desarrollo local en la actualidad tiene gran presencia en lo referente al estudio de evolución de ciertas localidades, según Formichella (2004), el "Desarrollo local es el proceso que mejora la calidad de vida, superando las dificultades por medio de la actuación de diferentes agentes socioeconómicos locales públicos y privados, con recursos endógenos y fomentando el aumento de capacidades" (p. 8). Podestá (1999) por su parte sostiene que el desarrollo local "es un proceso en el que una sociedad local, manteniendo su propia identidad y su territorio, genera y fortalece sus dinámicas económicas, sociales y culturales, facilitando la articulación de cada uno de estos subsistemas, logrando mayor intervención y control entre ellos" (p. 30). A lo que también se atribuye que:

En este proceso se pueden identificar tres dimensiones: una económica, en la que los empresarios locales usan su capacidad para organizar los factores productivos locales con niveles de productividad suficientes para ser competitivos en los mercados; otra, sociocultural, en que los valores y las instituciones sirven de base al proceso de desarrollo; y, finalmente, una dimensión político-administrativa en que las políticas territoriales permiten crear un entorno económico local favorable, protegerlo de interferencias externas e impulsar el desarrollo local (Boisier, 2001, p. 33).

Basado en esto también se debe tomar en consideración la cadena de valor que surge con la actividad la cual es definida por Porter (2007) como:

La suma de los beneficios percibidos que el cliente reci-
be menos los costos percibidos por él al adquirir y usar
un producto o servicio. La cadena de valor es esencial-
mente una forma de análisis de la actividad empresarial
mediante la cual descomponemos una empresa en sus par-
tes constitutivas, buscando identificar fuentes de ventaja
competitiva en aquellas actividades generadoras de valor.
Esa ventaja competitiva se logra cuando la empresa de-
sarrolla e integra las actividades de su cadena de valor de
forma menos costosa y mejor diferenciada que sus rivales.
Por consiguiente, la cadena de valor de una empresa está
conformada por todas sus actividades generadoras de va-
lor agregado y por los márgenes que éstas aportan.

En otra instancia se debe mencionar el impacto fomentado por la globalización como influencia para el surgimiento del desarrollo local. El Fondo Monetario Internacional (2007) define a este como "una interdependencia económica creciente del conjunto de países del mundo, provocada por el aumento del volumen y la variedad de las transacciones transfronterizas de bienes y servicios, así como de los flujos internacionales de capitales, al tiempo que la difusión acelerada y generalizada de tecnología".

En esta instancia Arocena (2001) destaca que "hay dos maneras de percibir la sociedad contemporánea, una primera es considerar la supremacía de los procesos globales y su carácter uniformizante sobre la cultura, mientras la segunda se enfoca a la diversidad que surge y se reafirma como oposición dialéctica a la globalización" (p. 4). Afirmando que con respecto a la segunda percepción la dimensión local puede aparecer como un lugar privilegiado que vincula la racionalidad instrumental propia de los procesos de desarrollo y las identidades locales necesarias para dinamizar esos procesos.

Con base en los conceptos anteriormente expuestos se puede determinar que la participación de las localidades con respecto a los procesos de desarrollo tanto económico, social y político es de importancia ya que con la intervención de los diversos autores a nivel político y público se puede lograr pro- 
cesos exitosos, es decir, como bien lo explica Varisco (2008) "la idea de un desarrollo local como proceso orientado por los actores locales, significa identificar oportunidades al interior del territorio y en el contexto, en el marco de los procesos de descentralización administrativa". Para las localidades la aparición de la globalización originó su inmediata respuesta, puesto como indica Vázquez (2009) "el objeto de neutralizar los efectos negativos de la globalización y del ajuste productivo sobre el empleo y el nivel de vida de la población, ha dado lugar a la política de desarrollo local endógeno en numerosas economías de los países emergentes y de desarrollo tardío".

Todos estos factores dieron paso a la creación de nuevas políticas para la toma de decisiones, en las que "las políticas de desarrollo local definen sus acciones con un enfoque territorial. Para actuar sobre el sistema productivo, conviene hacerlo teniendo en cuenta que las acciones se realizan en territorios caracterizados por un sistema social, institucional y cultural con el que interactúan. Por ello, las medidas son más eficaces cuando utilizan los recursos locales y se articulan con las decisiones de inversión de los actores locales" (Boisier y Canzanelli, 2009, p. 34). Es por ello que las políticas de desarrollo local que se generan, son de gran importancia puesto que estipulan las bases para la planificación y ejecución de actividades que activen el desarrollo a nivel local.

\subsection{Desarrollo turístico}

La aplicación del desarrollo local al turismo se inicia en la época de los noventa después de diversos cambios socio-económicos que surge en la época. Así pues, al referirnos al desarrollo turístico, se menciona que "tras el reordenamiento económico mundial, el turismo se ha convertido en un fenómeno socioeconómico globalizado, lo que ha llevado al desencadenamiento de nuevas formas y con esta de destinos turísticos, teniendo en cuenta sus especificidades, potencialidades e identidades" (Linares \& Morales Garrido, 2014). "Desde que el turismo se transformó en una actividad masiva, se ha considerado que existe una relación directa entre turismo y desarrollo al punto de considerar como equivalentes las expresiones desarrollo turístico y desarrollo regional. El origen de esta relación causal se basa en la generación de oportunidades económicas para un país y para sus regiones, por ser esta industria una de las mayores generadoras de ingresos, empleo, de captación de divisas y desencadenante de una serie de fenómenos socio-culturales de gran importancia" (Linares \& Morales Garrido, 2014).
Por otra parte, Pearce \& Buttler (1991) conceptualizan que "el desarrollo turístico puede definirse específicamente como la provisión y el mejoramiento de las instalaciones y servicios idóneos para satisfacer las necesidades del turista, y definido de una manera más general, puede también incluir los efectos asociados, tales como la creación de empleos o la generación de ingresos". En este contexto Sancho (2002) argumenta que "Al turismo se le considera como un sector generador de oportunidades, capaz de crear negocios y empleo; fundamentalmente de mujeres y jóvenes, potenciador de crecimiento y desarrollo de un área, estímulo importante para proteger el medioambiente y las culturas autóctonas, y desarrolla mecanismos que conduzcan a la paz y el entendimiento entre los pueblos".

En consecuencia, para poder comprender de mejor manera la sinergia de este modelo se indica que: (...) se hace evidente que las tres dimensiones, territorial, antropológica y económica del desarrollo turístico están íntimamente relacionadas. (...) A su vez, el desarrollo socio-económico inducido por el turismo también dependerá de las características de los servicios que demanden los turistas. La forma física que adopta el desarrollo turístico de un determinado destino está íntimamente relacionada con las características de los turistas que lo visitan, así como con el tipo de empresas que se pueden desarrollar en la localidad (Santana, 2003, p. 56).

Con base en esta información, se evidencia que el desarrollo turístico es un gestor de importancia en relación a la economía mundial, ya que al ser un modelo incluyente genera mayor beneficio a la economía. Pero también por ello es generador de impactos tanto negativos como positivos, como lo menciona Barbini et al. (2012) "Sin embargo, el tiempo evidenciaría impactos de tipo social y cultural que no fueron considerados y que pusieron en duda la afirmación del turismo como panacea. Estos efectos colaterales fueron denunciados en un informe denominado Turismo ¿Pasaporte al desarrollo? de Kadt (1979), el cual abrió camino a una nueva serie de estudios críticos acerca de la actividad turística" (p. 7).

Razón por lo cual se habla de desarrollo turístico sostenible, el cual en el informe Brundtland (1987) se define como: "Aquel que satisface las necesidades presentes sin poner en peligro la capacidad de las generaciones futuras para satisfacer sus propias necesidades". Acotando a esta conceptualización Sancho (2005) ratifica que "el hecho de que el desarrollo turístico sea sostenible resulta, a todas luces, absolutamente fundamental. Para alcanzar este fin es imprescindible disponer de una adecuada 
planificación que, aunando los diferentes intereses que puedan coincidir, se constituya en la necesaria guía de actuación para todos los actores implicados en el desarrollo turístico".

Todos los autores expuestos con anterioridad tienen en común conceptos claros y fundamentados, acerca del desarrollo local; tanto a nivel general como a nivel comunitario y turístico, por lo que la incorporación de estas definiciones ayuda a la mejor comprensión de la investigación que se realizó, así como también algunas pautas importantes acerca de un desarrollo socio-económico de las poblaciones que se encuentran involucradas en actividades turísticas.

\subsection{Desarrollo local en Ecuador}

Bajo los parámetros de desarrollo local es indispensable hablar acerca del desarrollo local con respecto a Ecuador el cual se ha llevado a cabo con el tiempo, como indican Ruiz \& Solís (2007) "a partir de la década de los 60 empezaron a diseñarse cambios importantes en el sector agrícola del Ecuador, como consecuencia de la crisis temporal de la producción bananera, la crisis cafetera y el momento político del país, en el que existía una gran pugna entre clases oligarcas de la Sierra y de la Costa. Estos aspectos fueron los que llevaron a la elaboración de un proyecto político-económico dirigido a la diversificación de la economía, la industrialización y la transformación de los rezagos feudales de producción hacia una modernización del sector agrícola" (p. 44). Cabe aclarar que, al ser un país exportador de productos como banano y cacao, la agricultura es uno de los pilares fundamentales de la economía.

En la actualidad los agentes más relevantes para un desarrollo local se manifiesta en actores públicos y privados siendo estos: ONG, autoridades locales y organizaciones de base para la realización de diversos proyectos cuyo fin es el desarrollo de las localidades, así pues lo anuncian Valarezo \& Torres (2004), "el municipio está incursionando con iniciativas productivas agropecuarias, de servicios ambientales, riego y turísticas, en áreas rurales que estarían "abriendo camino" al desarrollo local cantonal” (p. 154). Estos autores argumentan que el mayor logro de las experiencias de desarrollo local, es la participación ciudadana siendo el eje principal de las intervenciones públicas y las decisiones de política socio ambiental; en las que se encuentran con varias instancias de participación social como las asambleas ciudadanas, parlamentos, comités de gestión, entre otros que tienden a reconocerse como espacios colaborativos" (p. 157).

Como se ha mencionado anteriormente la innovación es necesaria para el desarrollo económico, es por ello que en lo que se refiere a desarrollo local la innovación es de importancia puesto que no solamente ayuda a una competencia justa entre otras localidades sino también a ver como factor de importancia la creación de planes, como lo indican Valarezo \& Torres (2004) "los municipios innovadores tienen o están formulando sus respectivos planes estratégicos de desarrollo local, (...) todos los planes independientemente de su escala, están cruzados por temas comunes como son el enfoque de cuencas hidrográficas, manejo sustentable de recursos naturales (...) identifican nichos estratégicos para la inversión que son diseñados en mesas de reuniones o asambleas" (p. 160).

En este contexto se menciona al turismo como uno de los factores para el desarrollo local, como lo indica Ruiz \& Solís (2007) "El turismo, como actividad económica en el Ecuador, nació hace menos de 50 años con los visitantes norteamericanos que iban hacia otros destinos - Macchu Pichu en Perú- y que poco a poco fueron transformando al Ecuador en un destino en sí mismo, tras la aparición de productos como el mercado indígena de Otavalo, la Mitad del Mundo y las Islas Galápagos, (...) décadas después, el turismo se consolidaba empresarial y económicamente en algunas regiones de Ecuador" ( p. 51).

Con referencia al turismo comunitario, cuyo tema se desarrollará más adelante, se puede indicar que "el turismo comunitario se ha constituido en una forma de gestión novedosa, complementaria a otras actividades, sobre todo las agrícolas, en la que la diferencia radica en la distribución de las ganancias, que se derivan a toda la comunidad bajo la forma de obras concretas en estructuras, saneamiento, educación, etc." (Valarezo \& Torres, 2004, p. 52). De esta manera "Para las organizaciones indígenas los escenarios locales constituyen un espacio privilegiado para avanzar hacia la democratización de la sociedad y para la construcción de propuestas de desarrollo local sustentable basadas en la participación directa de las organizaciones sociales" (Unda, 2005).

En contexto para el mejor desarrollo de la actividad turística como parte del desarrollo local, se realiza para el 2007 el Plan estratégico de desarrollo de turismo sostenible para Ecuador (PLANDETUR 2020), documento que se crea básicamente para implementar procesos de desarrollo turísticos sostenibles en los cuales estén vinculados tanto los agentes públicos como privados y a su vez sea eje dinamizador de la economía ecuatoriana mejorando 
así la calidad de vida de la población. Sostenibilidad, competitividad y fortalecimiento del marco legal son los objetivos de este plan.

\subsection{Turismo sustentable}

El turismo se ha convertido en fuente principal para el desarrollo socioeconómico en el mundo, el cual por su importancia y proyección ha llevado a que se tome en cuenta la preservación y protección de los factores ambiental, social y cultural. A pesar que la economía mundial en la actualidad ha sufrido grandes cambios, lo cual ha generado inestabilidad, la demanda de turismo internacional siguió siendo fuerte en el 2016, como lo menciona la OMT (2017a) "las llegadas internacionales aumentaron un 3,9\% hasta situarse en los 1.235 millones". Estos datos nos permiten tener una visión general referente al entorno turístico en la actualidad, pero también se debe tomar en consideración la movilidad turística interna, que en muchos países son mayores que las internacionales, datos que permiten observar un panorama de la importancia que tiene el turismo y de que también lo tendrá en el futuro.

En la actualidad, las tendencias indican que el turismo se expandirá y se buscará nuevas experiencias y diversificación a la hora de elegir un producto turístico, generando así que se desarrollen nuevas alternativas turísticas como es el caso de proyectos comunitarios en localidades en las cuales se ha implementado la actividad generando oportunidades para el desarrollo económico y mitigando la pobreza pero también ha dejado impactos a nivel ambiental y cultural.

La actividad turística, al contrario de otras actividades económicas, está ligada al estado de conservación de los factores social, cultural y ambiental. "El turismo puede y debe convertirse en un aliado del ambiente en el que se desarrolla; en una fuerza económica y política de apoyo que asegure la conservación de los espacios y medios que utiliza; así como en un elemento coadyuvante de regulación y control de su propia actividad que tiende a la depredación" (Savino, 2008, p. 37). En los últimos años con la amenaza de la desaparición de algunos sitios naturales fundamentales para el producto turístico y la posibilidad que vaya en aumento, ha dado paso a la toma de acciones para la mitigación del mismo. En consecuencia, dicho autor enfatiza que "Las actividades que realizan los turistas, durante sus desplazamientos, generan una serie de repercusiones positivas y negativas en los lugares que visitan, co- nocidos como impactos del turismo en la economía, la sociedad y la cultura local, y en consecuencia en el ambiente" (Savino, 2008, p. 45).

Un primer concepto acerca del Desarrollo Sustentable se encuentra en el informe publicado, conjuntamente por la Unión Internacional de Conservación de la naturaleza (UICN), el Programa de Naciones Unidas para el Desarrollo (PNUD) y la World Wildlife Fundation (WWF), en 1980; pero que se popularizó en el año 1987, cuando se publicó el informe denominado Nuestro futuro común, por la Comisión Mundial sobre Medio Ambiente y Desarrollo, documento en el cual se advierte que la población mundial debe cambiar su estilo de vida y comercial para evitar consecuencias catastróficas en el futuro. En este marco Brundtland de 1987 comenta que "La humanidad tiene la capacidad para lograr un "desarrollo sustentable", el cual garantice las necesidades del presente sin comprometer las posibilidades de las generaciones futuras para satisfacer sus propias necesidades". Siguiendo este parámetro, se realizaron varias reuniones como la Declaración de Río (1992), la Convención de Desarrollo Sostenible de las Naciones Unidas (2002) y el Código ético mundial para el turismo (2001), que proponen pautas para el turismo sustentable basados en 3 grandes ejes que son:

- Sustentabilidad económica

- Sustentabilidad social

- $\quad$ Sustentabilidad ambiental

Por otra parte, se debe establecer un equilibrio entre estos componentes (Savino, 2008), sugiriendo que en los ámbitos:

- "Económico: un turismo sustentable debe ser rentable para que sea viable. Ningún empresario querrá apostar por la sustentabilidad si su negocio no sale adelante.

- Social: un turismo sustentable debe ayudar a reforzar valores de relación, intercambio de experiencias, enriquecimiento cultural tanto de los visitantes como de los habitantes del lugar.

- Ambiental: un turismo sustentable tiene que colaborar en la protección y conservación del ambiente en el que se desarrolla porque de él depende".

Savino (2008, p. 46) también indica que "para llevar adelante una estrategia de turismo sustentable 
en un país, provincia o localidad, es indispensable que estén integrados todos aquellos que se encuentran involucrados, de una forma o de otra, en esta actividad, ya que se deben contemplar las diferentes posturas y motivaciones de las partes interesadas para lograr fines comunes". Hace referencia a parámetros que se deben tomar en cuenta a la hora de la ejecución de la actividad, los cuales se muestran en la figura 2.

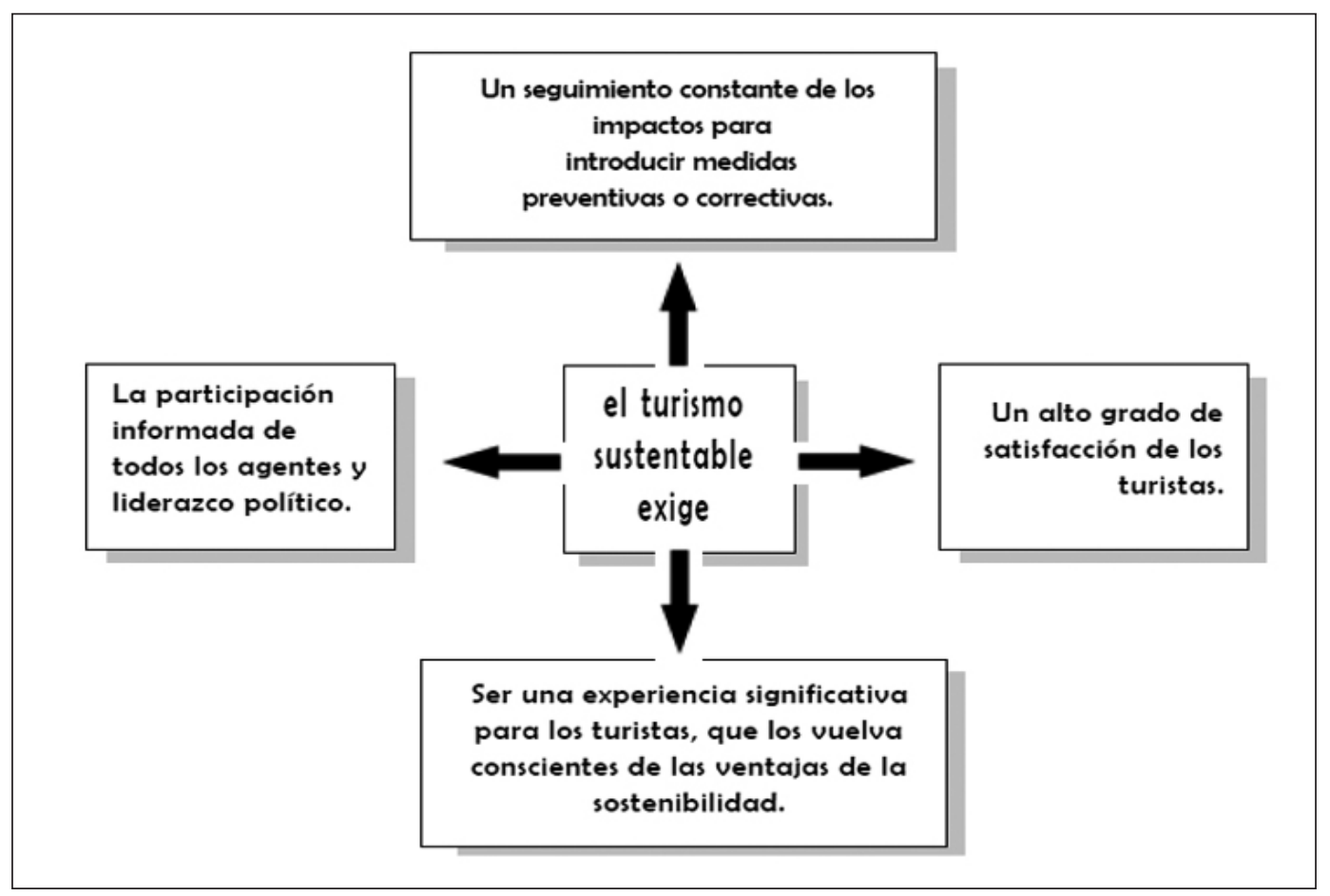

Figura 2. Parámetros para la ejecución de la actividad turística (Fuente: Savino, 2008).

"Las directrices para el desarrollo sostenible del turismo y las prácticas de gestión sostenible son aplicables a todas las formas de turismo en todos los tipos de destinos, incluidos el turismo de masas y los diversos segmentos turísticos. Los principios de sostenibilidad se refieren a los aspectos ambiental, económico y sociocultural del desarrollo turístico, habiéndose de establecer un equilibrio adecuado entre esas tres dimensiones para garantizar su sostenibilidad a largo plazo" (OMT, 2004).

\subsection{Importancia del análisis de la evaluación de proyectos turísticos sustentables}

Con el desarrollo sustentable y la diversificación del turismo se toma en consideración al turismo comunitario como una de las actividades turísticas que tratan de incorporar la conceptualización de sostenibilidad y sus principios. Por este lado aparece la triple rentabilidad que es "donde una compañía analiza los efectos sociales, ambientales y económicos de su desempeño sobre el entorno más amplio, comienza a mejorar su desempeño e informa públicamente sobre su progreso", según Elkington (1997).
Pero para la ejecución de estos parámetros se debe tener en consideración según Sancho, García, Pedro \& Yagüe (2001) "la planificación, desarrollo y gestión rigurosa, con lo que los beneficios del turismo podrán ser optimizados y los problemas reducidos a un mínimo, dado que la total eliminación de los mismos no parece posible" (p. 23), aseguran también que "La industria turística, los gestores del medio ambiente, las comunidades locales y en general todos aquellos que operan en este sistema, tienen un papel estratégico. El papel de la administración en el fomento y coordinación del desarrollo turístico reviste carácter esencial para alcanzar los objetivos globales de ese desarrollo y especialmente para hacer llegar los beneficios económicos a la comunidad sin que el turismo genere problemas ambientales, económicos o socioculturales" (Sancho, García, Pedro \& Yagüe, 2001, p. 43).

Según lo anteriormente expuesto las bases de la sostenibilidad pretenden, en rasgos generales, la obtención de beneficios sociales, culturales y económicos sin afectar al medio en el que se desarrolla. Las bases deben tener un seguimiento para poder constatar su efectividad, por lo que la valoración de 
impactos económicos, sociales y ambientales es de gran importancia para el análisis de los diferentes proyectos comunitarios implementados. Así como lo indica SECTUR (2007, p. 34) "es importante diseñar esquemas de seguimiento y evaluación que incorporen indicadores en varias dimensiones, basados en objetivos y criterios múltiples".

En lo referente a los proyectos comunitarios estos "surgen debido a las necesidades por un determinado grupo social, por lo que las acciones desarrolladas, tienen impacto a nivel social y económico, por lo que se requiere evaluar el impacto que ha tenido el proyecto en el lugar" (Pacheco, 2010, p. 54). Generando de esta manera que se realice el análisis respectivo de los diferentes proyectos, razón por la cual SECTUR (2007, p. 45) menciona que "Cuando existe una intervención sobre un sistema económico, social o ambiental, generalmente aparece una serie de cambios en las propiedades estructurales o funcionales, tanto a nivel cualitativo como cuantitativo. Estas transformaciones en el estado de los sistemas a su vez crean nuevas condiciones que pueden ser tanto aceptables como no deseadas en términos del cumplimiento de un objetivo".

La ONU define la evaluación como "el proceso encaminado a determinar sistemática y objetivamente la pertinencia, eficiencia y eficacia e impacto de todas las actividades a la luz de sus objetivos. Se trata de un proceso organizativo para mejorar las actividades todavía en marcha y ayudar a la administración en la planificación, programación y toma de decisiones futuras". En consecuencia, se evalúan los tres pilares de la sostenibilidad. Con respecto a la evaluación ambiental esta "pretende, como principio, establecer un equilibrio entre el desarrollo de la actividad humana y el ambiente, sin pretender llegar a ser una figura negativa u obstruccionista, ni un freno al desarrollo, sino un instrumento operativo para impedir sobrexplotaciones del medio" (Conesa et al., 2009) siendo así que el análisis de la misma ayude a:

- Mitigar o prevenir los efectos negativos de las actividades humanas en el ambiente.

- Detener o revertir el daño ambiental ya producido.

- Prevenir o conservar los recursos naturales.

Así también la evaluación de impacto social se encuentra orientada hacia "los resultados o efectos observables en los destinatarios, en cuanto a su contribución para satisfacer necesidades básicas o no básicas, propiciar el mejoramiento de las condiciones de vida, promover cambios de actitudes, condicionantes, aptitudes, comportamientos, mentalidades, etc., a través de la prestación de nuevos servicios y la ampliación de la cobertura de los ya existentes. Se refiere también a los cambios o variaciones observadas en el contexto situacional en que se inscriben los proyectos que pueden ser atribuidos a la presencia de estos" (Pichardo Muñiz, 1989, p. 67).

La evaluación de los impactos de proyectos comunitarios permite (Pacheco, 2010, p. 34):

- Registrar y analizar las experiencias (positivas y negativas) adquiridas en el marco del proyecto.

- Retroalimentación de prácticas anteriores.

- Propiciar aprendizajes.

- Determinar los niveles de desarrollo alcanzados.

- Valorar los procesos en su integridad.

- Obtener elementos de juicio fundamentados a fin de tomar decisiones que permitan orientar las acciones presentes y mejorar las futuras.

- Valorar si los cambios producidos se encuentran en correspondencia con lo previsto en los objetivos del proyecto, lo que supone además comprobar si como resultado de las acciones desarrolladas han emergido cambios no previstos y si son o no favorables.

Mientras tanto con respecto a lo económico, esta se direcciona a la obtención de "resultados que ayuden a fomentar nuevos proyectos productivos o de servicios tanto comunitarios como privados, incluyendo la participación de los residentes locales en la operación y dirección de los proyectos de turismo de naturaleza, así como también a la creación de nuevas fuentes de empleo directas e indirectas, para el incremento de ingresos en la población de las localidades" (SECTUR, 2007, p. 56).

Es decir que "la evaluación económica es un método de análisis útil para adoptar decisiones racionales ante diferentes alternativas. Es frecuente confundir la evaluación económica con el análisis o evaluación financiera. En este segundo caso se considera únicamente la vertiente monetaria de un proyecto con el objetivo de considerar su rentabilidad en términos de flujos de dinero. Mientras que la evaluación económica integra en su análisis tanto 
los costes monetarios como los beneficios expresados en otras unidades relacionadas con las mejoras en las condiciones de vida de un grupo" (Fernández, 2011, p. 34).

\subsection{Turismo sustentable en Ecuador}

La importancia de realizar la actividad turística basada en la sostenibilidad hace que se tome en cuenta que "el uso óptimo de espacios turísticos debe venir acompañado de un proceso de planificación en el cual se combinen las características intrínsecas de los sitios, con las potencialidades de uso y la interacción de la población local y los organismos planificadores" (Bayas, Avellán \& Bermúdez, 2014).

En el Ecuador la Constitución del año 2008, vigente en la actualidad, puntualiza que es deber del estado promover el desarrollo sustentable del país, el cual debe estar basado en los parámetros de sostenibilidad anteriormente expuestos y por ello se crea el Plan Nacional del Buen Vivir, la cual pretende ser una herramienta estratégica para el mejor desarrollo de las actividades, como ya se ha explicado anteriormente. Al ser un país extractivista, los impactos socioeconómicos y ambientales han incentivado a la realización de proyectos basados en políticas de sostenibilidad. Así pues, se señala que "con el advenimiento del turismo de masas se logra el reconocimiento justo y tardío de la necesidad de una cuidadosa planificación y gestión de la actividad si se quiere un turismo que no agote sus recursos" (Bayas, Avellán \& Bermúdez, 2014).

Tomando en cuenta estas consideraciones se realiza el PLANDETUR 2020, el cual también está ligado fuertemente a los objetivos de la OMT con respecto a las prácticas apropiadas de un turismo sostenible. Al ser un país megadiverso y pluricultural la implementación de estas medidas es de importancia, considerando que a nivel mundial las nuevas tendencias ecologistas y de los turistas interesados en preservar el medio ambiente ha impulsado que en su mayoría estén interesados en actividades que tengan como eje la sostenibilidad, siendo así el caso que la Asamblea General de la ONU declaró el 2017 como Año Internacional del Turismo Sostenible para el Desarrollo.

Cabe destacar que hay que implementar las buenas prácticas para el turismo sostenible, con lo cual, siguiendo esta dirección se destaca la producción del documento Turismo en áreas naturales con gestión comunitaria, realizado en conjunto entre el Estado ecuatoriano, la OMT y el Programa de Pequeñas Do- naciones para el Desarrollo (PPD), cuyo objetivo es la implementación metodológica apropiada para las operaciones turísticas en áreas protegidas en Ecuador destacando puntos relevantes en cuestiones de prácticas turísticas apropiadas y recomendaciones.

En la actualidad las políticas públicas dirigidas al sector turístico ponen especial énfasis en incluir a la población rural, entendiendo que existe una creciente demanda del mercado por experiencias turísticas que signifiquen un contacto con medios naturales conservados y encuentros interculturales. Las poblaciones rurales poseen un rico patrimonio cultural y natural que les permite montar emprendimientos de este tipo, sin embargo necesitan el apoyo de programas de capacitación y promoción por parte de los gobiernos municipales, regionales y nacional (Fuller, 2011, p. 45).

\subsection{Turismo comunitario}

El turismo comunitario hasta la actualidad ha estado precedido por distintos parámetros, los cuales han incidido de forma directa e indirecta para la generación de nuevas bases para la mejora del desarrollo local comunitario. A fin de poder comprender de mejor manera acerca del turismo comunitario iniciaremos con la conceptualización del mismo. La comunidad como definición socio-antropológico, es un "grupo de personas que viven en un área geográficamente específica y cuyos miembros comparten actividades e intereses comunes, donde pueden o no cooperar formal e informalmente para la solución de los problemas colectivos" (Arias, 2003, p. 34). Así también Ander-Egg (2005), menciona que "una comunidad puede ser considerada también un conjunto de personas que comparten una herencia social común: tradiciones, costumbres, lengua o pertenencia a una misma etnia. Esto connota, en la misma noción de comunidad, un reconocimiento de una historia, una identidad y un destino común".

Dentro del contexto también se menciona que "en el seno de las comunidades se desarrollan modelos de intercambio capitalista que conviven con modelos de reciprocidad" (Temple, 2003). Así como también explica Willmott (1986), la comunidad viene a significar tener algo en común y, por consiguiente, se debe tomar en cuenta estos tres parámetros que son lugar, interés y apego.

Con base en lo anteriormente expuesto se da apertura a la interpretación del desarrollo de actividades turísticas comunitarias, en la cual el turismo ha implementado grandes cambios en el ambiente, 
considerando estos cambios socio-económicos de gran importancia puesto que reactivan la economía en los países.

"En los últimos años, nuestro sector ha mostrado una fuerza y una resistencia extraordinarias pese a los innumerables retos a los que se ha enfrentado, en particular los relativos a la seguridad. Los viajes internacionales siguen incrementándose y consolidándose y contribuyen a la creación de empleo y el bienestar de las comunidades en todo el mundo", afirmó el Secretario General de la OMT, Taleb Rifai (OMT, 2017b).

El incremento de la misma se debe en gran medida al potencial que poseen los recursos naturales y a las diferentes características a nivel sociocultural de los diversos destinos turísticos y al tomar importancia ha llevado a la búsqueda de nuevos productos innovadores generando así el turismo alternativo en el que se encuentra inmerso el turismo comunitario como uno de los principales de esta categoría. "Este se reconoce como experiencias con las comunidades receptoras, contacto con la naturaleza, actividades de reto físico, búsqueda de emociones fuertes, etc." (Zamorano, 2002). El cual asegura que este tipo de turismo es considerado como una actividad que ayuda al desarrollo sostenible en las comunidades que poseen gran valor cultural y natural.

Mientras que para Ruiz et al. (2011) en la publicación Turismo comunitario en Ecuador. Comprendiendo el community-based tourism desde la comunidad, nos dice que "No todo agregado humano puede ser considerado comunidad; un colectivo, la sociedad civil, un grupo, una ciudad, no son comunidades en el sentido que aquí requerimos" sino más bien "es una estructura de funcionamiento con entidad en sí misma, sin que ello quiera decir autónoma del exterior". Explicando que lo principal a ser tomado en cuenta son relaciones sociales, así como la capacidad de auto organización y acción colectivas en la cual definiría a la comunidad no con una cosa, sino como una forma.

Con respecto a esto, Fernández (2011) en su ensayo Turismo comunitario y empresas de base comunitaria turísticas: ¿estamos hablando de lo mismo? define que la comunidad basada en turismo "es un modelo teórico complejo que implica procesos igualmente complejos, tales como: la participación comunitaria, el empoderamiento, la colaboración con actores sociales externos, la expansión y diversificación del capital social comunitario", por lo que comenta que la evolución de los pro- cesos que configuran el CBT (Comunidad Basada en Turismo) es incierta pues éstos dependen de la historia del grupo y su particular contexto social, político y cultural. Por ello, el CBT es un fenómeno que puede tomar diversas facetas en cada caso específico, dependiendo de la situación local en la que se encuentran dichos procesos. Por ello, no es tan sencillo pronosticar la viabilidad o el futuro éxito o fracaso de un proyecto de CBT.

La actividad turística comunitaria ha ido incrementando sobre todo en países subdesarrollados donde se han adquirido esta forma de turismo para potencializar los recursos ambientales, patrimoniales y culturales, aunque para Ruiz \& Cantero (2011, p. 2) "turismo comunitario es una forma de organizar la actividad turística (no una modalidad de turismo) en la que la comunidad tiene el papel protagonista en su diseño y gestión, y en la que los beneficios obtenidos tienen aplicación, al menos parcial, en ámbitos de interés colectivos".

Como lo sostienen Ruiz \& Solis (2007, p. 56) "el turismo comunitario se ha convertido en muchos países en una estrategia de desarrollo local desde abajo, protagonizada por comunidades que habían sido tradicionalmente objetos de desarrollo antes que sujetos del mismo". Con esta perspectiva Ecuador acoge la iniciativa del turismo comunitario como fuente que dinamizará la economía del territorio

\subsection{Turismo comunitario en Ecuador}

El turismo en el Ecuador se ha posesionado en tercer lugar en la economía del país. "De acuerdo con datos de la Dirección de Migración, un total de 1'352.405 ciudadanos extranjeros ingresaron a Ecuador desde el 1 de enero al 31 de diciembre de 2016", según cifras del MINTUR (2017). El cual informa de igual manera que "En tanto que en 2017, entre enero y julio ingresaron 914.477 turistas extranjeros, un 9,3\% más que el año pasado en el mismo periodo. En el mismo informe, el Ministerio señala que los establecimientos de alojamiento de lujo a nivel nacional (excepto Galápagos), en junio de 2017 tuvieron una ocupación del 59,6\% y $42 \%$ en los de primera categoría, lo que representa el crecimiento del $1,1 \%$ y $15,6 \%$, respectivamente" (MINTUR, 2017).

$\mathrm{Al}$ encontrarse en un lugar estratégico a nivel geográfico y geopolítico, y tener variedad geológica, topológicas, climáticas, etc., ha generado el desarrollo de variedad de vida en el país. Es con- 
siderado "Uno de los diecisiete países de mayor diversidad que ocupan menos del $10 \%$ de la superficie del planeta, pero albergan siete de cada diez especies reconocidas. El Ecuador forma parte de esta lista" (Burneo, 2009), como también por ser un país pluricultural. Al tener estas características, con respecto a América Latina, Ecuador es considerado pionero en actividades comunitarias por su "peso cuantitativo y cualitativo de sus experiencias de turismo comunitario" como lo señalan Ruiz \& Solís (2007).

La actividad turística da sus primeros pasos a partir del posicionamiento del producto Galápagos; lugar de gran riqueza y fragilidad, generando gran afluencia de visitantes extranjeros por lo que para el año de 1976 se inicia la creación de áreas protegidas como medidas de protección para la naturaleza, acciones que fueron de beneficio para las grandes empresas. La predisposición de institucionalizar lo ambiental fue una excusa para que las grandes empresas puedan extraer recursos de zonas naturales de manera sostenible, apoyando el consumismo bajo una bandera verde. En turismo, un sinnúmero de tour operadores adoptando las tendencias del mercado, empezaron a poner sus ojos en zonas de gran riqueza natural y con identidad cultural generando mayormente subempleo y consecuencias irreparables en el ambiente y la cosmovisión de pueblos originarios (Patiño, 2016).

En la época de los 70 Ecuador vive la etapa de desarrollo petrolera causando no solamente impactos a nivel ambiental sino también social, "los años sesenta estuvieron marcados por el inicio de transformaciones de toda la sociedad" (Ayala, 2008, p. 24). Y fueron esas transformaciones lo que marcó también como tendencia en el territorio el ecoturismo como una modalidad de turismo responsable para frenar los impactos que estaba generando el desarrollo petrolero y turístico en el país. Pero al desarrollarse la actividad se estaba dejando de lado a las comunidades, por ello para los años 80 se inicia esta nueva actividad como lo indica Cabanilla (2014, p 14) la "actividad surgió de manera espontánea desde los años ochenta, en respuesta a la fuerte sensación de exclusión de las comunidades, que se manifestaron más como un objeto de apreciación que como un sujeto en el desarrollo del turismo en sus territorios".

Con base en esto, para el año "2000 el reconocimiento oficial de la actividad y el registro de la Federación Plurinacional de Turismo Comunitario en Ecuador (FEPTCE) como su interlocutor colectivo" (Ruiz et al., 2008, p. 34), ayuda a la construcción de bases para una gestión turística planificada y desde una perspectiva de política de Estado. Con ello en el 2007 se desarrolla el PLANDETUR 2020, para implementar un desarrollo paulatino y eficiente de la actividad, cuyo objetivo es establecer bases de gestión turística sostenible, participativa e integral alineados a los objetivos del milenio y vinculada con Plan Nacional del Buen Vivir lanzado por el Estado, para la erradicación de la pobreza, economía social y solidaria, entre otras. En este contexto se ha realizado las actividades tradicionales de turismo como es hospedaje, transporte, guianza y también el desarrollo de proyectos comunitarios en varias zonas del país.

Con el transcurso del tiempo se ha evidenciado la tendencia de desarrollo turístico comunitario en zonas rurales, que en su mayoría son gestionadas por unidades familiares campesinas o pueblos indígenas que ha incorporado la actividad turística a sus actividades tradicionales. En una investigación realizada por Cabanilla (2016, p. 16) se señala que "La actividad inició con aproximadamente 50 centros de turismo comunitarios, pero para el año 2015 se cuenta con más de 230. Algunas comunidades que se encuentran registradas en la base de datos del MINTUR hasta el 2014, son Piedra Blanca en la provincia de Bolívar, Comunidad Palacio Real, Quilla Pacari en la provincia de Chimborazo, Organización comunitaria de desarrollo turístico Lago Verde en la provincia de Cotopaxi, Runa Huasi en la provincia del Napo, entre otras".

Basándose en esta tendencia se busca desarrollar proyectos, los que han sido catalogados como "productos de un proceso emergente en la construcción del desarrollo local, que, al mismo tiempo, buscó reafirmar los contenidos filosóficos culturales de las comunidades receptoras", argumenta Cabanilla cuya intención es "buscar la compatibilidad de la competitividad económica, la sostenibilidad ambiental, el equilibrio territorial, el bienestar y la cohesión social, y la innovación y el trabajo en redes locales y nacionales" (Cabanilla, 2014). Para el 2015, el MINTUR lanza el "Plan Minga Nacional del Turismo Comunitario" en el que se pretendía generar asistencia técnica a las comunidades a nivel de mercadeo y financiamiento, puesto que solamente 14 proyectos se encontraban registrados. Acciones que lastimosamente no se han concretado. El turismo comunitario en Ecuador comienza en la década de los ochenta generando emprendimientos en las cuatro regiones del país (figura 3). 


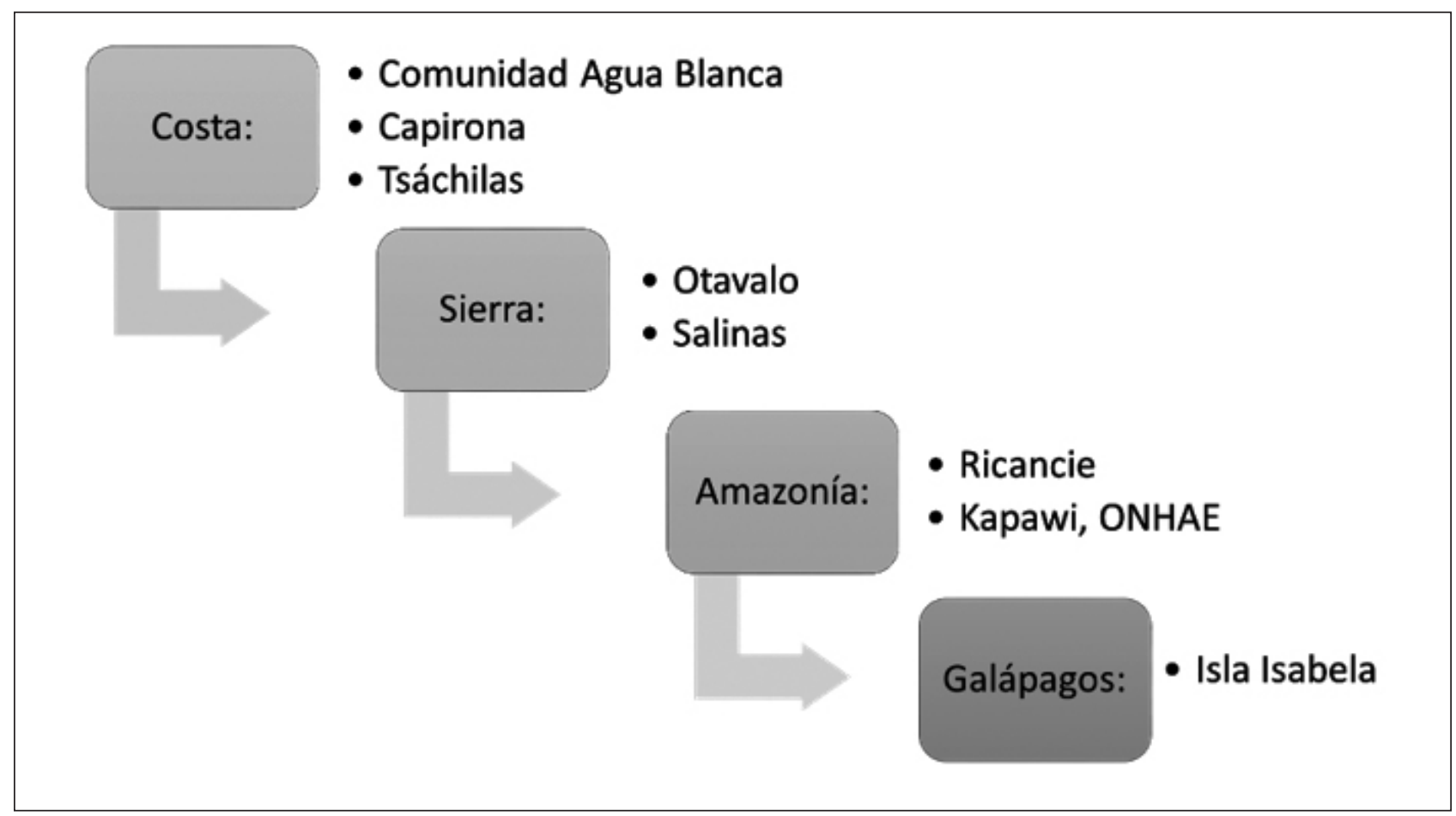

Figura 3. Proyectos turísticos comunitarios en Ecuador (Fuente: Cabanilla, 2016, p. 143)

\subsection{Turismo ferroviario}

Para empezar se explicará la evolución del tren a nivel mundial y la importancia del mismo para el turismo, para mejor comprensión de la actividad turística férrea en el Ecuador. En la historia de la humanidad el constante desplazamiento ha sido un factor fundamental para su desarrollo, ya sea a nivel de conquista de territorios, placer o negocios siempre el ser humano se encuentra en movimiento. En el siglo XIX, la creación del ferrocarril supuso uno de los grandes avances a nivel económico, social, político y también turístico, "la máquina a vapor aplicada al barco y al tren, revolucionaron completamente el mundo de los viajes" (Pérez de las Heras, 2004, p. 45). Así pues, como lo indican Lickorish \& Jenkins (1997), "El primer objetivo del ferrocarril había sido transportar mercancías y en segundo lugar ofrecer transporte para los viajeros de aquel momento a unos precios más baratos". A pesar de ello en el año de 1841, Thomas Cook, es el primero en organizar el primer viaje en Europa con referencias turísticas, a lo que Barquín (2013) indica que "seguramente en ningún otro período el turismo fue tan dependiente de un único medio de transporte como en ese siglo. De ahí que resulte lógico esperar la existencia de estrechas relaciones entre uno y otro, y que sean, sobre todo, de dependencia del turismo con respecto al ferrocarril”, puesto que ayudó a la difusión de nuevos destinos turísticos y desarrollo de los ya existentes. Para el año de 1950, el Ferrocarril de transporte público "Talyllyn de Gales", en el Reino Unido, se convierte en el primer tren turístico. "Con tan sólo $760 \mathrm{~mm}$ de sendero, el cual forma parte de los 150 ferrocarriles de patrimonio turístico de Gran Bretaña e Irlanda, transportando a más de 8 millones de turistas al año" (ALAF, 2000).

En la actualidad en Europa el ferrocarril continua operando las más famosas rutas como son: Glacier Express, VSOE, Venecia-Simplon-Orient Express, El Transiberiano que es en realidad una red, parte del sistema ferroviario de Rusia, que conecta la sección europea del país con la red de China. Las cuales son rutas turísticas reconocidas a nivel mundial que han servido como ejemplo para implementar nuevos proyectos turísticos basados en las rutas del ferrocarril. "Muchos trenes sobrevivieron gracias a que fueron recreados como ferrocarriles turísticos a lo largo del planeta consiguiendo encontrarlos en los lugares más recónditos de la tierra, como en Asia o África, también en Europa, Oceanía y por supuesto en América. Los trenes turísticos que se mantienen vigentes son invaluables por su riqueza cultural" (ALAF, 2000).

Según la Sociedad Internacional de Viajeros en Ferrocarril (2015), en Latinoamérica, en las tierras Incas el Belmond Hiram Bingham se destaca por sus cómodos coches panorámicos y servicios de lujo, 
conectando lugares de gran atractivo turístico como Cuzco y Machu Picchu. El Ecuador se encuentra formando parte de esta lista de los 25 mejores trenes del mundo El Tren Crucero, una maravillosa forma de disfrutar de la variedad de paisajes del país.

Así pues, la recuperación de ferrocarriles incentiva al desarrollo de las ciudades, como lo argumenta el ministro de Economía de Chile, Céspedes (BioBioChile, 2015), quien destacó que los trenes turísticos "contribuyen a dinamizar las economías locales, al ofrecer opciones para que las comunidades y pequeños emprendedores difundan su gastronomía, productos típicos y actividades tradicionales, generándoles fuentes de ingreso y también aportando a mantener vivas sus costumbres".

\subsection{Turismo ferroviario en el Ecuador}

El sistema de transporte ferroviario data del año 1872 , y fue considerado uno de los proyectos más importantes realizados en esa época ya que pretendía unir dos grandes ciudades como era el caso de Quito, capital del país, con Guayaquil, puerto principal. El ferrocarril representó la modernidad. Su construcción abrió no sólo el espacio de interrelaciones regionales, sino la reforma económica. Tuvo por mira la ampliación del mercado interno y el flujo comercial entre Sierra y Costa. Contribuyó a la valorización de las tierras por donde pasaba y a su mercantilización. (...) impulsó la superación de la actividad y el fortalecimiento de pequeños y medianos abaceros, así como de diversos núcleos artesanales, determinando incluso la formación de nuevos circuitos de comercialización entre poblados y microrregiones (Paz y Miño, 2011, p. 53). El precursor de la obra fue el presidente Gabriel García Moreno quien logró construir alrededor de cuarenta kilómetros. En el transcurso del tiempo avanzó muy poco puesto que los sucesivos contratistas no lograron conseguir el financiamiento necesario, más sin embargo al triunfar la revolución liberal la obra fue realizada en su totalidad por el presidente Eloy Alfaro Delgado, quien firmó un acuerdo de construcción con los contratistas norteamericanos Archer Harman y Edward Morely, constituyéndose en New Jersey la empresa privada Guayaquil and Quito Railway Company.

La construcción de la obra tuvo entre tantas otras dificultades tintes políticos, económicos y también geográficos, puesto que la red diseñada tenía que atravesar los Andes ecuatorianos, afirmar terrenos cenagosos, como también los diferentes climas extremos que existen en varios puntos del tramo, incorporando grandes rellenos, realizando puentes de complejos diseños e introducir sistemas de acceso en zigzag. Después de superar los distintos inconvenientes, 11 años después el ferrocarril logra conectar la Costa con la Sierra ecuatoriana el 17 de junio de 1908. La obra del ferrocarril ha sido la de mayor envergadura de nuestra historia. No solo por el esfuerzo económico que demandó sino también por sus dimensiones. Muchos han calificado a este ferrocarril como "el más difícil del mundo".

Además del impacto económico y fiscal del tren, también influenció en el desarrollo de la arquitectura de las ciudades y vida urbana, como también impulsó otros medios de transporte dando paso a la construcción vial de importantes redes de carreteras que surgieron en los años de 1950 y 1980. La operación de frecuencias aéreas en las 2 principales ciudades, fueron grandes competencias para el ferrocarril, razón por la cual comienza el decaimiento del mismo. En los años de 1998, las líneas férreas quedaron en muy mal estado a causa de las precipitaciones provocadas por la corriente de El Niño, razón por la cual la ruta ya no podía ser recorrida en su totalidad.

A diferencia de otros países, el ferrocarril no fue abandonado o desmontado por completo, conservándose en operación pequeñas secciones que han quedado en las rutas turísticas, como es el caso de Quito-Cotopaxi y el de la Nariz del Diablo. "En el año 2007 , se inicia la rehabilitación del antiguo sistema férreo por mandato presidencial de Rafael Correa, pero como parte de patrimonio cultural del país, para poder transformarlo en producto turístico con el fin de desarrollar la actividad y activar la economía de las localidades por las que recorre dicha vía" (Barreno, 2015, p. 34). Pasando desde ese momento la empresa "Ferrocarriles del Ecuador Empresa Pública" a formar parte del Estado.

\subsection{Creación de la empresa Ferrocarriles Ecuador Empresa Pública}

La empresa Ferrocarriles Ecuador Empresa Pública es la encargada de mantener, construir operar y administrar el ferrocarril ecuatoriano. Inicialmente fue creada a nivel privado con el nombre de Quito and Guayaquil Railway Company (Q\&G) con el objetivo de transportar carga de pasajeros y carga. Con el transcurso del tiempo la compañía no pudo solventar sus gastos y generar utilidades con lo que el Estado ecuatoriano adquiere la empresa. A partir del 8 de abril de 2005, el Congreso Nacional cambia su denominación a Ferrocarriles Ecuador con el objetivo de restaurar el sistema ferroviario. Así pues, para el año 2008 mediante decreto presidencial pasa a ser Ferrocarriles Ecuador Empresa Pública, generando 
cambios de estructura y dirección de la empresa. Con la incorporación de la empresa al Estado, para el año 2008, el Ministerio de Cultura y el Instituto Nacional de Patrimonio Cultural (INPC), mediante decreto, declara a la red Ferroviaria del Ecuador como bien del Patrimonio del Estado, catalogándolo como "Monumento civil y patrimonio histórico, testimonial, simbólico". Por tanto, a través de los decretos ejecutivos de Emergencia Vial y Patrimonio Cultural se inician las acciones y designación de presupuesto para la rehabilitación de la red ferroviaria.

Según investigaciones de Carrera (2012), "la gestión se inicia con dos líneas de trabajo: la importante y la urgente, $(. .$.$) donde se definió los pasos para el dise-$ ño, implementación y evaluación del mismo. Se incluyó en la agenda del plan nacional, se diseñó el proyecto, consiguió la definición de prioritario y plurianual, se consiguió el presupuesto, se creó la normativa jurídica para su ejecución, se diseña una estructura para su ins- titucionalidad, se lo ejecuta y se diseña un proceso de evaluación financiera, social y económica" (p. 43).

En base a todo ese trabajo realizado la implementación de infraestructura, el desarrollo local y fortalecimiento de la empresa fue un eje principal pues se aspiraba a cumplir con 3 objetivos primordiales:

1. Dinamizar las economías locales y de las comunidades por donde pasara el tren.

2. Recuperar la memoria histórica y el patrimonio del ferrocarril ecuatoriano.

3. Operar el tren patrimonial de uso turístico de Ecuador.

Por lo cual, la empresa incorpora un plan de gestión que se encuentre acorde a las necesidades que se han identificado (figura 4).

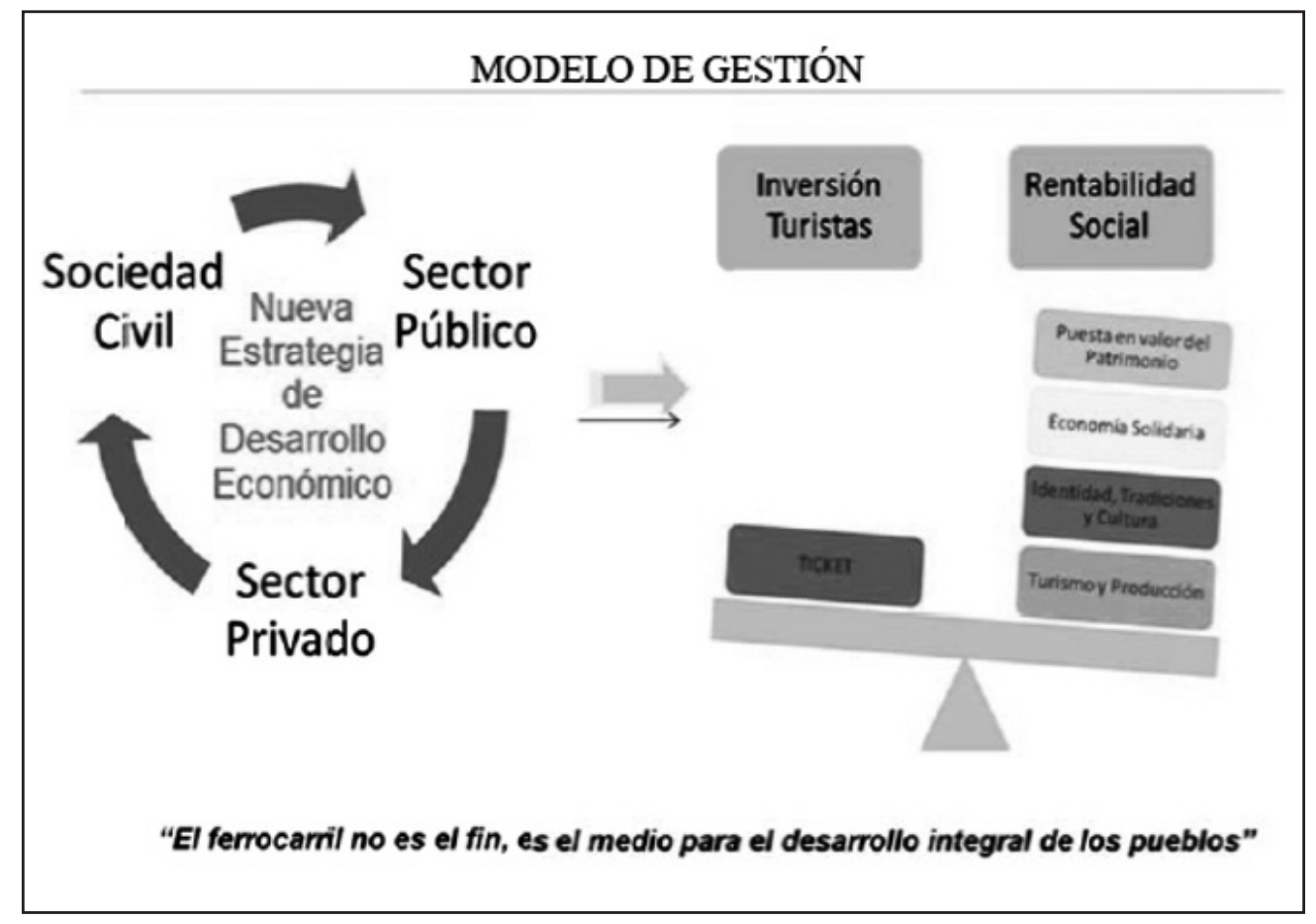

Figura 4. Modelos de Gestión FEEP (Fuente: FEEP, 2015).

Con base en estos parámetros en el 2016 la Empresa Pública de Ferrocarriles del Ecuador incorporó una serie de productos turísticos que comprenden diferentes tramos en la ruta de recorrido entre Quito y Durán. Entre sus productos se encuentran las excursiones (rutas cortas) y el tren crucero (ruta completa). Al ser tan diversificado los productos de FEEP, para fines de esta investigación se ha seleccionado el producto turístico Tren crucero para su estudio.

\section{1,14. Producto turístico Tren Crucero}

En el 2012 se lanza un nuevo producto turístico Tren Crucero que es una marca comercial de Ferrocarriles Ecuador Empresa Pública (FEEP), el cual consiste en un tren exclusivo para excursiones el cual consta de una capacidad para 54 pasajeros en una ruta operativa que empieza en Quito hasta la ciudad de Durán, 
con un itinerario que consta de 4 días y 3 noches. "Éste producto de alta calidad, ha sido creado para dar a conocer al Ecuador en su diversidad y riqueza patrimonial; y, así cumplir con uno de los objetivos de Ferrocarriles del Ecuador EP que es vincular las actividades socio-productivas económicas que existen en esta ruta" como lo anuncia Carrera, gerente general de FEEP (El Ciudadano, 2009).

El viaje recorre $450 \mathrm{~km}$ entre la Sierra y Costa ecuatorianas, que inicia en la estación de Chimbaca1le, Quito. En la jornada se visita el Parque Nacional Cotopaxi, así como también se realiza la presentación de danzas clásicas del sector. Con respecto al segundo día, se realiza el recorrido de Lasso a Riobamba, provincia de Chimborazo donde se encuentra comunidades procedentes de Urbina, también se ingresa al museo del tren y se conoce acerca de las tradiciones de los hieleros de la provincia. En el tercer día el crucero se dirige de Riobamba a Huigra, visitando la iglesia Balbanera, primer centro católico de Ecuador. En Guamote se encuentra la siguiente comunidad con la que los turistas interactúan para después dirigirse a la ruta denominada Nariz del Diablo. Con respecto al cuarto día se conduce a los visitantes a Bucay donde se genera la visita a la comunidad Shuar, para conocer sus costumbres, y después se traslada a los turistas hasta Durán donde finalizan los servicios.

La rehabilitación del ferrocarril culminó en el 2012, pero a partir del 2013 se inicia la operación del producto, con la recuperación de 22 estaciones. "Nos fijamos tres objetivos fundamentales: dinamizar las economías locales, construir las tiendas artesanales del tren y, en tercer lugar, hemos gestionado las estaciones vivas" (El Ciudadano, 2009). El mismo que asegura que "a 350 millones de dólares asciende la totalidad del proyecto, incluida la primera etapa que significaba la rehabilitación de la línea férrea desde Durán a Quito, la segunda etapa que incluía la rehabilitación de la ruta Ibarra-Salinas, Ibarra-Otavalo, aparte de la adquisición del equipo tráctil (locomotoras) que permitirán aumentar la capacidad instalada para que el país pueda recibir muchísimos más turistas, pero lo más importante es que puedan quedarse y gastar en las comunidades" (Carrera, 2012).

El tren ha conseguido desde su funcionamiento premios y reconocimientos, como: Premio Wider World Project, o mejor producto turístico fuera de Europa, por parte del gremio de escritores ingleses British Guild of Travel Writer en Inglaterra (El Ciudadano, 2009). También se destaca los galardones que ha obtenido, "debido tanto a la dinamización de las comunidades locales por donde cruza el Tren Crucero, como a la vinculación de las comunidades con el proyecto ferroviario, dos razones por las cuales Ferrocarriles del Ecuador recibe en Madrid el Premio Excelencia, galardón otorgado por el Grupo Excelencias y entregado en la trigésimo quinta edición de la Feria Internacional de Turismo" (Villaruel, 2015). Y en el 2015 el Tren Crucero es designado ganador como Mejor Tren de Lujo de Sudamérica, galardón otorgado por los World Travel Awards, considerados como los premios Oscar del turismo (MINTUR, 2015). Así también, según MINTUR en el listado de los principales destinos del Ecuador para el turismo receptivo se encuentra incluido el Tren Crucero, indicando la importancia del mismo a nivel del sector.

A diciembre del 2016 se han generado "5.526 empleos a nivel nacional y 1.534 unidades productivas que se encuentran en la ruta del tren" (figura 5).

\begin{tabular}{|c|c|c|}
\hline \multirow{2}{*}{ TRAMO } & \multicolumn{2}{|c|}{ DICIEMBRE } \\
\cline { 2 - 3 } & $\mathbf{N}^{\circ}$ Empleos & $\begin{array}{c}\mathbf{N}^{\circ} \text { Unidades } \\
\text { Productivas* }\end{array}$ \\
\hline $\begin{array}{c}\text { Quito - Cevallos } \\
\text { Mocha }\end{array}$ & 1.245 & 409 \\
\hline Otavalo - Ibarra & 512 & 186 \\
\hline Ibarra - Salinas & 266 & 49 \\
\hline $\begin{array}{c}\text { Urbina - } \\
\text { Riobamba }\end{array}$ & 1.088 & 288 \\
\hline Riobamba - Colta & 208 & 48 \\
\hline $\begin{array}{c}\text { Alausi - Sibambe } \\
\text { - Huigra }\end{array}$ & 950 & 122 \\
\hline $\begin{array}{c}\text { Tambo - } \\
\text { Coyoctor }\end{array}$ & 104 & 13 \\
\hline $\begin{array}{c}\text { Duran - Bucay } \\
\text { TOTAL } \\
\text { NACIONAL }\end{array}$ & 1.153 & 419 \\
\hline
\end{tabular}

Figura 5. Actividades productivas desarrolladas por el Tren (Fuente: FEEP, 2016). 
Los turistas transportados en el 2016 fueron "113.498 pasajeros. El producto más demandado fue el de excursión, con 112.135 pasajeros, y el producto crucero fue de 1.363 pasajeros. Un dato muy importante que se observa en el producto de excursión es que en 2016, la zona más demandada por los turistas fue los Andes Sur, con un 51\%; Andes Centro, con un $22 \%$; Andes Norte, con $17 \%$ y la Costa del Pacífico, con un $10 \%$ ", así también la gráfica demuestra que en el 2016 el mayor porcentaje de ingresos fueron por las expediciones con un 71\% (FEEP, 2016).

En el informe de rendición de cuentas del 2016 se indica que se han realizado actividades para la vinculación de las comunidades de las cuales se destacan:

- Emprendimientos del filial centro recibieron charlas de capacitación "Liderando un servicio de calidad".

- Vinculación de nuevas comunidades indígenas como son: La Moya y Jatari Campesino, con nuevos emprendimientos.

\section{Metodología}

\section{1. Área de estudio}

Para esta investigación se puso en consideración las poblaciones involucradas en el proyecto Tren Crucero; en el presente caso se tomó como objeto de estudio las comunidades de Nizag y Palacio Real, las cuales se encuentran dentro de la provincia de Chimborazo. Las comunidades que se han elegido para este caso de estudio están inmersas en el trayecto por donde pasa el Tren y se encuentran involucradas en proyectos y operaciones del mismo, por lo cual el estudio de estos lugares proporcionará información de importancia para la evaluación de los factores socio-económicos de estas colectividades.

\section{Comunidad Nizag}

La comunidad de Nizag se encuentra ubicada al sur del cantón Alausí en la provincia de Chimborazo. Limita al norte con la comuna de Shushilcón, al sur con Pistishi, al este con la comunidad La Moya y al oeste con la comunidad de Jushihuaico. Las actividades económicas más importantes de su población se basan principalmente en la agricultura y ganadería. Con el transcurso del tiempo la población se ha ido adentrando en actividades turísticas (Siguencia, 2005), desarrollando el turismo comunitario e ingre- sando a las diferentes operaciones que realiza el Tren Crucero en su travesía.

\section{Comunidad Palacio Real}

En el caso de la comunidad de Palacio Real se encuentra ubicada en el cantón Riobamba, provincia de Chimborazo. La población es de origen étnico Kichwa de la Sierra centro, y también es parte del pueblo Puruhá, conocido por sus costumbres y tradiciones. Sus principales actividades económicas "están basadas en la agricultura, ganadería, artesanías y actividades turísticas, tal es el caso del centro turístico Sumak Kawsay" (Consorcio de juntas parroquiales rurales de Chimborazo, 2015, p. 25).

\subsection{Materiales y métodos}

La investigación fue de carácter descriptiva, la cual, según Hernández, Fernández \& Baptista (2010) "busca especificar las propiedades, las características y los perfiles de personas, grupos, comunidades, procesos, objetos o cualquier otro fenómeno que se someta a un análisis" (p. 15), misma que ayudó a determinar el aporte socio-económico del turismo comunitario y el impacto que ha generado el Tren Crucero en estas localidades.

Para la realización de la metodología se procedió a implementar un enfoque mixto, el cual para Hernández, Fernández \& Baptista (2003), indica que se “... llevan a cabo observación y evaluación de fenómenos, establecen suposiciones o ideas como consecuencia de la observación y evaluación realizadas, prueban y demuestran el grado en que las suposiciones o ideas tienen fundamento, revisan tales suposiciones o ideas sobre la base de las pruebas o del análisis y proponen nuevas observaciones y evaluaciones para esclarecer, modificar, cimentar y/o fundamentar las suposiciones o ideas; o incluso para generar otras" (p. 36).

El enfoque mixto brindó, por un lado, aporte cuantitativo a través de encuestas y cualitativo por las entrevistas realizadas por conveniencia. Información que fue analizada e incorporada al trabajo, ayudando a la obtención de información verídica y de importancia para la obtención de respuestas a las preguntas planteadas. La información se obtuvo de los comuneros, de acuerdo con sus comportamientos, opiniones y características; también de voceros de las comunidades y, de igual manera, de los Ministerios del Ambiente y de Turismo. Las respuestas a las preguntas planteadas permitieron obtener datos que fueron analizados e incorporados al trabajo, lo 
que ayudó a la obtención de información importante y verídica.

\subsection{Herramientas implementadas}

La investigación se apoyó en la recolección de información bibliográfica, la cual fue analizada para conceptualizar las diferentes formas de turismo y desarrollo implementadas en el estudio, como es el caso del turismo sostenible, turismo comunitario, y desarrollo local, con lo que se obtuvo un panorama general de la situación en la que se encuentra el producto y las comunidades. El estudio de otras experiencias referentes al desarrollo local enfocado al turismo comunitario a nivel mundial fue un importante aporte para la comprensión de la dinámica que se produce en las localidades.

Después de la revisión del aporte bibliográfico acerca del fenómeno estudiado, se procedió a elaborar las herramientas correspondientes para recolección de datos de importancia en las visitas de campo, las cuales se implementaron a la muestra universo de los principales actores implicados en el desarrollo turístico local de la población, los cuales son:

- La realización de varias visitas de campo a las comunidades implicadas en el estudio para la validación del estado de desarrollo. El principal objetivo de las visitas fue entablar conversaciones con los comuneros para conocer las opiniones que tienen acerca del producto turístico y su influencia.

- Visita a los emprendimientos comunitarios, para la ejecución de entrevistas a los responsables, y encuestas a las personas de la comunidad cuyo objetivo fue la recolección de información y evaluación acerca del desarrollo de estos emprendimientos y sus resultados.

- Las entrevistas fueron diseñadas para cada tipo de actor, es decir, estuvieron orientadas a municipios y autoridades; a profesionales y academia; a prestadores de servicios y representantes comunitarios.

- Con respecto a la encuesta estuvo enfocada a los comuneros para recolección de información referente al involucramiento de las comunidades con el proyecto Tren Crucero. La encuesta se realizó al azar a miembros de la comunidad. Se llevó a cabo en el lapso de un día. Al terminar la recopilación de información, se analizaron dichos datos, lo cual ayudó a la presentación de resultados y conclusiones del trabajo de investigación.

\subsection{Población y muestra}

La provincia de Chimborazo está compuesta por 10 cantones, entre ellos están los cantones de Alausí y Riobamba, lugares donde se encuentran las parroquias de Alausí y Calpi, respectivamente. Aquí se ubican las comunidades seleccionadas, es decir, Nizag y Palacio Real, las cuales son los actores principales para la investigación y realización de este trabajo. Para llevar a cabo las entrevistas se seleccionó a los dirigentes y representantes principales de cada rama de acuerdo con el vínculo con las comunidades.

Para determinar el tamaño de la muestra se empleó la fórmula para poblaciones infinitas, la cual ayudó a obtener el número de la muestra pertinente para la implementación de la encuesta. A saber, la fórmula para calcular la muestra fue:

$$
n=Z^{2} \frac{p * q}{i^{2}}
$$

donde,

- $\mathrm{n}=$ tamaño de la muestra

- $\quad \mathrm{Z}=$ grado de confiabilidad, $95 \%$ en cuestiones académicas es equivalente a 1.96 según tabla de Gauss.

- $\quad$ p y q = probabilidad y prevalencia: que indica el comportamiento habitual de la población estudiada. Según Cabanilla (2011), en "turismo novel ciencia y en construcción de sus métodos lo más usual es considerar un $50 \%$ a cada una de estas variables, lo que indica que puede manifestarse de forma recurrente o no recurrente de igual forma" (p. 14).

- $\quad \mathrm{i}=$ margen de error es de 0,5. A menor porcentaje de error la cantidad de entrevistados debe ser mayor (Cabanilla, 2011).

Aplicando las variables, la fórmula usada fue:

$$
n=(1,96)^{2} \frac{0,5 * 0,5}{0,05^{2}}
$$

Obteniendo un resultado 384 individuos a encuestar. La muestra fue estratificada en función de las dos comunidades (Tabla 1) 
Tabla 1. Población y muestra

\begin{tabular}{|c|c|c|c|c|}
\hline Comunidades & $\begin{array}{l}\text { Habitan- } \\
\text { tes }\end{array}$ & $\begin{array}{c}\text { Porcentaje respecto } \\
\text { al total }\end{array}$ & $\begin{array}{c}\text { No de personas para muestra } \\
\text { mínima }\end{array}$ & $\begin{array}{c}\text { No de encuestas realizadas } \\
\text { para la muestra real }\end{array}$ \\
\hline Palacio Real & 338 & 47,74 & 183 & 190 \\
\hline Nizag & 370 & 52,26 & 201 & 209 \\
\hline Total & 708 & 100,00 & 384 & 399 \\
\hline $\begin{array}{l}\text { Muestra míni- } \\
\text { ma }\end{array}$ & 384 & \multicolumn{3}{|c|}{ Al $95 \%$ de confiabilidad, $+/-5 \%$ de error y un $50 \%$ de varianza. } \\
\hline Muestra Real & 399 & \multicolumn{3}{|c|}{ Al $95 \%$ de confiabilidad, $+/-5 \%$ de error y un $50 \%$ de varianza. } \\
\hline
\end{tabular}

Una vez que se conoció la muestra de las comunidades a investigar, se procedió a contactar con líderes comunitarios que se mostraron abiertos para llevar a cabo las encuestas en las comunidades.

\subsection{Entrevistas}

La presenta entrevista tiene como objetivo final contar con su valioso aporte y opinión como experto (a) calificado (a), para la investigación Influencia económica del Tren Crucero en las comunidades por las que transita. La información que usted brinde será de gran aporte para proyectos de desarrollo económico local de las comunidades a nivel turístico.

\section{Gracias por su colaboración}

1. ¿Cómo definiría usted desarrollo local en las comunidades ecuatorianas?

2. ¿Considera usted que las actividades turísticas en las comunidades, se ha consolidado en los nichos de mercado?

3. Con referencia al producto turístico Tren Crucero, ¿cómo calificaría usted el resultado del proyecto con respecto a la vinculación de las comunidades al mismo?

4. ¿Han encontrado las comunidades soporte en otros actores para su desarrollo local?

5. ¿Cómo se ha desarrollado el proceso del producto Tren Crucero a nivel de vinculación comunitaria?

6. ¿Cree usted que FEEP debe potencializar las actividades productivas turísticas en las comu- nidades para impulsar el desarrollo local?

7. Explique ¿Cómo usted consideraría que se puede potencializar dicha actividad?

8. ¿Cuáles considera usted que son las principales dificultades que surgen al implementar proyectos que vinculen a las comunidades?

9. ¿Cuál considera usted que podría ser un ejemplo de implementación exitosa de proyectos estatales con la vinculación a las comunidades?

\subsection{Encuesta a comuneros}

La presente encuesta se ha realizado con el fin de descubrir la visión que se genera sobre el turismo comunitario, su desarrollo y la actividad turística. $\mathrm{Su}$ aporte ayudará al desarrollo de nuevas estrategias para la implementación proyectos turísticos a las comunidades del Ecuador.

Edad:

18-24 25-34 $\quad 35-44 \quad 45-54 \quad 55-64 \quad 65$ o más

Género: Masculino Femenino

¿Cuántas personas componen su hogar?

$\begin{array}{lllll}1 & 2 & 3 & 4 & 5\end{array}$

En qué medida está de acuerdo con estas afirmaciones

1. ¿Cuánto conoce sobre el funcionamiento de los emprendimientos turísticos de la comunidad con el Tren Crucero? Nada Poco Mucho Bastante 
2. Los emprendimientos vinculados con el Tren Crucero igeneran informes anuales de su estado? Nada Poco Mucho Bastante

3. ¿Cuán satisfecho está usted con por los logros obtenidos por los emprendimientos turísticos que se ha generado en torno al Tren Crucero? Nada Poco Mucho Bastante

4. ¿Se auspician actividades recreativas juegos, concursos deportes, por parte de FEEP en la comunidad? Nada Poco Mucho Bastante

5. La vinculación de las comunidades al proyecto Tren Crucero ¿Ha ayudado a mejoras de vías de acceso? Nada Poco Mucho Bastante

6. La vinculación de las comunidades al proyecto Tren Crucero ¿Ha ayudado a mejoras de medios de transporte? Nada Poco Mucho Bastante

7. La vinculación de las comunidades al proyecto Tren Crucero ¿Ha ayudado a mejoras de servicios de salud? Nada Poco Mucho Bastante

8. La vinculación de las comunidades al proyecto Tren Crucero ¿Ha ayudado a mejoras de servicios educativos? Nada Poco Mucho Bastante

9. Cree usted que la rehabilitación del Tren Crucero y la vinculación con la comunidad ¿Ha mitigado la migración de sus habitantes? Nada

\section{Poco Mucho Bastante}

10. La vinculación con el producto turístico ¿Ha ayudado a que se desarrolle nuevas actividades productivas como es el caso de artesanías, ganadería, etc.? Nada Poco Mucho Bastante

11. La vinculación con el producto turístico ¿Ha ayudado a que se desarrollen nuevas fuentes de trabajo? Nada Poco Mucho Bastante

12. La vinculación con el producto turístico ¿Ha ayudado a generar nuevos ingresos económicos en las familias de la comunidad? Nada Poco Mucho Bastante

\section{Resultados}

\subsection{Resultado de las encuestas en Nizag}

La encuesta se realizó al azar a miembros de la comunidad. Se lo hizo en el lapso de un día. La encuesta se efectuó de forma diversa a personas de diferentes edades, y permitió evidenciar que la población que integra esta comunidad se encuentra en edades entre 2544 años, por lo que se considera una población joven (Figura 6). La pirámide poblacional que tiene la República del Ecuador indica que la tercera edad es más pequeña según información del INEC (2010), por lo que los datos obtenidos según edades, en Nizag, están dentro de los parámetros poblacionales.

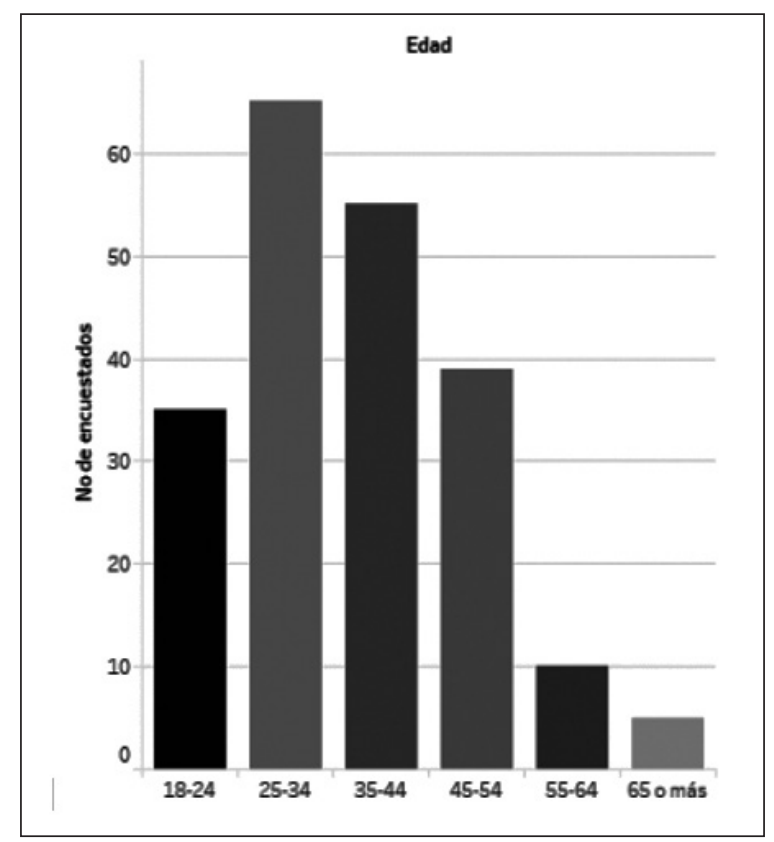

Figura 6. Composición de edades de la comunidad Nizag. 
La figura 7 muestra que la población se encuentra integrada en su mayoría por mujeres, circunstancia que es común en Ecuador puesto que según el INEC (2010) existen en el país más mujeres que hombres. No existe sesgo significativo en los resultados.

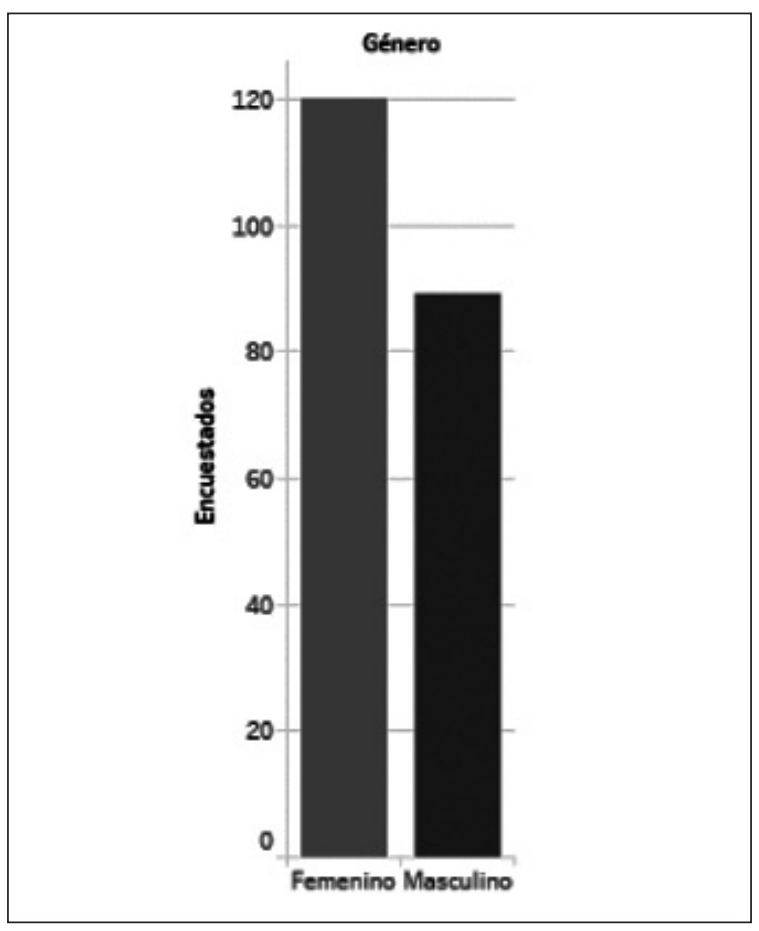

Figura 7. Composición de género de la comunidad Nizag.

El número de personas que componen un hogar de la comunidad estudiada (Nizag) en su mayoría es de más de 5 integrantes (Figura 8). Este dato está acorde a la realidad rural del país, ya que las familias son numerosas y superan la media de 1,6 hijos por familia, a diferencia de las familias del sector urba- no, según el INEC (2010). Es decir que Nizag, al estar ubicada en una zona rural del país, se encuentra dentro de los parámetros de personas promedio que tiene cada familia rural, con 3,8, según datos del INEC (2010), por ende, el número de miembros está acorde con las estadísticas nacionales.

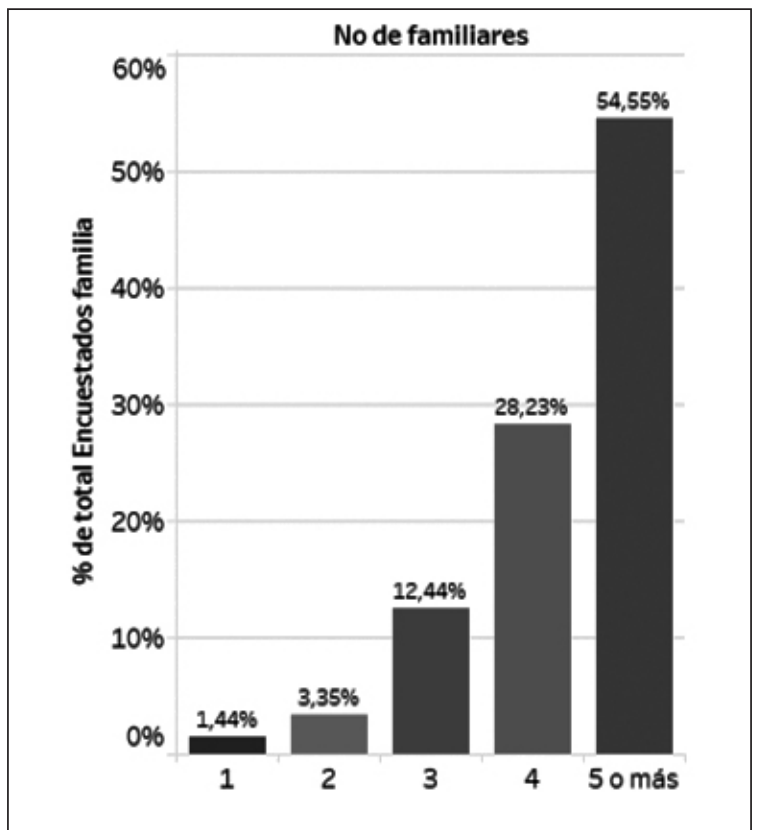

Figura 8. Número de personas que componen el hogar. 
A continuación, se presenta el resultado de las preguntas planteadas a la comunidad las cuales tienen como objetivo conocer la percepción de los comuneros acerca de la vinculación y desarrollo de la comunidad con el producto turístico Tren Crucero.

Sobre la primera pregunta referente a cuánto conocen los comuneros acerca del funcionamiento de los emprendimientos turísticos de la comunidad con el Tren Crucero, estos supieron manifestar en un $61,24 \%$, que conocen poco acerca del funcionamiento de em- prendimientos turísticos (Figura 9). Es decir, que 9 de cada 10 personas manifestaron que no conocen los emprendimientos. El resultado es que no existe involucramiento total de la población, ya que solamente las personas elegidas que se encuentran en constante comunicación con la empresa, refiriéndonos a presidentes de las asociaciones y de la comunidad, los que componen el 2,39\%, son quienes conocen la sinergia que se efectúa. En conclusión, el producto Tren Crucero no llega a ser productivo para los habitantes de Nizag.

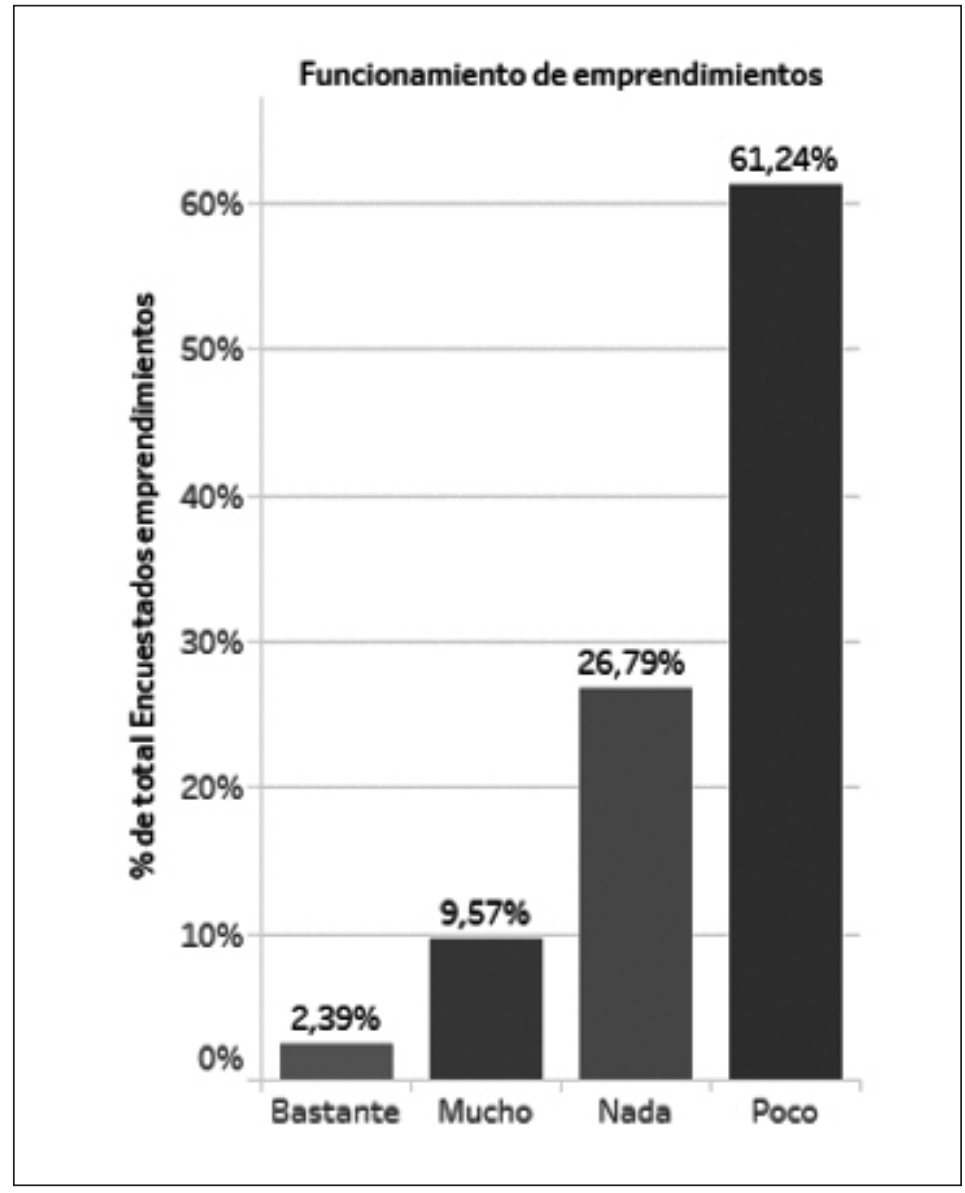

Figura 9. Funcionamiento de emprendimientos turísticos.

De forma similar a la pregunta anterior, 9 de cada 10 personas dan una evaluación negativa acerca de no conocer nada de la evolución de los emprendimientos (Figura 10). Además, los comuneros en las conversaciones generadas sobre el tema comentan que muchos de los emprendimientos relacionados con el producto turístico son de asociaciones que se crearon para poder trabajar con la empresa. Tal es el caso de la "Asociación Nariz del Diablo", cuyos integrantes trabajan en conjunto con la comunidad de Tolde, quienes se encargan de la demostración de danza y se turnan para las presentaciones. En el caso de la "Asociación de mujeres tejedoras de Nizag", que se originó en el año 2006 con 80 mujeres apadrinadas por el Programa de Pequeñas Donaciones de las Naciones Unidas, procedieron a la creación jurídica y a gestionar para que la comunidad de Nizag fuese tomada en consideración para la obtención de stands. Los productos realizados por la Asociación son comercializados en la estación Nariz del Diablo, cuyos contratos son renovados anualmente. Entre tanto en el museo étnico, las personas que trabajan en el lugar son parte de FEEP, las cuales se encargan de su administración y organización. 


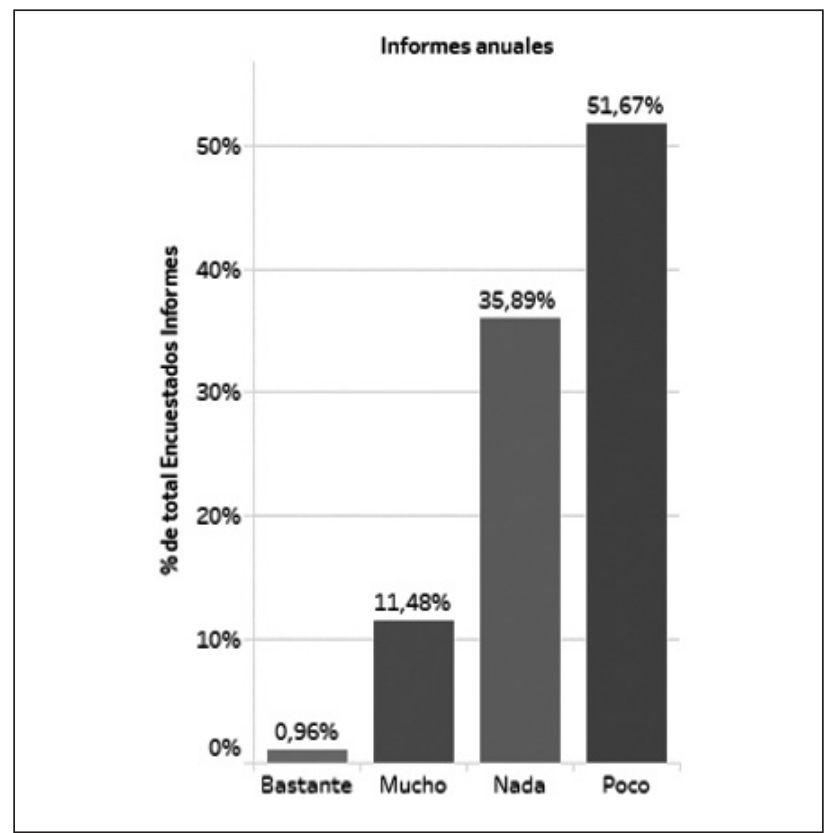

Figura 10. Informes anuales de emprendimientos.

En suma, las diferentes asociaciones que posee Nizag son básicamente elementos ajenos a la comunidad, a pesar que las personas que trabajan en dichos lugares son habitantes del lugar. Por consiguiente, no rinden cuentas de las actividades que se realiza con el producto turístico en las diferentes asambleas, ciertamente porque el porcentaje que es entregado a la comunidad por parte del Tren Crucero en cuestiones de ventas, no son lo suficientemente importantes para darlos a conocer.
La población de Nizag manifiesta tener insatisfacción, con un $62,20 \%$, respecto a los logros obtenidos en la vinculación de la comunidad con el Tren Crucero (Figura 11). La percepción que tiene la comunidad con respecto al Tren Crucero no es necesariamente que este sea el eje principal de su economía y mucho menos ayude al desarrollo local. En consecuencia, la comunidad se encuentra desinteresada de comentar acerca del tema por desconocimiento de sus actividades y poca importancia con la que es tomado el producto turístico dentro de la comunidad.

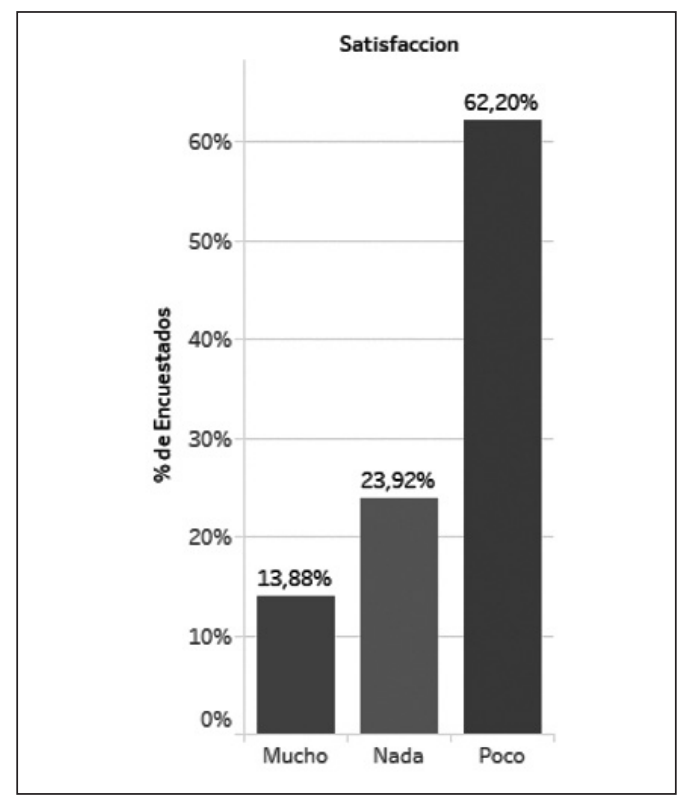

Figura 11. Satisfacción de logros obtenidos por emprendimientos turísticos mediante el Tren Crucero. 
Con respecto al incentivo de actividades recreativas por parte de FEEP, se manifiesta que su participación es nula, con un 57\% (Figura 12), pues- to que la mayoría de habitantes indica el desconocimiento de las actividades que realiza la empresa en la comunidad.

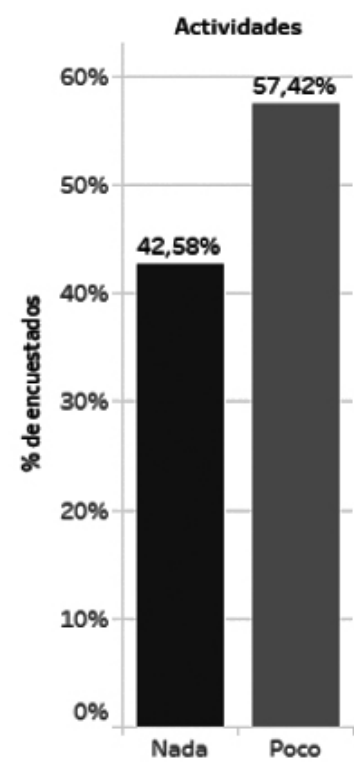

Figura 12. Realización de eventos recreativos por parte de FEEP.

La muestra de la comunidad de Nizag supo manifestar que la vinculación con el proyecto Tren Crucero no ha ayudado a mejorar las vías de acceso a la comunidad (Figura 13). En la visita de campo se pudo evidenciar la decadencia de las vías de acceso puesto que hasta llegar a la entrada a la comunidad la vía es de primer orden, por tratarse de la carretera que conduce a la ciudad de Cuenca, pero al llegar al desvío para ingresar a la comunidad esta se torna de tercer orden o camino de tierra (Figura 14). Al realizar la visita de campo se constató el mal estado por la temporada de invierno, lo que genera deslizamientos de tierra y, en general, el acceso a la comunidad se torna difícil.

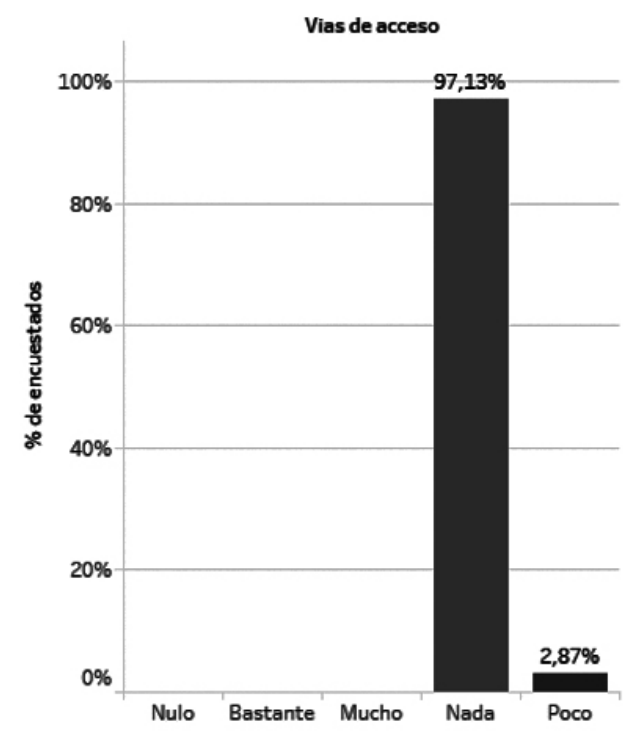

Figura 13. Mejoras de vías de acceso. 


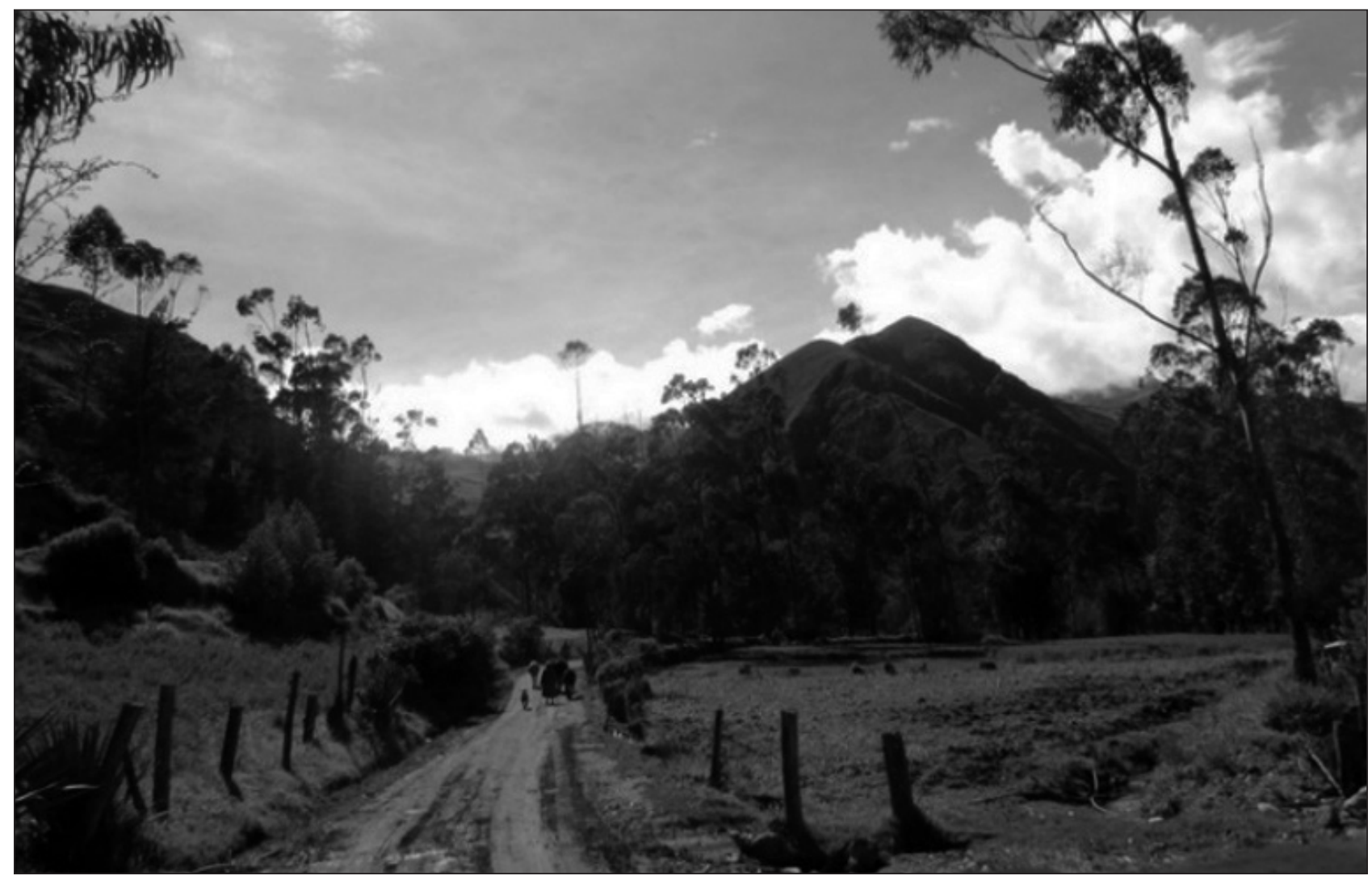

Figura 14. Fotografía de vías de acceso a Nizag.

Según las entrevistas realizadas, los comuneros comentan que el tener las vías en ese estado genera un gran problema para su movilización, puesto que muchas veces los medios de transporte se niegan a ingresar a la comunidad por el peligro que representa la vía, dejando en muchos casos incomunicados a sus habitantes que deben caminar, en ocasiones alrededor de una hora. Según Zoila Guamán, ex presidenta de la Asociación de Mujeres Tejedoras de Nizag la empresa de Ferrocarriles no ha intercedido para la realización de mejoras en las vías, a pesar que la comunidad como tal se encuentra a una hora y media a pie por un camino de tercer orden hasta la estación Nariz del Diablo. La empresa solamente ha puesto interés en las mejoras alrededor de la estación y Nizag al estar tan alejada de esta no recibe ayuda de este tipo.

La evaluación acerca de las vías de acceso en la investigación se la realizó por ser una de las pautas que se encuentran dentro del Plan Nacional de Desarrollo, el que habla en el Objetivo 6 sobre desarrollar las capacidades productivas y del entorno para lograr la soberanía alimentaria y el Buen Vivir rural. Ya que al no tener vías de acceso adecuadas para el ingreso a la comuna no se puede desarrollar de manera eficiente la productividad y mucho menos mejorar el entorno de la población. En conclusión, estos inconvenientes son de gran importancia y con la vinculación al Tren el deseo de la comunidad era cambiar esta situación lo cual no se ha producido.

Al igual que la anterior pregunta se evidencia que no han existido mejoras en los medios de transporte para el ingreso a la comunidad (Figura 15), y las camionetas que lo hacen solamente trabajan hasta las 5 de la tarde. Con respecto al tipo de transporte que ingresa a la comunidad, en la visita de campo se pudo observar que se trata de camiones y camionetas las cuales muchas veces no tienen las seguridades necesarias para el transporte de personas, lo que genera incomodidad en el traslado hasta la comunidad. El valor por la 'carrera' en camioneta es de 6 dólares americanos y en camiones de 0,50 centavos, recorrido que dura aproximadamente $30 \mathrm{~min}$ si no hay inconvenientes en el camino de ingreso a la comunidad. El señor transportista Miguel Mendoza supo manifestar que el peligro que representa el ingreso en la noche a la comunidad genera que su trabajo se detenga a las 5 de la tarde por lo que a partir de esa hora la población debe caminar para su ingreso o esperar en Alausí hasta el siguiente día para poder regresar a sus hogares, es por ello que la población prefiere solamente salir del lugar cuando es necesario, evitándose de ese modo inconvenientes en su travesía. 


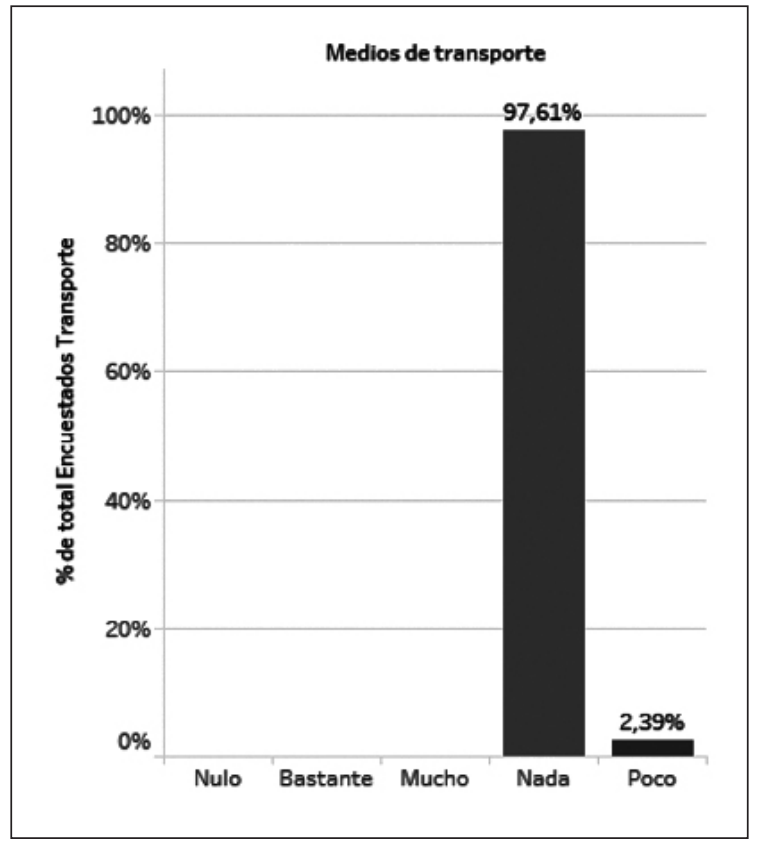

Figura 15. Mejoras en medios de transporte.

Con respecto a la pregunta sobre la mejora de la salud pública se evidencia que el desarrollo de mejoras es nulo (Figura 16), aunque la comunidad cuente con un subcentro de salud que atiende situaciones básicas de la población. La comunidad esperaba que en base a la vinculación con el producto turístico se generara la resolución a esta problemática, lo que lleva nuevamen- te al Plan Nacional de Desarrollo con el que trabajan todas las empresas públicas. Cuyo objetivo 1 indica que se garantizará una vida digna con iguales oportunidades para todas las personas, sin embargo, la población no ha podido satisfacer las necesidades básicas como es la salud y la empresa FEEP no ha logrado establecer uno de los principales objetivos del plan.

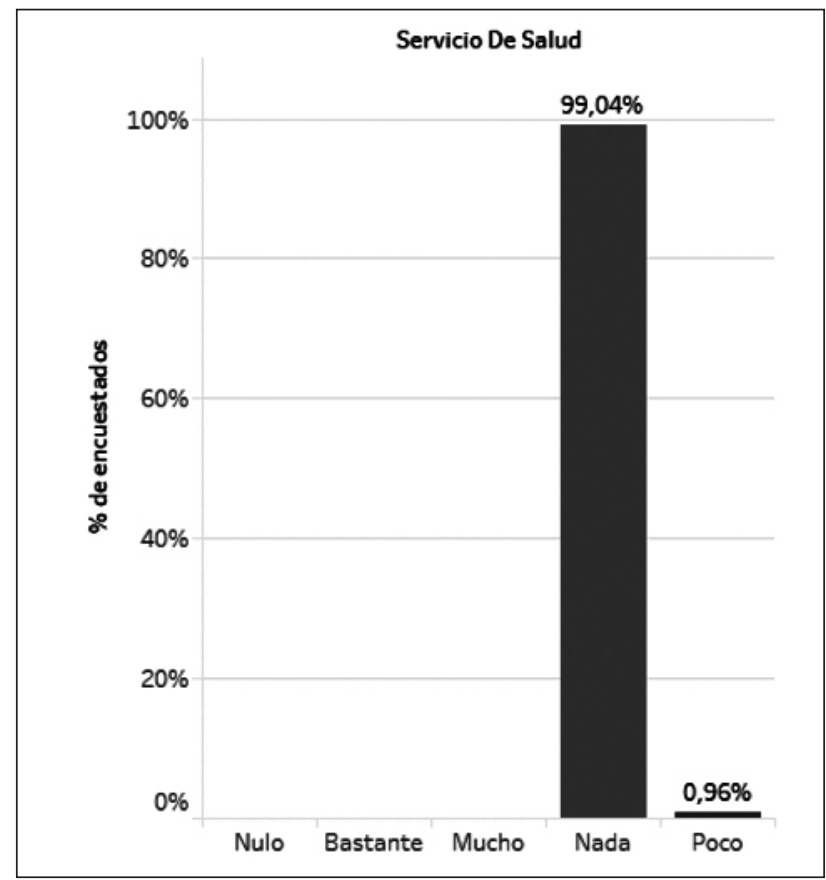

Figura 16. Mejoras en servicios de salud.

En lo referente a mejoras de los servicios educativos por la vinculación de la comunidad al pro- yecto, se señala que su participación es nula con un $85,17 \%$, con respecto a este punto (Figura 17). 


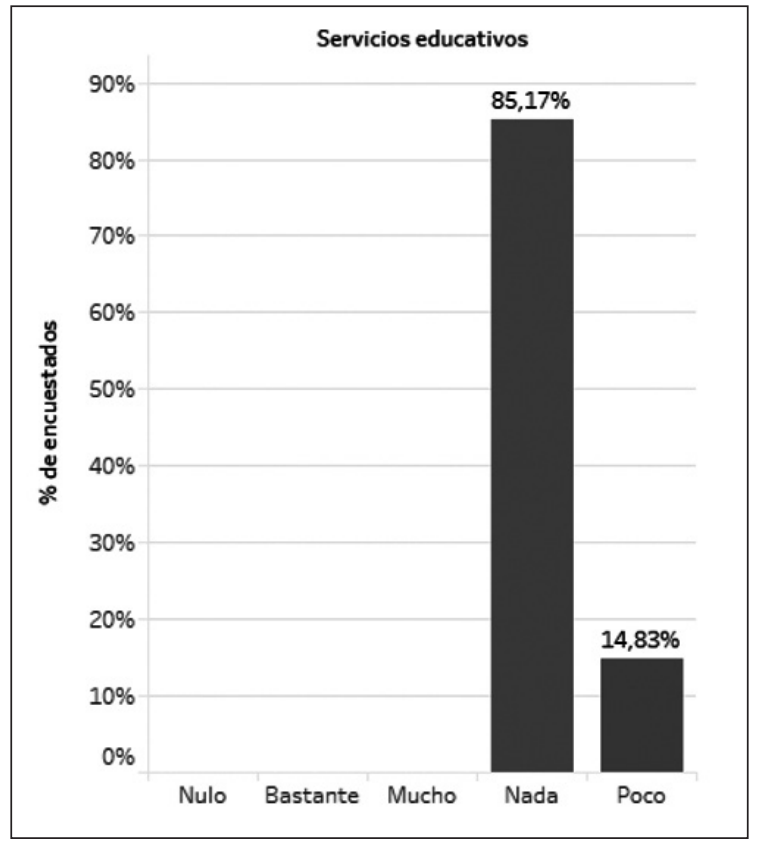

Figura 17. Mejoras de servicios educativos

Tomando en cuenta los análisis anteriores de las preguntas efectuadas a la población, se evidencia que no existe un trabajo integral entre las instituciones públicas para lograr el desarrollo local en la comunidad por lo que surge el cuestionamiento de ¿cuál es la diferencia que existe entre FEEP y el producto turístico Tren Crucero con una cadena hotelera privada? Al realizar la visita de campo se pudo evidenciar a simple vista que el desarrollo local en la comunidad es nulo y su realidad es ajena a lo que se comercializa a nivel mundial sobre el Tren Crucero, de ser una empresa pública sostenible. Que como consecuencia ha ganado varios reconocimientos por su labor con las comunidades, generando la duda de cuáles son realmente los parámetros que se evalúan para conseguir dichos premios y si estos de verdad son constatados en las comunidades donde se supone debe existir dicho desarrollo local según el marketing del Tren Crucero.

Sobre el tema de la migración, la comunidad manifiesta en un $77 \%$ que es Poco el impacto generado por la vinculación de la comunidad al proyecto Tren Crucero (Figura 18). Ya que las asociaciones desarrolladas en la comunidad no han tenido la influencia necesaria para mitigar dicho fenómeno. Por tanto, el Tren Crucero no ha creado suficiente empleo para evitar la migración y ciertamente no ha generado tampoco expectativa en los jóvenes de la comunidad para desarrollar carreras referentes a las actividades con el Tren Crucero.

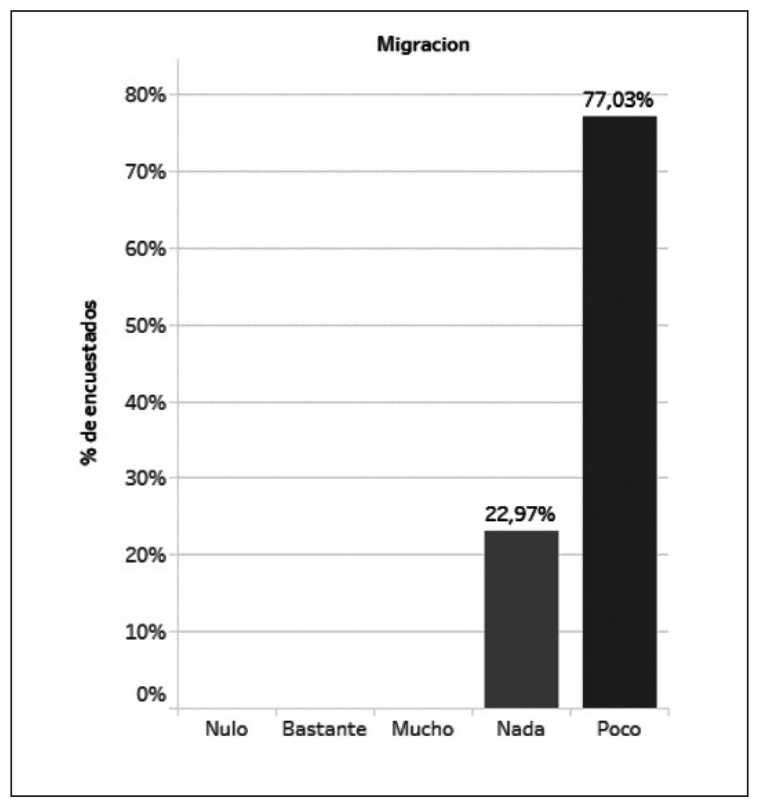

Figura 18. Migración. 
Con respecto al desarrollo de nuevas actividades en la comunidad, en la figura 19 se indica que esto sí se ha presentado en un $42,58 \%$, puesto que una de las actividades con las que colaboran con el Tren Crucero son las artesanías que se elaboran con la materia prima que se obtiene de los pencos que la misma población cosecha; así también aportan con productos típicos de la región para la venta en la cafetería de la estación, pero la actividad económica aún es débil.

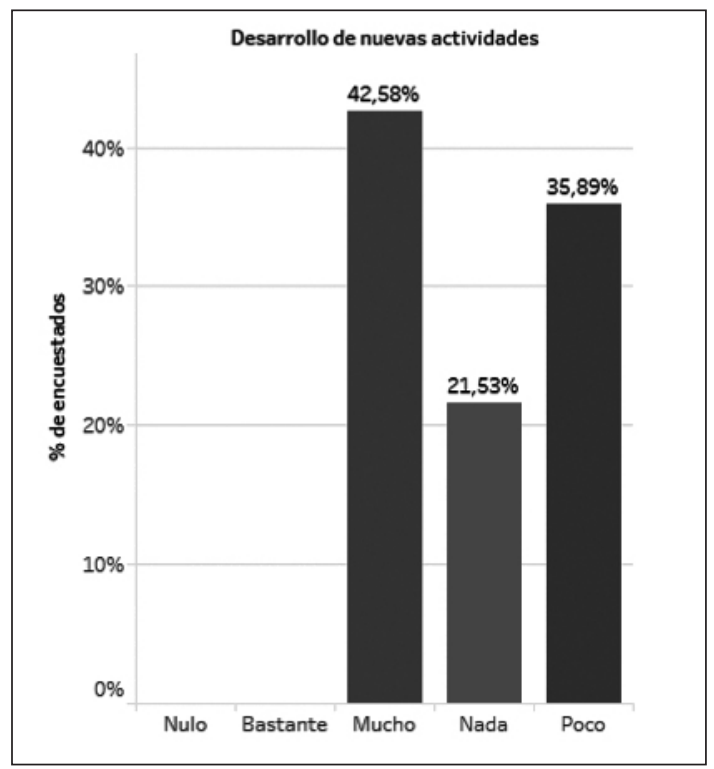

Figura 19. Desarrollo de nuevas actividades productivas.

En lo que respecta a la pregunta sobre fuentes de empleo la comunidad estudiada indica con un $49,76 \%$ que Poco (Figura 20), Es decir, la evaluación es algo positiva puesto que 4 de cada 10 personas señalan que sí ha contribuido al desarrollo de nuevas (aunque pocas) fuentes de trabajo la vinculación del Tren Crucero con la comunidad, ya que hay una variedad de actividades que ofertan a la empresa, pero todavía no es suficiente. En las asociaciones los puestos de trabajo son:

- Asociación Nariz del diablo, con 5 integrantes.

- Asociación de Mujeres Tejedoras Nizag, en la actualidad cuenta con 31 socias.

- Museo étnico y cafetería en la estación Nariz del Diablo, cuenta con 8 personas.

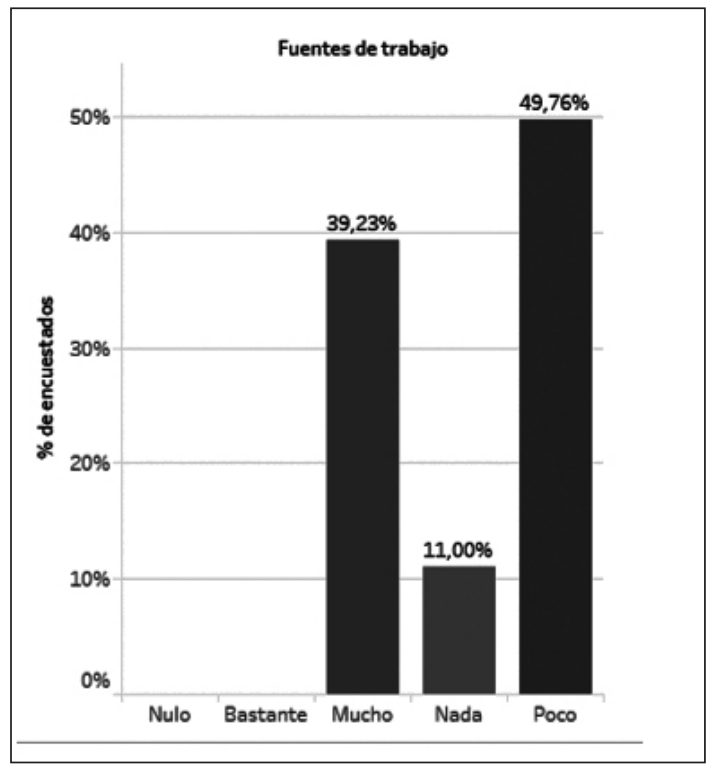

Figura 20. Desarrollo de nuevas fuentes de trabajo. 
Según la comunidad de Nizag, en un 50,72\% es poco el ingreso económico que genera la vincu- lación del proyecto con la comunidad (Figura 21).

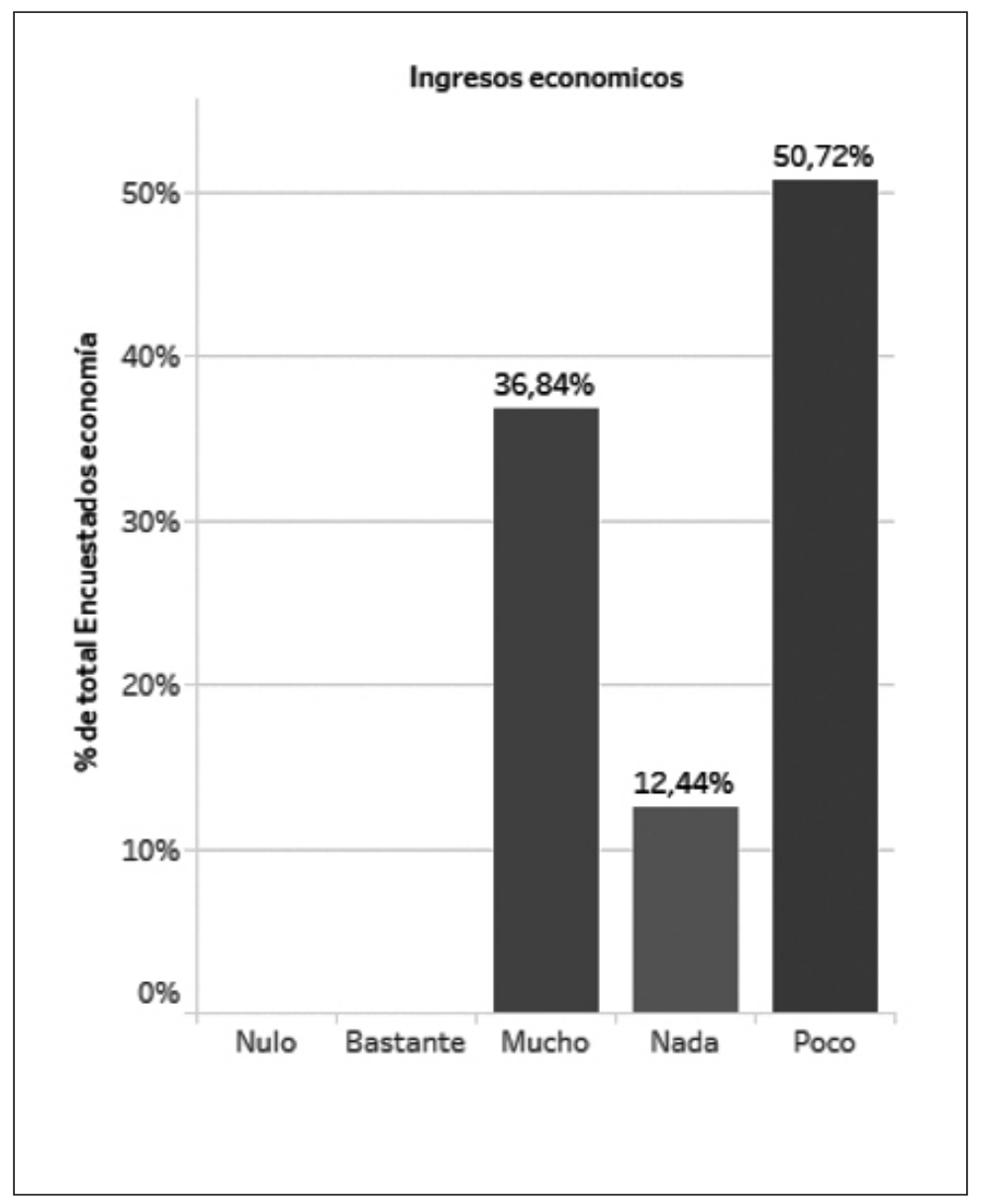

Figura 21. Nuevos ingresos económicos

\subsection{Resumen de encuestas}

La percepción de los habitantes de la comunidad de Nizag acerca de los beneficios de la vinculación con el proyecto Tren Crucero es negativa, puesto que aún hay mucho trabajo que realizar para el desarrollo de la misma, por tanto, existe una brecha en ciertos aspectos que no se han realizado para el impulso del desarrollo local. Una de las deficiencias detectadas en la investigación de campo es la poca o nula comunicación e interacción que existe entre la empresa FEEP con la comunidad lo que genera no solamente desconocimiento de las actividades, sino también contribuye a que la población no se sienta identificada con la empresa y sus actividades. En consecuencia, la percepción de la comunidad con respecto al Tren Crucero es de un agente ajeno a la comunidad, el cual no ha podido generar una cadena de valor local significativa para que todas las fami- lias o la mayoría de ellas se encuentren involucradas en el proceso de desarrollo local que supuestamente genera el producto turístico Tren Crucero.

En conclusión, los resultados son incipientes con base en la medición de impactos, pues la evidente fragmentación que existe en la comunidad respecto a quienes trabajan con el Tren Crucero y quienes no tienen conocimiento de la actividad, genera exclusión dentro de la comunidad respecto a la participación y obtención de beneficios.

\subsection{Resultados de encuestas en Palacio Real}

La comunidad Palacio Real está conformada en su mayoría por jóvenes (37,37\%), que oscilan entre 3544 años de edad (Figura 22). Datos que ingresan en los parámetros correspondientes a la pirámide poblacional del Ecuador en la cual la tercera edad constituye uno de los grupos más pequeños, según datos del INEC (2010). 


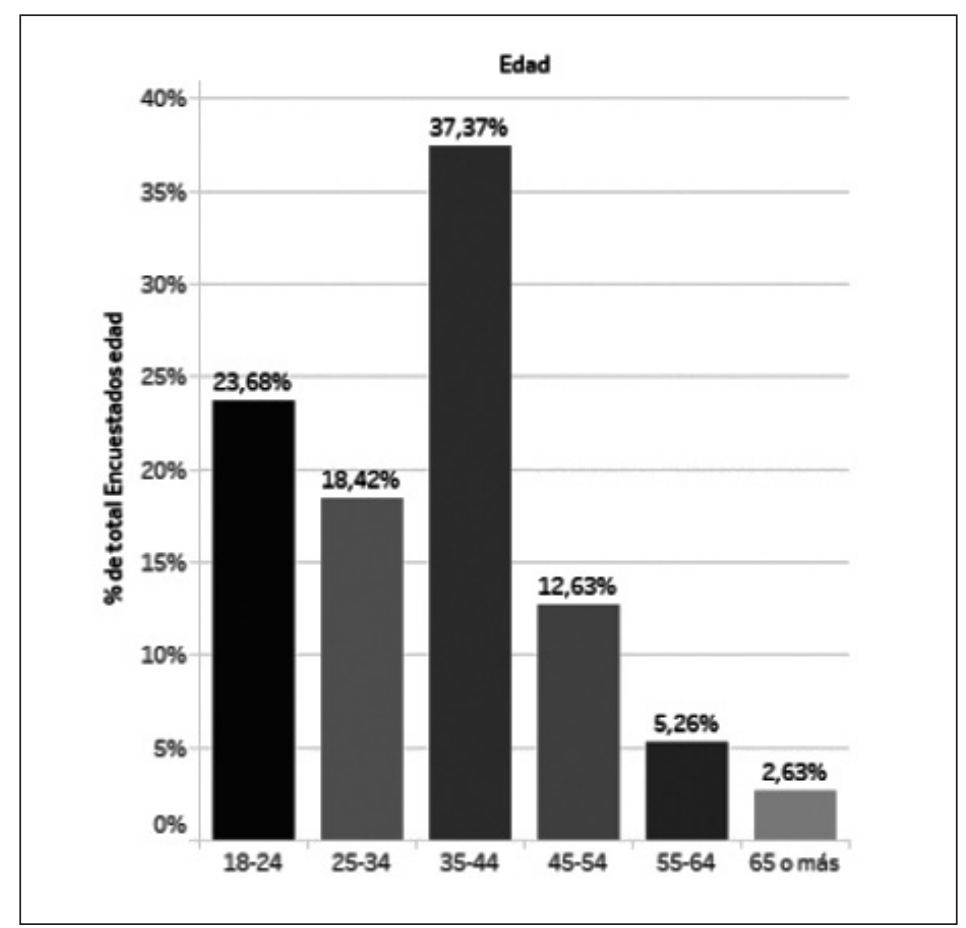

Figura 22. Edades.

La comunidad Palacio Real se encuentra integrada en su mayoría por mujeres $(58,95 \%)$, en relación con los hombres (41,05\%), según la muestra estudiada (Figura 23). Datos que de igual manera ingresan dentro de los parámetros típicos de las zonas rurales del Ecuador relacionados al mayor porcentaje de mujeres que habitan en la comunidad, según datos del INEC (2010).
Con respecto a la composición del número de personas que componen el hogar se evidencia un $55,26 \%$ de 5 o más personas (Figura 24), lo que indica que se encuentran en el índice de personas que conforman los hogares en las zonas rurales del Ecuador, según datos del INEC (2010).

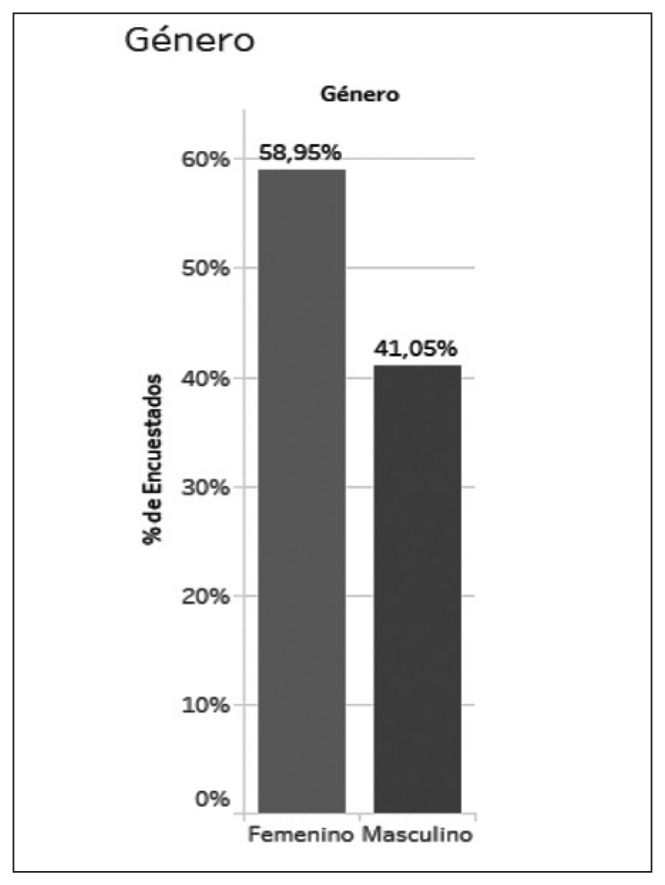

Figura 23. Género. 


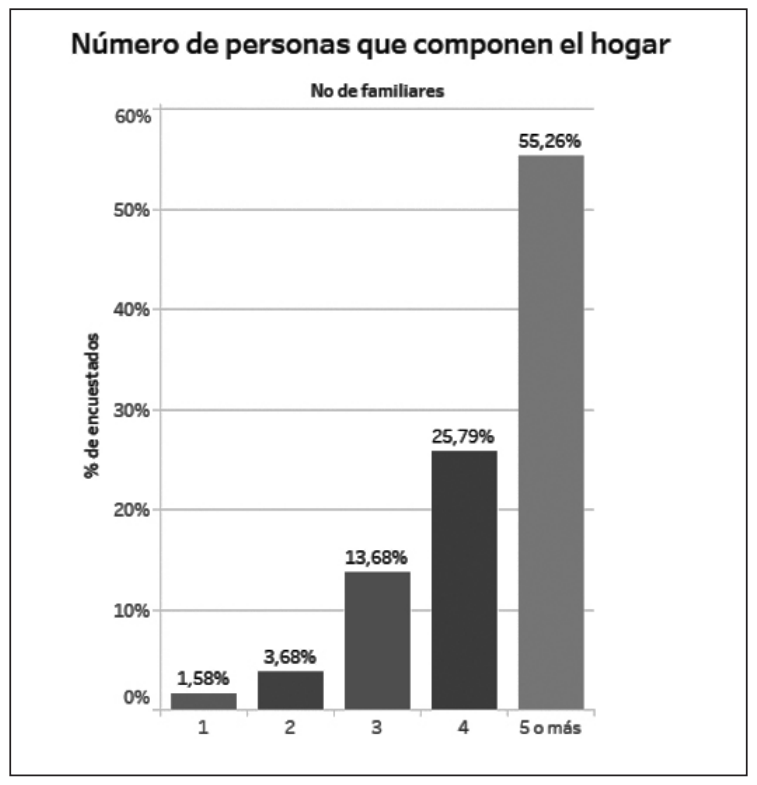

Figura 24. Número de integrantes que componen el hogar de la comunidad Palacio Real.

A continuación, se presenta el resultado de las preguntas planteadas, las cuales tienen como objetivo conocer la percepción de los comuneros acerca de la vinculación y desarrollo de la comunidad con el producto turístico Tren Crucero.

Sobre el funcionamiento de los emprendimientos turísticos de la comunidad con el Tren Crucero el conocimiento es Poco con un porcentaje de 57,89\% (Figura 25). Es decir, 9 de cada 10 personas manifiestan que casi no conocen acerca de los emprendimientos turísticos generados por el Tren Crucero. Aunque tienen conocimiento acerca de que el producto envía turistas al igual que otros operadores con los que trabajan pues la comunidad como tal tiene establecido ya su propio centro turístico comunitario.

Esta comunidad comenzó con la actividad turística desde hace 10 años por iniciativa del párroco de la zona, el cual organizó a la comunidad para la implementación de un centro turístico comunitario (Figura 26). En la actualidad ha tenido buena acogida en el sector turístico razón por la cual mantiene otras asociaciones que ayudan al desarrollo de la actividad.

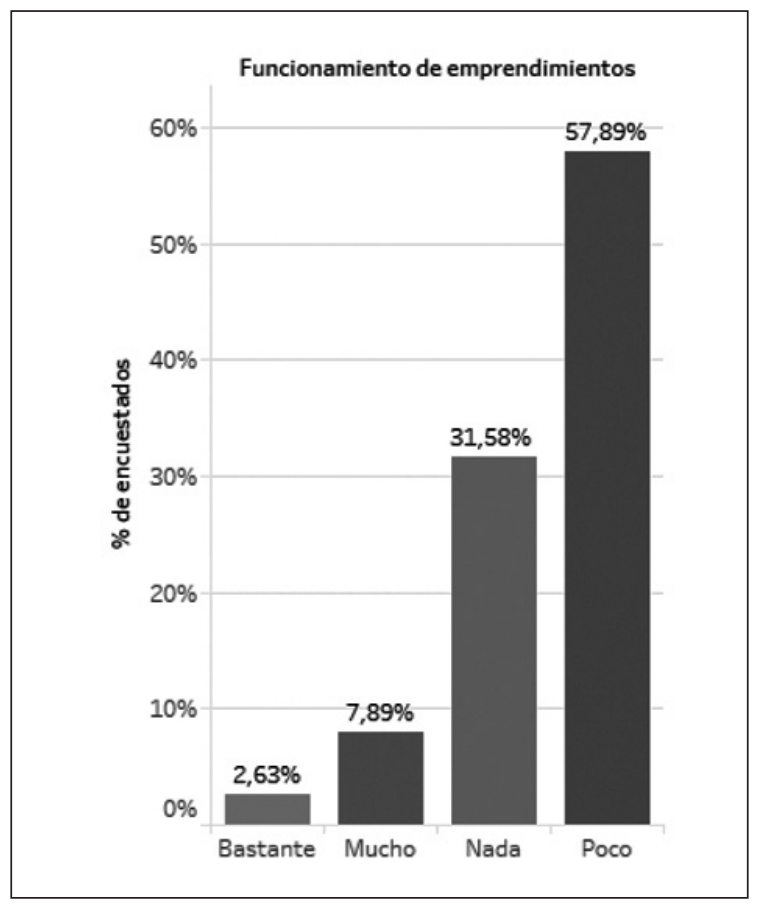

Figura 25. Funcionamiento de emprendimientos turísticos. 


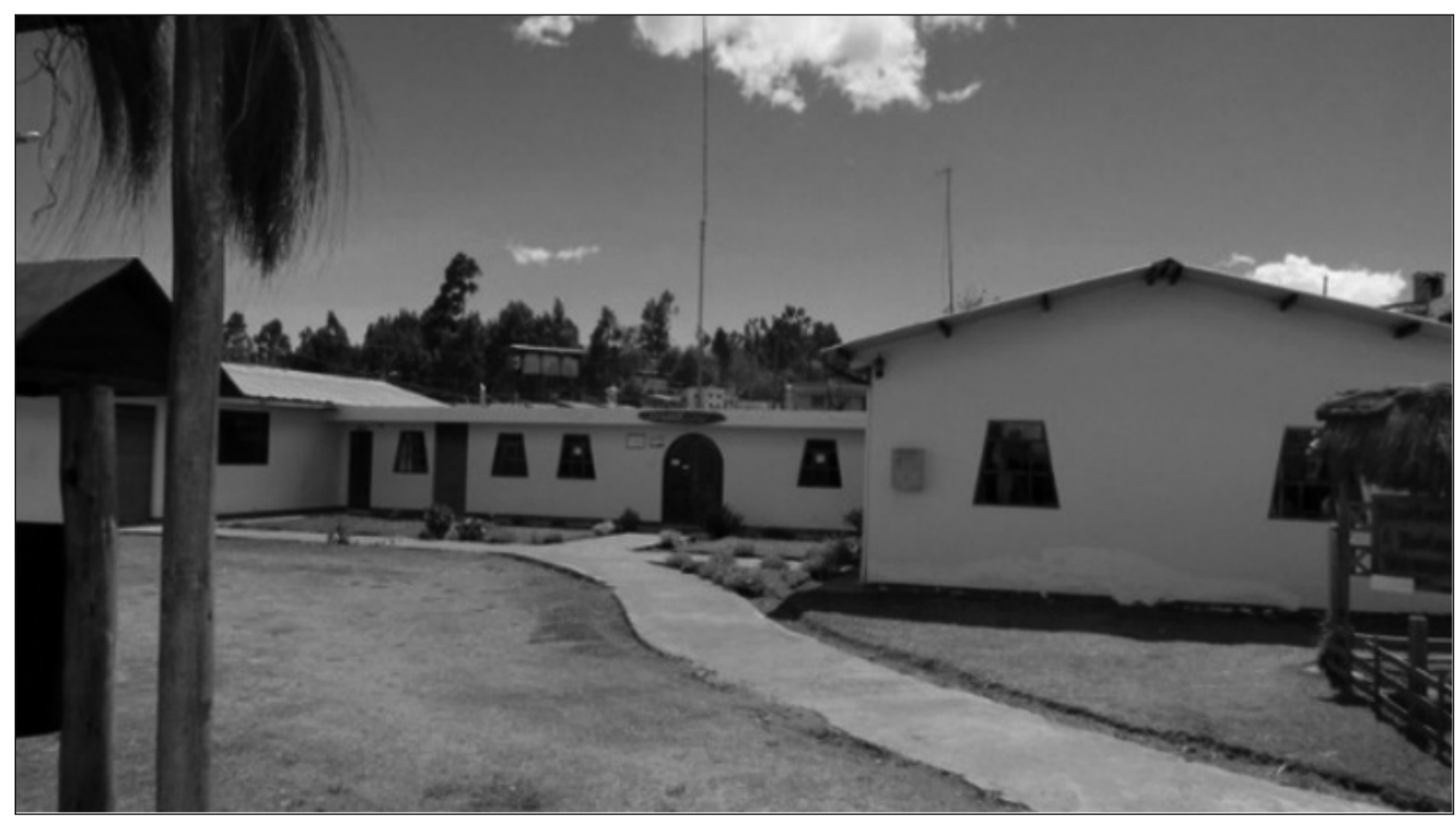

Figura 26. Foto del centro comunitario turístico Sumak Kawsay Palacio Real.

Los emprendimientos vinculados con el Tren Crucero generan informes de sus actividades a la comunidad con un 64,74\% (Figura 27), es decir 8 de cada 10 personas conoce sobre el estado del emprendimiento con respecto a la vinculación con el producto Tren Crucero. Se realizan asambleas entre 4-5 veces al año para dar a conocer el desarrollo de la actividad con referencia al turismo en general, es decir que dentro de los informes se encuentra también incluidos datos sobre el producto turístico Tren Crucero y el desarrollo del mismo. Además, la comunidad comentó que los informes son fundamentales para ellos, pues así pueden saber cuál es el nivel de desarrollo que se está obteniendo con respecto a la actividad turística en general, pero que el tema Tren Crucero no es primordial al realizar las sesiones puesto que es considerado un proveedor más.

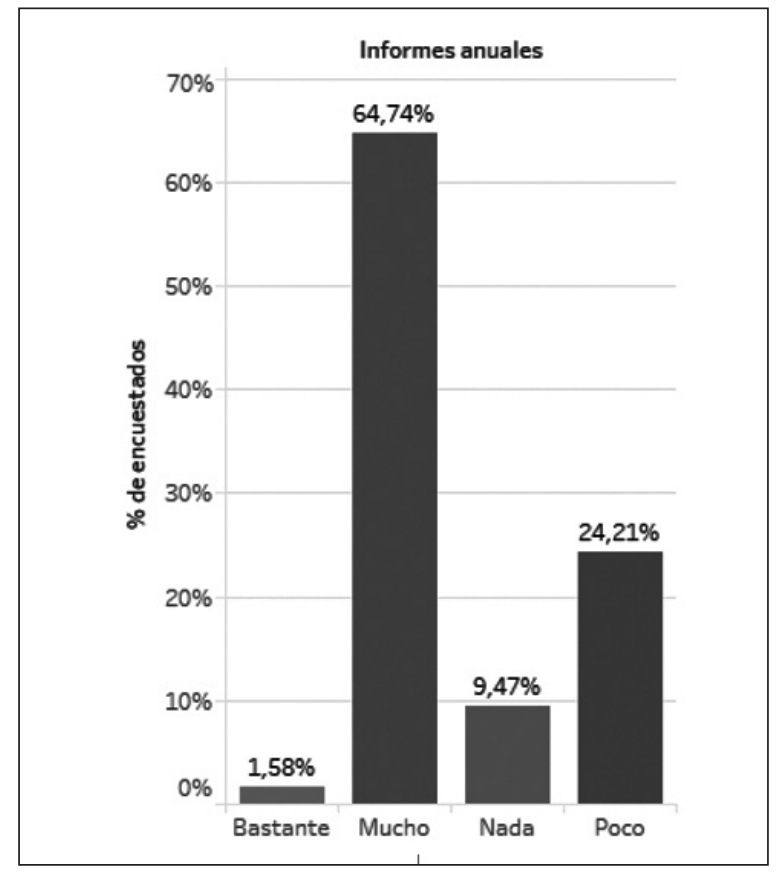

Figura 27. Informes anuales de estado de emprendimientos. 
Según la muestra de la comunidad un $44,21 \%$ se encuentra muy satisfecho con los logros obtenidos, seguido por un poco de satisfacción con $40 \%$ (Figura 28), lo que indica que la comunidad en general tiene una acogida positiva de los logros. Aunque estos datos como lo indica Luis Alberto
Pagalo, poblador de la comunidad, son en general con respecto a la actividad turística comunitaria ya que ellos perciben al Tren Crucero como un proveedor el cual ayuda con el traslado de turistas a la comunidad al igual que otras operadoras con las que trabajan.

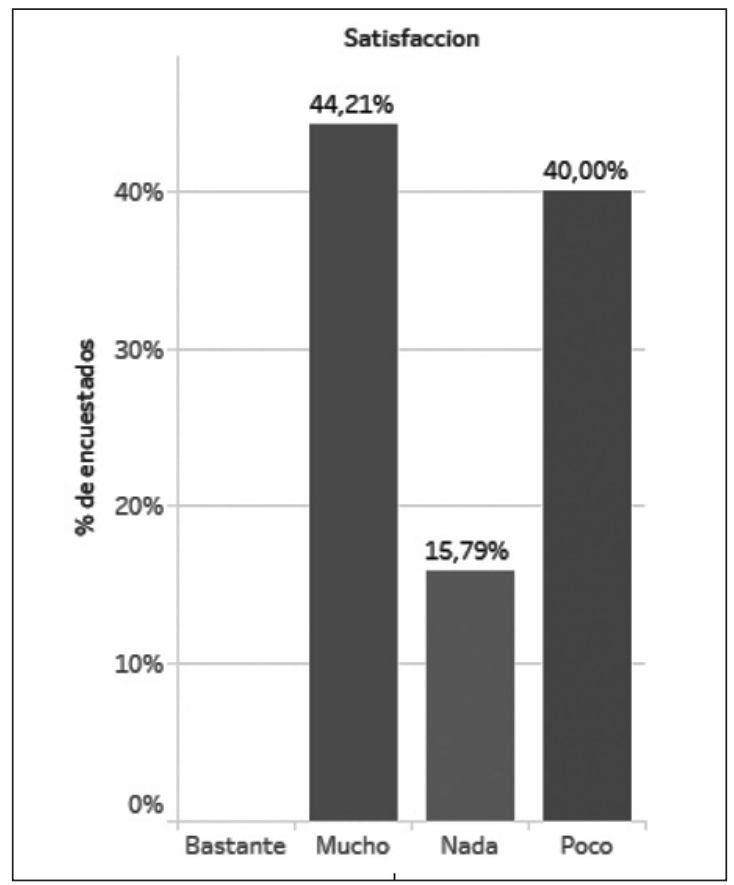

Figura 28. Satisfacción de logros obtenidos.

Con respecto a la pregunta sobre actividades recreativas se indica que es poco el auspicio por parte de ferrocarriles con un 65,26\% (Figura 29). Es decir que 9 de cada 10 personas perciben que no existe integración con la empresa mediante activi- dades recreativas. En charlas realizadas con trabajadores del restaurante de la comunidad comentaron que no se realizan actividades recreativas por parte de FEEP, y si en algún momento se realizó dicha actividad no hubo difusión.

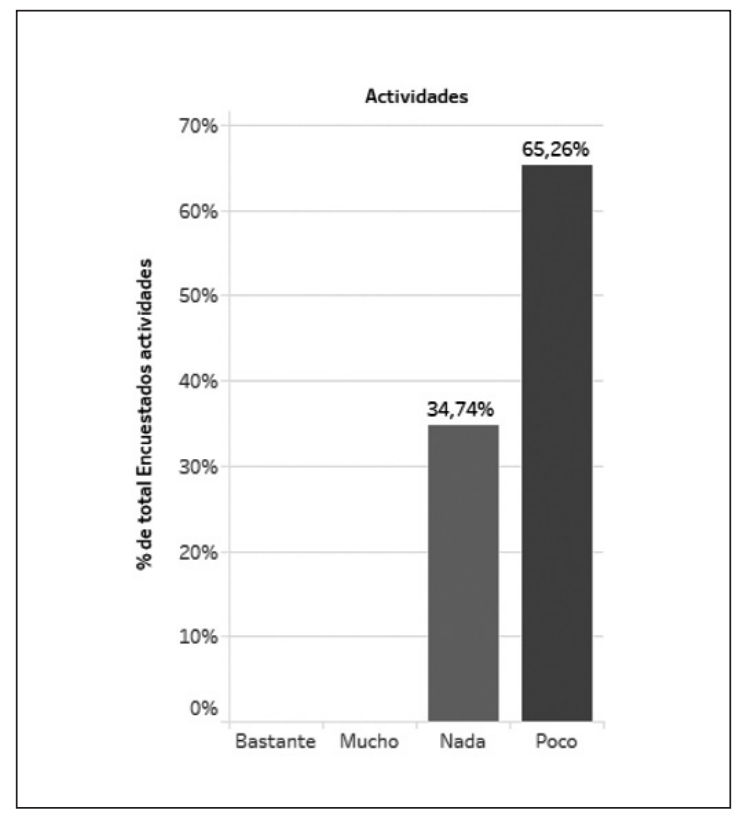

Figura 29. Auspicio de actividades recreativas. 
En cuanto al mejoramiento de vías de acceso, un $92,63 \%$ señala que no se han realizado mejoras de vías por pertenecer al proyecto turístico Tren Crucero (Figura 30). Más bien argumentan que la ayuda proviene del Consejo Provincial, el cual ha efectuado las respectivas mejoras en las vías que van hacia la comunidad. Las vías de ingreso a la comunidad se encuentran en excelente estado. Para el ingreso se debe tomar el bus que va por la vía a Guaranda, hasta la entrada a la comunidad Palacio Real en la cual se debe caminar alrededor de $1 \mathrm{~km}$ para el ingreso.

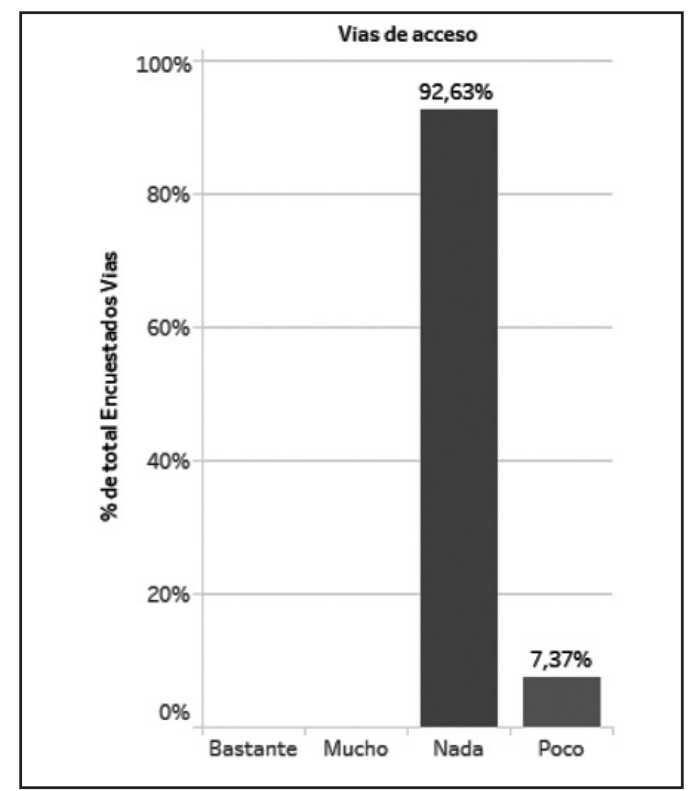

Figura 30. Mejoramiento de vías.

La vía terrestre es de primer orden por lo que llegar no representa mayor dificultad (Figura 31). Otra opción es tomar desde Riobamba una 'carrera', la cual tiene un costo de $\$ 3,00$. Por ser una comunidad conocida es fácil encontrar el camino de entrada y por la señalética que se encuentra al inicio de la vía hacia la comunidad la cual indica que es implementada por el MINTUR. Al comparar este ítem con los objetivos del Plan Nacional de Desarrollo, las vías que posee la comunidad son adecuadas para permitir el ingreso de turistas, y además ayudan a su desarrollo, por lo tanto, las entidades públicas han realizado su trabajo, aunque no ha sido por colaboración de FEEP.

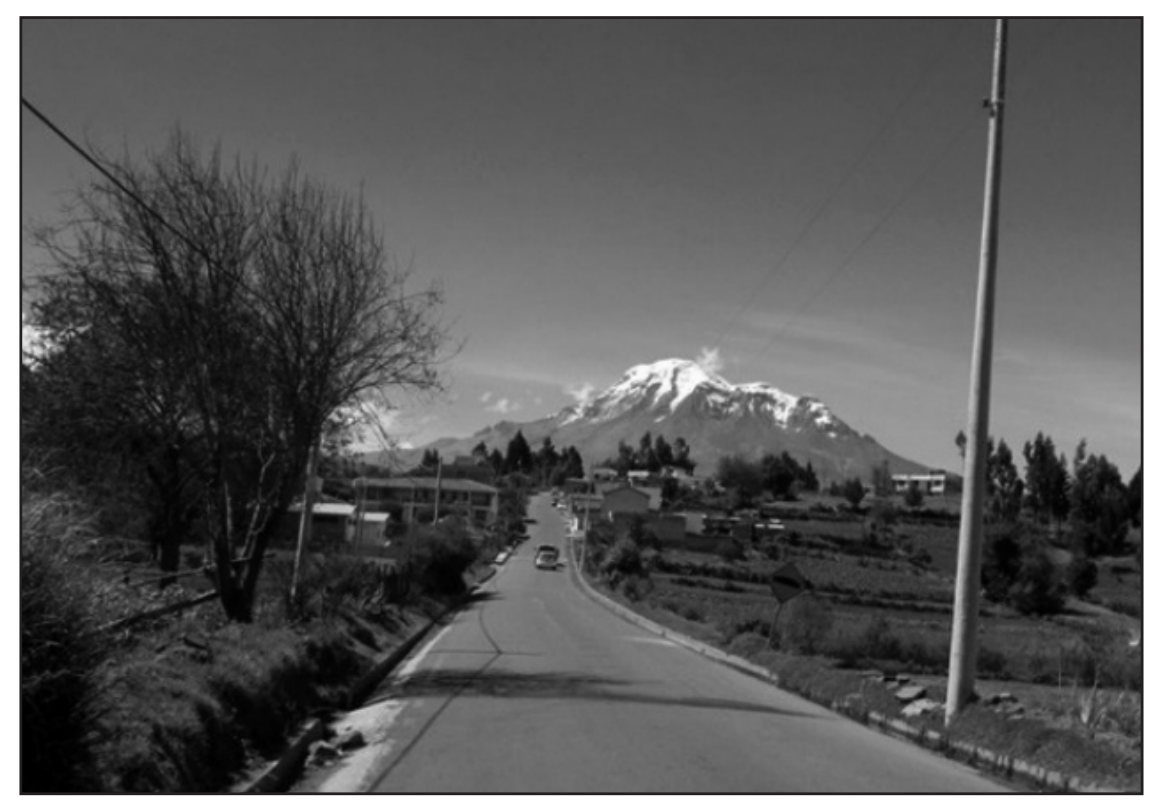

Figura 31. Foto de la vía de ingreso a la comunidad Palacio Real. 
En cuanto a la percepción que tiene la comunidad acerca de la mejora de los medios de transporte, un $76,32 \%$ dice que poco se ha ayudado respecto al tema (Figura 32). Es decir que 9 de cada 10 personas aseguran que no existe intervención en las mejoras de transporte por parte de FEEP. Para el ingreso a la comunidad se debe tomar una camioneta o transporte propio, aunque aseguran que con la implementación del turismo en la comunidad es más constante el flujo de transporte. Las 'carreras' de las camionetas son tomadas en grupo para abaratar costos ya que se divide el total para los que integran el grupo.

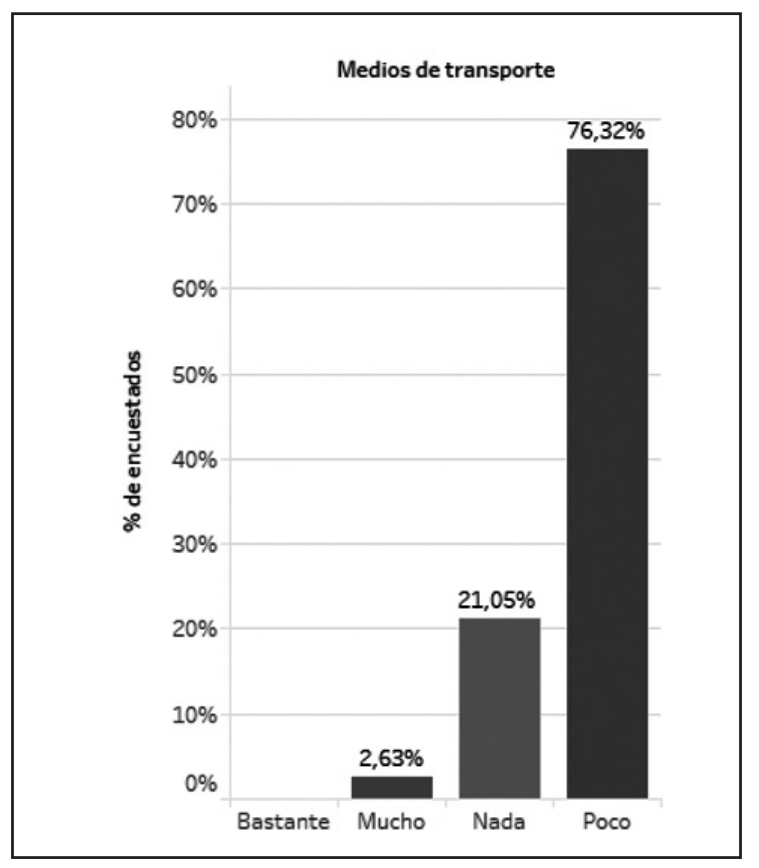

Figura 32. Mejora de medios de transporte.

El mejoramiento del aspecto salud en relación con la vinculación con el proyecto turístico es nulo (Figura 33), pues en este sentido el estar dentro del proyecto Tren Crucero no ha generado dicha ayuda. A pesar que la comunidad tiene su centro de salud, este lugar aún no se encuentra equipado debidamente para atender mayores problemas, razón por la cual la población esperaba mejorar el estado del mismo con la ayuda de la vinculación al Tren Crucero.

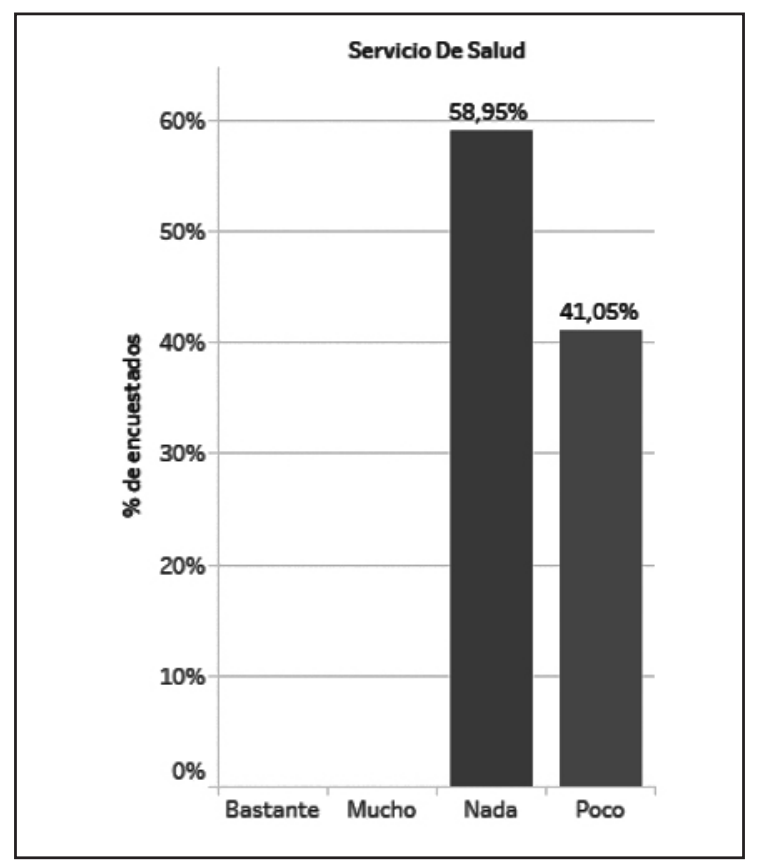

Figura 33. Mejoras de servicios de salud. 
Con respecto a la mejora de los servicios educativos la comunidad indica que es nula la ayuda proporcionada por parte de la empresa, puesto que 9 de cada 10 personas opina que el Tren Crucero no ha ayudado a la implementación de mejoras (Figura
34). En cuanto a las preguntas relativas a la mejora de servicios de transporte, vías de acceso, educación y servicios de salud estos han sido implementados por gestiones realizadas por los mismos comuneros en las instituciones públicas para la obtención de resultados.

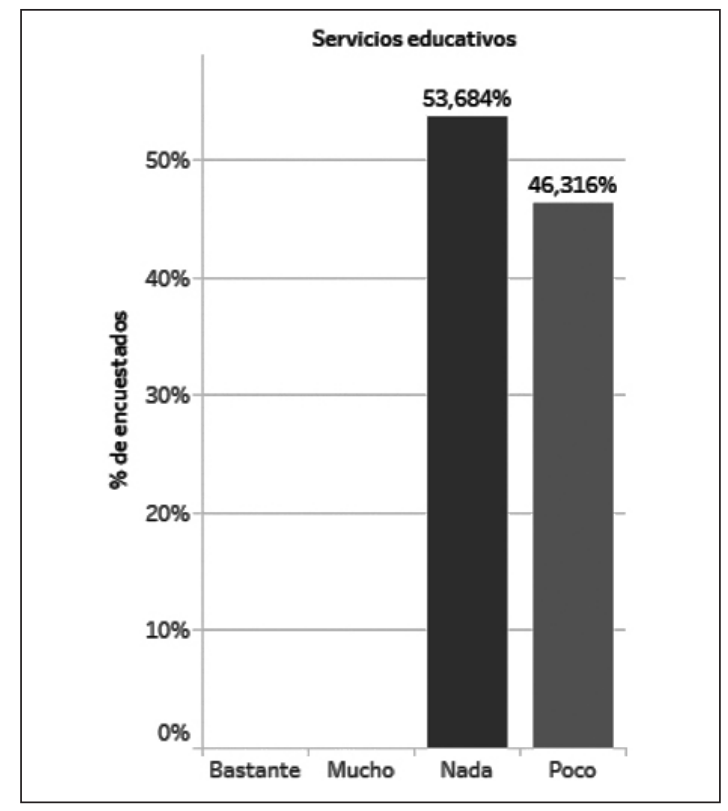

Figura 34. Mejoras de los servicios educativos.

Tomando en cuenta el análisis de estas preguntas se plantea el cuestionamiento ¿será que FEEP y el Tren Crucero se han planteado la realización de proyectos de impacto en las comunidades para mejorar su nivel vida o como cualquier empresa privada piensa que la generación de trabajo es suficiente para su desarrollo?

En lo referente a la migración, un $63,16 \%$ señala que este aspecto sí se ha mitigado (Figura 35), pero este no solamente ha sido como consecuencia de la vinculación del Tren Crucero con la comunidad. En parte ha sido por la implementación del turismo comunitario que aquí se ha desarrollado, puesto que en la comunidad se oferta alojamiento, alimentación, guianza y venta de artesanías en la que participa toda la comunidad, ya sea de forma directa o indirecta.

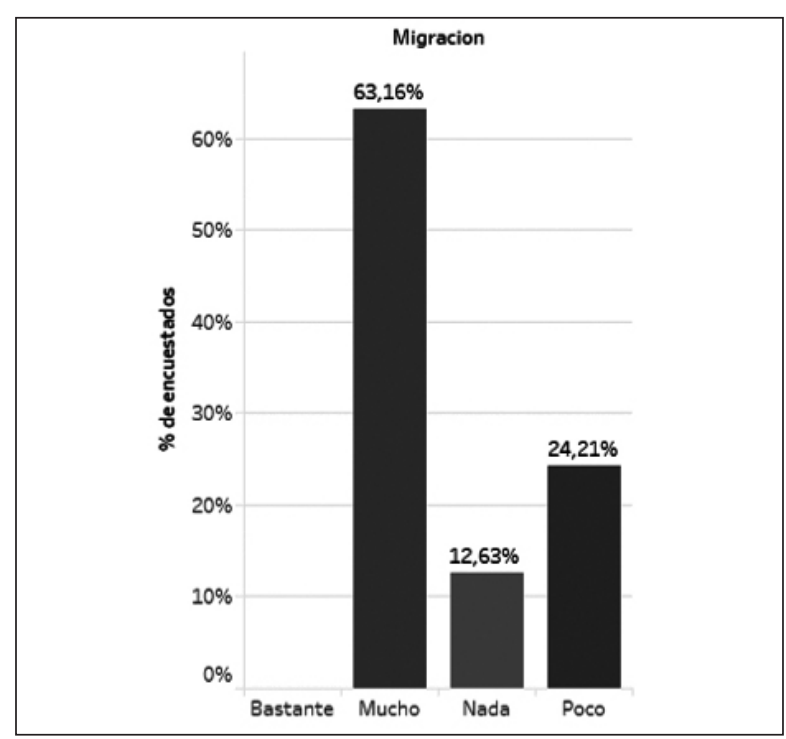

Figura 35. Mitigación de migración en la comunidad Palacio Real. 
En lo que respecta al desarrollo de nuevas actividades productivas en la comunidad, el gráfico indica que un 63,16\% (Figura 36), es decir, 6 de cada 10 personas, tienen una percepción muy positiva sobre el mismo, puesto que toda la comunidad se encuentra involucrada de forma directa e indirecta en las actividades relacionadas con la oferta turística que propor- cionan al Tren Crucero, ya que los turistas llegan hasta la comunidad para la obtención de los servicios los cuales consisten en almuerzo, guianza por el Museo Cultural de La Llama y visita al mirador Mira Loma, lugar privilegiado para la observación del volcán Chimborazo; por esta razón la actividad que se genera en la comunidad es directa con los turistas.

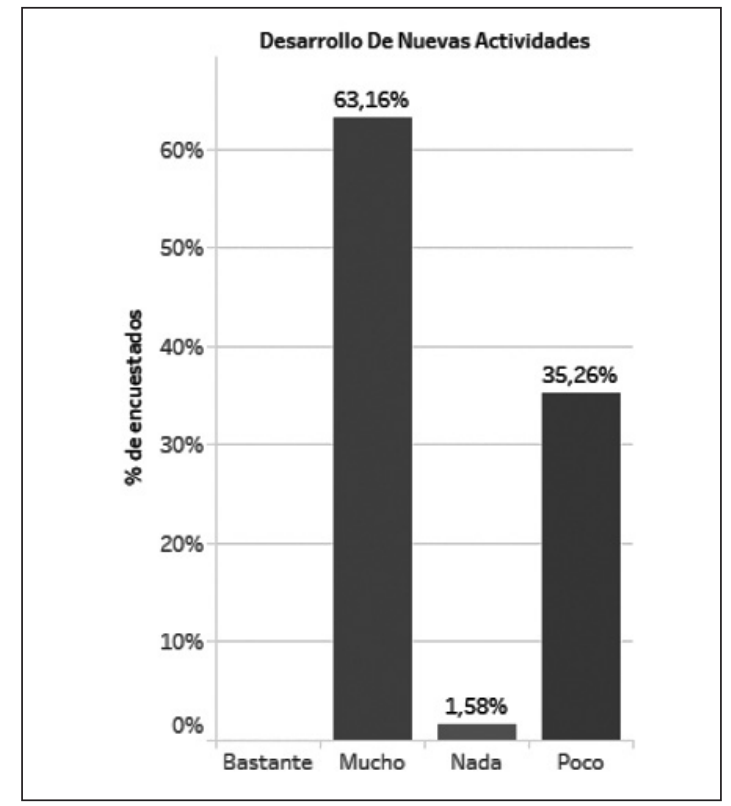

Figura 36. Desarrollo de nuevas actividades productivas

El desarrollo de fuentes de trabajo en la comunidad se encuentra en un $51,58 \%$ de aceptabilidad, puesto que la población aporta para la operación de las actividades turísticas y no solamente con el Tren Crucero sino en general con la actividad turística comunitaria implementada (Figura 37).

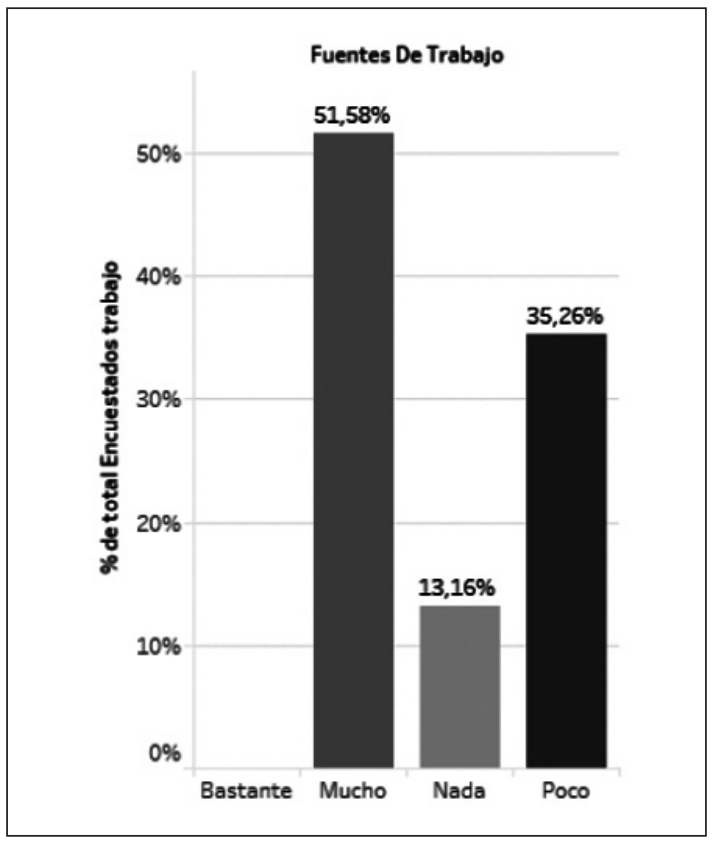

Figura 37. Desarrollo de nuevas fuentes de trabajo. 
Con respecto a los ingresos un 46,84\% manifiesta que es poco lo desarrollado en relación al tema de nuevos ingresos a la economía familiar por estar vinculados al proyecto Tren Crucero (Figura 38). Por ello la comunidad busca otras formas de ofertar nuevos productos para su desarro1lo. En la actualidad la comunidad se encuentra trabajando junto con ONGs para la realización de un centro de rehabilitación con llamas para personas que necesiten de este tipo de servicio. A pesar que la mayoría de la población aún se dedica a la comercialización de productos agrícolas, los que no generan grandes ganancias, pero ayudan a mejorar la economía familiar.

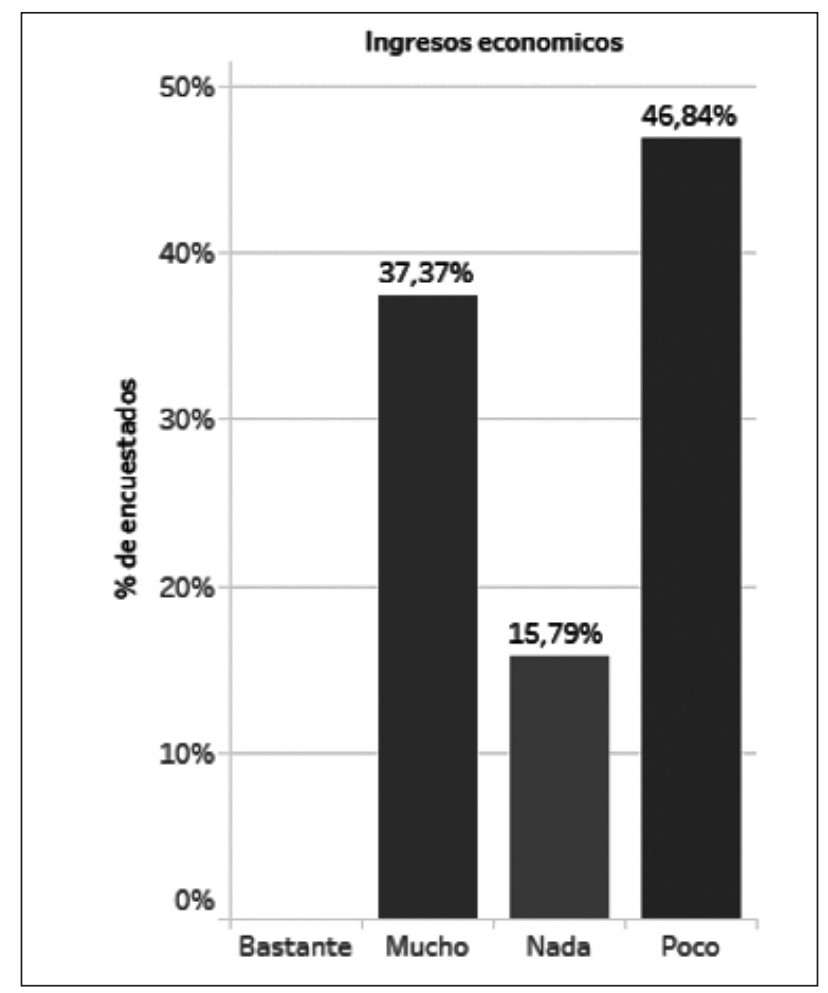

Figura 38. Nuevos ingresos económicos.

\subsection{Resumen de encuestas}

La percepción de los habitantes de la comunidad Palacio Real con respecto a los diversos beneficios de la vinculación al proyecto turístico es positiva pues la comunidad se encuentra en su mayoría contenta con lo generado con la vinculación. Pero a pesar de ello aún existen varios parámetros que no han sido tomados en cuenta para mejorar este enlace existente entre la empresa y la comunidad. La primera es la poca integración que existe de FEEP con la comunidad, la que a pesar de su ayuda con el envío de turistas y consumo de sus productos no ha logrado generar un ambiente propicio para interrelacionarse con sus habitantes. Otro de los factores que se detecta es el débil desarrollo local que se ha producido en la comunidad a pesar de la integración de la mayoría de familias de la misma, por lo que la cadena de valor local que se encuentra instaurada en la población es muy débil aún.

En las dos comunidades se encuentra un tema repetitivo que llama la atención como es el caso de las preguntas respecto al buen vivir relacionado con la migración, fuentes de empleo, nuevas actividades productivas y la generación de fuentes de trabajo. Los resultados son semejantes no solo en las dos comunidades sino también en diferentes estudios realizados en otras comunidades del país como es el caso de Shandia, Yunguilla, Salinas de Bolívar las que manifiestan también que el turismo comunitario implementado ha generado cierto desarrollo, pero no es el deseado (Cabanilla, 2016, p. 340). A pesar de los esfuerzos aún no se ha logrado detener en su totalidad la migración de la población que en su mayoría son jóvenes y que la actividad llegue a ser fuente principal de la economía de las comunidades.

Al finalizar el análisis surge la reflexión acerca de que no necesariamente una comunidad debe estar vinculada con una empresa pública para su desarro1lo, sino que con otros mecanismos esta comunidad en concreto ha logrado lo que el Tren Crucero y FEEP no han podido. 
3.5. Diferencias y semejanzas de las comunidades estudiadas con la vinculación y el impacto del producto turístico Tren Crucero

Al término del análisis de las encuestas implementadas es necesario realizar las respectivas consideraciones de diferencias y semejanzas que se han encontrado en la investigación de campo (Tabla 2), la cual fue de suma importancia para observar la realidad de las comunidades y con base en estas se pueda extraer información de importancia para poder apreciar de forma general cómo se han desarrollado dos comunidades indígenas que se encuentran vinculadas con el producto Tren Crucero.

Tabla 2. Comunidad Nizag vs. Comunidad Palacio Real

\begin{tabular}{|c|c|c|}
\hline \multicolumn{2}{|c|}{ Diferencias } & Semejanzas \\
\hline Comunidad Nizag & Comunidad Palacio Real & Comunidad Nizag vs. Comunidad Palacio Real \\
\hline \multicolumn{3}{|c|}{ 1. Composición de edades } \\
\hline No hay diferencias & & $\begin{array}{l}\text { Las poblaciones estudiadas se encuentran en un rango de } \\
\text { edad de } 25-44 \text { años, resultados que se encuentran acordes } \\
\text { con parámetros registrados por INEC } 2010 \text {. }\end{array}$ \\
\hline \multicolumn{3}{|c|}{ 2. Composición de género } \\
\hline No hay diferencia & & $\begin{array}{l}\text { Las comunidades muestran rasgos idénticos referente al } \\
\text { porcentaje de mujeres que componen las comunidades, } \\
\text { pues según datos del INEC } 2010 \text {, la población de mujeres } \\
\text { en las zonas rurales es mayor siendo una característica } \\
\text { común en Ecuador. }\end{array}$ \\
\hline \multicolumn{3}{|c|}{ 3. Número de personas que componen el hogar } \\
\hline No hay diferencia & & $\begin{array}{l}\text { Los integrantes del hogar superan las } 5 \text { personas, por lo } \\
\text { que los datos se encuentran en concordancia con resulta- } \\
\text { dos del INEC (2010), que indica que en las zonas rurales } \\
\text { las familias son numerosas. }\end{array}$ \\
\hline
\end{tabular}

4. ¿Cuánto conoce sobre el funcionamiento de los emprendimientos turísticos de la comunidad con el Tren Crucero?

\begin{tabular}{|c|c|c|}
\hline & $\begin{array}{l}\text { La comunidad al tener implementado el } \\
\text { Centro Turístico Comunitario Sumay Kaw- } \\
\text { say, vincula a la idea del Tren Crucero como } \\
\text { un proveedor más y el conocimiento del } \\
\text { mismo es como emisor de turistas. }\end{array}$ & $\begin{array}{l}\text { Tanto la comunidad Nizag como Palacio Real no tienen } \\
\text { conocimiento respecto al funcionamiento de los empren- } \\
\text { dimientos turísticos. }\end{array}$ \\
\hline $\begin{array}{l}\text { Referente a esta co- } \\
\text { munidad, no tiene co- } \\
\text { nocimiento acerca del } \\
\text { Tren Crucero ya que la } \\
\text { vinculación producida } \\
\text { se encuentra registrada } \\
\text { como asociaciones y } \\
\text { no como un Centro de } \\
\text { Turismo Comunitario } \\
\text { (CTC), por lo que los } \\
\text { conocimientos de la } \\
\text { actividad solo llegan a } \\
\text { personas puntuales de } \\
\text { las asociaciones. }\end{array}$ & $\begin{array}{l}\text { Genera informes respecto a las actividades } \\
\text { con el Tren Crucero, pues en las asambleas } \\
\text { manifiestan el estado del Centro Turístico } \\
\text { Comunitario por lo que el tema del tren se } \\
\text { encuentra adherido al tema en discusión. }\end{array}$ & No hay semejanzas \\
\hline
\end{tabular}




\section{6. ¿Cuán satisfecho está usted con los logros obtenidos por los emprendimientos turísticos que se ha generado en torno al} Tren Crucero?

Nizag por su parte se encuentra insatisfecha con los logros obtenidos, ya que perciben al Tren Crucero como agente desconocido, el cual no ha generado impacto en la población.
La comunidad se encuentra satisfecha por los logros obtenidos, ya que en su caso con la implementación del turismo en la comunidad se ha evidenciado cambios positivos, pero los logros obtenidos han sido por el turismo en general que se ha desarrollado en el lugar por lo que Tren Crucero solo es tomado como un proveedor más que genera emisiones de forma esporádica.
No hay semejanzas

7. ¿Se auspician actividades recreativas como juegos, concursos, deportes, etc. por parte de FEEP en la comunidad?

No hay diferencias

No existe vinculación con la comunidad respecto a las actividades recreativas, ya que las dos poblaciones indican que desconocen de esta actividad.

8. La vinculación de las comunidades al proyecto Tren Crucero ¿Ha ayudado a mejorar vías de acceso?

9. La vinculación de las comunidades al proyecto Tren Crucero ¿Ha ayudado a mejorar medios de transporte?

10. La vinculación de las comunidades al proyecto Tren Crucero ¿Ha avudado a mejorar servicios de salud?

11. La vinculación de las comunidades al proyecto Tren Crucero ¿Ha ayudado a mejorar servicios educativos? *

Las comunidades estudiadas manifiestan que la vinculación al Tren Crucero no ha generado ningún beneficio respecto a vías de acceso, medios de transporte, salud y educación.

12. ¿Cree usted que la rehabilitación del Tren Crucero y la vinculación con la comunidad ha mitigado la migración de los habitantes?

Nizag indica que la mitigación de la migración es nula ya que no se ha generado suficientes fuentes de empleo necesarias para frenar esta situación
Mientras que Palacio Real manifiesta que se ha mitigado en cierta manera la migración, pero esto se debe al desarrollo del CTC por lo que el Tren Crucero es solamente un elemento más para la disminución de la migración.
No hay semejanzas

\section{La vinculación con el proyecto turístico ¿Ha ayudado a que se desarrollen nuevas actividades productivas como es el caso} de artesanías, ganadería, etc.?

No hay diferencias
Las dos comunidades concuerdan que se ha generado nuevas actividades productivas puesto que, dependiendo de los productos comercializados, la comunidad participa de forma directa o indirecta, pero a pesar de aquello aún la producción económica es deficiente.

14. La vinculación al proyecto turístico ¿Ha ayudado a que se desarrollen nuevas fuentes de trabajo? 


\begin{tabular}{|c|c|c|}
\hline $\begin{array}{l}\text { Nizag al estar frag- } \\
\text { mentado en asociacio- } \\
\text { nes que trabajan con } \\
\text { FEEP, el desarrollo de } \\
\text { fuentes de empleo es } \\
\text { poca ya que solamen- } \\
\text { te existen ciertas pla- } \\
\text { zas de trabajo para un } \\
\text { cierto porcentaje de la } \\
\text { población. }\end{array}$ & $\begin{array}{l}\text { Al contrario, en Palacio Real, la evaluación } \\
\text { fue positiva lo que indica que sí se han desa- } \\
\text { rrollado fuentes de trabajo, pero esto se debe } \\
\text { a la influencia producida por el CTC. }\end{array}$ & No hay semejanzas \\
\hline
\end{tabular}

15. La vinculación con el proyecto turístico ¿Ha ayudado a generar nuevos ingresos económicos en las familias de la comunidad?

\begin{tabular}{|c|c|c|}
\hline & No hay semejanzas & $\begin{array}{l}\text { Tanto Palacio Real como Nizag indican que los ingresos } \\
\text { por el producto turístico son pocos y no benefician a la } \\
\text { economía familiar. }\end{array}$ \\
\hline $\begin{array}{l}\text { La comunidad depende } \\
\text { del Tren Crucero y los } \\
\text { recorridos de la ruta } \\
\text { Nariz del Diablo para } \\
\text { poder comercializar } \\
\text { sus productos. }\end{array}$ & $\begin{array}{l}\text { La comunidad es un órgano independiente } \\
\text { del producto turístico Tren Crucero, puesto } \\
\text { que es considerado solamente como un pro- } \\
\text { veedor más para la comercialización de sus } \\
\text { productos. }\end{array}$ & No hay semejanzas \\
\hline $\begin{array}{l}\text { La actividad turística } \\
\text { en la comunidad se en- } \\
\text { cuentra aún en una fase } \\
\text { de implementación a } \\
\text { pesar de trabajar con } \\
\text { FEEP desde 2012. }\end{array}$ & $\begin{array}{l}\text { La actividad turística en la comunidad Pala- } \\
\text { cio Real se encuentra en fase de desarrollo, } \\
\text { la cual ha sido gestionada por la misma co- } \\
\text { munidad. }\end{array}$ & $\begin{array}{l}\text { Las dos comunidades han recibido ayuda para su desarro- } \\
\text { llo por parte de ONGs y en menor escala de instituciones } \\
\text { públicas. }\end{array}$ \\
\hline $\begin{array}{l}\text { La comunidad Nizag } \\
\text { no recibe a los turistas } \\
\text { en su comunidad, sino } \\
\text { que en la estación Na- } \\
\text { riz del Diablo realizan } \\
\text { las diferentes activida- } \\
\text { des por el lapso de } 20 \\
\text { min que el Tren Cruce- } \\
\text { ro para en el lugar. }\end{array}$ & $\begin{array}{l}\text { La comunidad Palacio Real recibe a los tu- } \\
\text { ristas en su comunidad por alrededor de } 1 \\
\text { hora y media en la cual son atendidos por los } \\
\text { comuneros. }\end{array}$ & No hay semejanzas \\
\hline
\end{tabular}

\subsection{Resumen de análisis de informes de FEEP}

Para la complementación de la información que se ha estado analizando en este estudio se procedió a estudiar los últimos informes de la empresa, la cual proporciona datos de cómo se ha ido desarrollando el producto turístico en los últimos años y el impacto generado. Se ha tomado en consideración estos informes publicados vía internet para su análisis puesto que es importante saber acerca de la contraparte, ya que se debe tener presente que la actividad se genera en un solo conjunto que involucra tanto a la comunidad como a la empresa pública.

En primer lugar, al no obtener respuestas positivas por parte del área de comercialización del pro- 
ducto turístico Tren Crucero, al intentar conseguir una entrevista para conocer su percepción acerca del trabajo que se realiza con las comunidades se procedió a analizar documentos de rendición de cuentas de los últimos 4 años. La información se encuentra en la página principal de la empresa pública, aunque solamente se pudo obtener los 3 últimos reportes ya que el correspondiente al 2017 no se encontraba disponible hasta el momento de este análisis. En general todos los informes indican el desarrollo que se ha producido durante estos años con respecto a las rutas turísticas implementadas y los impactos generados en las poblaciones por las que atraviesa. Es decir que respecto al Tren Crucero en la información recopilada se asegura que el producto es un éxito total, al ser uno de sus productos estrellas y más costoso ha ayudado al desarrollo local comunitario.

\section{Discusión: expectativa vs. realidad}

Al tener el análisis de las dos partes que se encuentran involucradas en este estudio se evidencia que la realidad es muy lejana a lo que asegura FEEP con respecto al desarrollo local comunitario. Surge la reflexión de que las comunidades a pesar de estar involucradas con el producto turístico y de pertenecer el mismo tiempo, se han desarrollado de manera muy diferente.

En el caso de Nizag su desarrollo es nulo ya que la población ha creado en cierta manera dependencia del producto turístico por lo que todas sus actividades están sujetas en torno a este. Pero, ¿qué pasaría si el tren dejara de operar con la comunidad? ¿Existe acaso estudios acerca de cómo mitigar este impacto si llegara a pasar? ¿Cuál sería el futuro de la comunidad o mejor dicho de las asociaciones?

Por otro lado, la comunidad Palacio Real tiene desarrollo local visible, pero este no es por la vinculación al Tren Crucero, sino que la comunidad ha llevado a cabo su propio proyecto turístico, en el cual el Tren Crucero es considerado como proveedor estratégico para el aumento en el ingreso de turistas. $\mathrm{Si}$ FEEP dejara de trabajar con la comunidad el impacto económico no sería tan importante y la comunidad seguiría desarrollándose por sus propias gestiones.

Las conclusiones están basadas en las encuestas realizadas, ya que como se ha indicado es evidente la desigualdad que existe en el desarrollo, la poca o nula ayuda generada por la empresa y la falta de compromiso por parte de los elementos implicados.

La empresa pública FEEP proporciona dinero a la comunidad por sus servicios, pero esto no significa que por ello exista vinculación con la empresa y ayu- de a la mejora de calidad de vida de la zona. En este contexto se debe ver cuál es el concepto generado por la FEEP, acerca de ¿qué es desarrollo local y calidad total?, ya que tomando en consideración la Constitución ecuatoriana y el Plan Nacional de Desarrollo la consideración de estos conceptos y los parámetros que indican para su desarrollo evidentemente no son compatibles con los resultados que se han obtenido.

Ahora bien, si tomamos en consideración conceptos de desarrollo local comunitario la población debe ser quien administre, gestione y ejecute las actividades turísticas y no dependa de una sola organización para su desarrollo. Es decir, debe ser un órgano independiente, el cual debe, con ayuda de agentes externos como sería el caso de empresas públicas y privadas, conseguir establecer estrategias importantes para su desarrollo.

Con la mejora de la vida de las comunidades en los ámbitos de educación, salud, vías de acceso, transporte, que satisfagan sus necesidades básicas, se da paso a la evaluación de calidad; ya que al hablar de calidad primero debemos enfocarnos en que las comunidades se encuentren en ambientes propicios para su desarrollo. Al encontrarse vinculadas con empresas públicas o privadas lo que desean ciertamente es conseguir elementos que les permitan tener un Buen Vivir. Es decir, acciones que cumplan lo que dispone la Constitución ecuatoriana que se sintetizan en:

- Mejorar la calidad y esperanza de vida.

- Aumentar las capacidades y potencialidades de la población.

- Construir un sistema económico, justo, democrático, productivo, solidario y sostenible basado en la distribución igualitaria de los beneficios del desarrollo, de los medios de producción y en la generación de trabajo digno y estable.

- Fomentar la participación y el control social.

- Recuperar y conservar la naturaleza y mantener un ambiente sano y sustentable.

- Garantizar la soberanía nacional, promover la integración latinoamericana e impulsar una inserción estratégica en el contexto

\section{Conclusiones}

El desarrollo local comunitario es el objetivo de todos los proyectos comunitarios que se imple- 
mentan en las poblaciones, alcanzar el éxito de esto implica gran trabajo, determinación y, sobre todo, involucramiento de todos los habitantes. Las zonas vulnerables que se encuentran en el territorio ecuatoriano necesitan tener alternativas viables para poder desarrollar su economía, siendo de este modo el turismo comunitario una de las opciones a implementar para buscar las mejoras de vida.

En los últimos años se ha producido gran cantidad de información referente al desarrollo que ha tenido Ecuador acerca de la dinamización de economías de zonas más necesitadas, incorporando para esto al turismo como alternativa viable para el desarrollo de zonas rurales. Ecuador es un país pluricultural, megadiverso, con fuentes naturales suficientes para el desarrollo de atractivos y productos turísticos, los cuales para un futuro no muy lejano se espera sean un recurso económico principal del país.

El primer objetivo específico planteado en la investigación era analizar la gestión y operación turística de Ferrocarriles Ecuador, de esto se obtuvo como resultado que la empresa pública abarca toda la responsabilidad de las actividades rezagando a las comunidades a espectadores de la experiencia turística, en la cual no se puede hablar de vinculación y mucho menos de desarrollo. La empresa ha creado burbujas de comunicación, las cuales son incorporadas por personas elegidas en donde las únicas beneficiadas son las integrantes de las mismas, respuesta que no se encuentra acorde con los objetivos de la empresa y de los proyectos desarrollados para mitigar los problemas de las comunidades involucradas. La idea general según rendición de cuentas de la empresa FEEP era la realización de proyectos turísticos inclusivos para poder implementar los objetivos que plantean tanto la Constitución como el Plan Nacional para el Buen Vivir. Pero en la práctica la realidad es diferente, ya que se evidencia que dichos proyectos lejos de ser inclusivos, no han tenido la guía adecuada para su planificación y, por consiguiente, la ejecución no es la deseada. Al término de esta investigación se evidencia que la implementación del proyecto Tren Crucero para ayudar al desarrollo local de las comunidades no ha llegado a generar el impacto deseado.

Por otro lado, en el objetivo específico dos se propuso investigar el desarrollo del turismo en las poblaciones por las que atraviesa el Tren Crucero: Nizag y Palacio Real, comunidades que fueron seleccionadas por encontrarse en la provincia de Chimborazo lugar donde según datos del INEC se encuentra concentrada la mayor parte de pobreza extrema del país, estableciéndose el estudio en las poblaciones de Nizag y Palacio Real por ser consideradas extremos opuestos en lo referente a la actividad turística. Ya que en el transcurso de la investigación se evidenció que independientemente de la vinculación con el Tren Crucero las comunidades gestionaban las actividades para el desarrollo de manera diferente. En el caso de Palacio Real esta es conocida a nivel turístico, mientras que en el caso de Nizag la comunidad es desconocida en este ámbito. Por tal razón, el interés surgió porque al ser tan diferentes y manejadas de distinta manera a nivel turístico se requería analizar ¿cómo se desarrollaron las comunidades con la vinculación al producto Tren Crucero? y si esta acción generó el inicio del desarrollo de Nizag y la consolidación de Palacio Real dentro de las actividades turísticas del país.

Al hablar de la comunidad de Nizag se evidencia que no existe desarrollo en ninguna forma, ya que la población se encuentra excluida del proyecto turístico en el cual la comunidad ha puesto esperanzas para mejorar su calidad de vida. Si no se extiende los beneficios a todos y la comunidad no genera informes acerca de las actividades no se puede considerar como una labor comunitaria sino como micro empresas. Así pues, el resultado ha sido la insatisfacción total por los logros que querían obtener con ayuda de la vinculación, dando paso a la inconformidad por el trabajo que realiza FEEP.

Respecto a la comunidad Palacio Real su realidad es muy diferente ya que aquí se ha promovido el desarrollo comunitario. A pesar de estar vinculada al trabajo de operación con el Tren Crucero, este no ha aportado de forma significativa al progreso de la zona, por lo cual la comunidad ha encontrado vías alternas, que han generado mayor impacto en la población para mejorar su calidad de vida, ya que es un órgano independiente en la que se evidencia que realmente existe la organización comunitaria de un Centro Turístico, en donde la asociación con FEEP es considerada una alianza estratégica que tiene como fin el promover y mejorar la experiencia turística en la comunidad.

Las dos comunidades no han registrado un evidente desarrollo con la vinculación al tren, más bien se ha generado cierto malestar e incertidumbre sobre cuál será el futuro con referencia a la vinculación con el producto turístico Tren Crucero. En consecuencia, en este estudio se propone lineamientos operativos para mejorar la contribución en las comunidades por parte de FEEP y el Tren Crucero a fin de que tenga un impacto positivo real, en esta y en todas las comunidades implicadas en su ruta.

Los lineamientos planteados están basados en la guía de buenas prácticas turísticas, en la que la OMT insta a que las instituciones tanto públicas como privadas generen proyectos que ayuden al desarrollo de las comunidades. Así también, en el ámbito interno, en el Ecuador tanto la Constitución como el Plan Nacional para el Buen Vivir exigen 
que se dé una vinculación real con las comunidades, las cuales también se encuentran amparadas bajo la FEPTCE que regula y trata de que se maneje de forma equitativa en las comunidades las actividades turísticas. Los lineamientos son recomendaciones de cómo debería ser realmente la empresa FEEP y qué debe considerar como importante al realizar proyectos sostenibles con involucramiento social.

Para concluir, la hipótesis planteada al inicio del estudio se cumple medianamente, ya que la vinculación no ha generado el beneficio esperado a las comunidades dejando como es el caso de la población de Nizag incertidumbre acerca de su futuro y en Palacio

\section{Referencias}

Alburquerque, F. (2004a). Desarrollo económico local y descentralización en América Latina. Revista de la Cepal. 82, 157-171.

Alburquerque, F. (2004b). El enfoque del desarrollo económico local. Cuaderno de capacitación: Desarrollo económico local y empleabilidad. Argentina: Programa AREA- IOT en Argentina.

Ander-Egg, E. (2005). Metodología y práctica del desarrollo de la comunidad. 2da edición, Buenos Aires: Editorial Lumen Hvmanitas.

Arias, H. (2003). Estudio de las comunidades. En Portal, R., \& Recio, M. (comp.), Comunicación y comunidad. La Habana: Editorial Félix Varela.

Arocena, J. (2001). Capítulo IX: Una investigación de procesos de desarrollo local. En El desarrollo local. 201-229. Montevideo: Ediciones Santillana.

ALAF, Asociación Latinoamericana de Ferrocarriles. (2000). Tren Turístico. Buenos Aires, Argentina. Obtenido en: www.alaf.int.ar/?pag=revista\&id $=165$

Ayala Mora, E. (2008). Resumen de Historia del Ecuador. Quito: Corporación Editora Nacional.

Barbini, B., Cruz, G., Roldán, N., \& Cacciutto M. (2012). Modelos de desarrollo e implicancias en el turismo: un análisis histórico. Registros, 9, 117-120.

Barquín, R. (2013). El turismo y los primeros ferrocarriles españoles (1855-1900). TST, 24, 110-136.
Real el cuestionamiento de si su alianza estratégica funcionará favorablemente a largo plazo. En el caso del involucramiento de actores, se evidencia la presencia de varios para la implementación del proyecto en las comunidades, como es el caso del Ministerio de Turismo y algunas ONGs, pero no se han realizado actividades contundentes que ayuden a las comunidades. Al término de la investigación se puede decir que los proyectos estatales pueden y deben generar mejoras en los proyectos que se implementan en zonas vulnerables del país, ya que si la planificación, organización y ejecución son adecuados pueden llegar a ser una alternativa viable para el desarrollo local.

Barreno, A. (2015). La rehabilitación del ferrocarril en Ecuador, como actor transformador en el territorio. En De la Riva, J. (Ed.), Análisis espacial y representación geográfica: innovación y aplicación. España: Universidad de Zaragoza.

Bayas Escudero, J. P., Avellán Loor, W. A., \& Bermúdez Revelo, A. M. (2014). Plan estratégico de turismo rural sostenible de las parroquias San Isidro y Charapotó-Manabí, Ecuador. Revista ESPAMCIENCIA, 6(2), 87-95.

BioBioChile. (2015). Autoridades dan a conocer trenes turísticos para el periodo estival. Obtenido de: https://www.biobiochile.cl/noticias/2015/01/16/ autoridades-dan-a-conocer-trenes-turisticos-para-el-periodo-estival.shtml

Boiser, S. (1999). Desarrollo (Local). ¿De qué estamos hablando? En Madoery, O., \& Vázquez Barquero, A. (eds.), Transformaciones globales, instituciones y politicas de desarrollo local. Buenos Aires: Editorial Homo Sapiens, Rosario.

Boisier S., \& Canzanelli G. (2009). Local Economic Development and Globalization.Universitas Forum $N^{\circ} 1$

Burneo, S. (2009). Megadiversidad. Pontificia Universidad Católica del Ecuador

Cabanilla, E. (2011). Metodología para elaborar un estudio por encuestas de la satisfacción del turista: Aplicación Quito, Ecuador. RICIT: Revista Turismo, Desarrollo y Buen Vivir, 2, 8-26. 
Cabanilla, E. (2014). Desarrollo del turismo comunitario en Ecuador, bajo el paradigma de la complejidad desde la perspectiva local del SumakKawsay. Revista BioScriba, 7(1), 30-49.

Cabanilla, E. (2016). Configuración socio-espacial del turismo comunitario, caso República del Ecuador. Universidad Nacional del Sur. Bahía Blanca.

Carrera, J. (2012). Incidencia de la rehabilitación de Ferrocarriles del Ecuador en el desarrollo local de las comunidades atravesadas por la vía férrea. Universidad Politécnica Salesiana. Quito.

Casanova, F. (2004). Desarrollo local, tejidos productivos y formación. Abordajes alternativos para la formación y el trabajo de los jóvenes. Montevideo: CINTERFOR.

Conesa Fernández-Vítora, V., Conesa Ripoll, L. A., Conesa Ripoll, V., Bolea, E., Teresa, M., \& Ros Garo, V. (2009). Guía metodológica para la evaluación del impacto ambiental. Mundi-Prensa.

Consorcio de juntas parroquiales rurales de Chimborazo. (2015). Actualización del plan de desarrollo y ordenamiento territorial. Parroquia Santiago de Calpi. Calpi: GAD de Calpi.

Elkington, J. (1997). Cannibals with forks: The triple bottom line of 21 st Century Business. Capstones.

El Ciudadano. (2009). El Tren Ecuador y su ruta de premios internacionales. 15 de abril de 2014.

Fernández, M. (2011). Turismo comunitario y empresas de base comunitaria turísticas. ¿Estamos hablando de lo mismo? (Ensayo). El Periplo Sustentable, 20, 31-74.

FEEP, Ferrocarriles Ecuador Empresa Pública. (2015). Tren Crucero. Un viaje de Quito a Durán.

FEEP, Ferrocarriles Ecuador Empresa Pública. (2016). Rendición de cuentas. Quito: FEEP

Formichella, M.M. (2004). El concepto de emprendimiento y su relación con el empleo, la educación y el desarrollo local. VII Congreso Nacional e internacional de Administración, y XI CONAMerco (Congreso de Administración del MERCOSUR).
Fuller, N. (2011). Reflexiones sobre el turismo rural como vía de desarrollo. El caso de la comunidad de Antioquía, Perú. Estudios y Perspectivas en Turismo, 20(4), 929-942.

Hernández, R., Fernández, C., \& Baptista, M. (2010). Metodología de la investigación. Quinta Edición. México. D.F.: McGraw-Hill / Interamericana Editores, S.A. DE C.V.

INEC, Instituto Nacional de Estadística y Censos. (2010). Fascículo Provincial Chimborazo. Ecuador: INEN.

Juárez, G. (2013). Revisión de conceptos de desarrollo local desde una perspectiva territorial. Revista Lider, 23, 9-28.

Lickorish, L. \& Jenkins, C. (1997). Una introducción al turismo. Madrid: Síntesis.

Linares, H., \& Morales Garrido, G. (2014). Del desarrollo turístico sostenible al desarrollo local. Su comportamiento complejo. Pasos. Revista de Turismo y Patrimonio Cultural, 12(2), 453-466.

MINTUR, Ministerio de Turismo del Ecuador. (2015). Ecuador ama la vida. Obtenido de: http://www.turismo.gob.ec/tag/wta-2015/

MINTUR, Ministerio de Turismo del Ecuador. (2017). Boletín Mensual de Estadisticas Turísticas 2016-2017.Quito: MINTUR.

Múnera, M. (2007). Resignificar el desarrollo. Escuela del Hábitat. Universidad Nacional de Colombia.

OMT, Organización Mundial de Turismo. (2004). Desarrollo Sostenible del Turismo - OMT. OMT

OMT, Organización Mundial de Turismo. (2017a). Panorama OMT del turismo internacional, edición 2017. OMT

OMT, Organización Mundial de Turismo.(2017b).El turismo internacional mantiene un crecimiento sostenido pese a las dificultades. Obtenido de: https:// www2.unwto.org/es/press-release/2017-01-17/ el-turismo-internacional-mantiene-un-crecimiento-sostenido-pese-las-dificul

Pacheco, F. (2010). Evaluación del impacto social del proyecto social "Laúd y Guayabera". Universidad Pinar del Río. Cuba. 
Patiño, A. (2016). Turismo rural comunitario como estrategia de desarrollo local para el municipio de Mejía. Universidad de Buenos Aires.

Paz y Miño, J. (2011). La época cacaotera en el Ecuador. Historia y Economía, 3, 5-15.

Pearce, D. G., \& Butler, R. (eds.). (1999). Contemporary issues in tourism development (Vol. 6). Psychology Press.

Pérez de las Heras, M. (2004). Manual de turismo sostenible. Madrid: Ediciones Mundi-Prensa.

Pérez Lao, A. (2008). El papel de la innovación en el desarrollo económico. ¿Inversión o gasto? En Moya-Angeler Cabrera, J., Innovación y desarrollo económico (pp. 35-49). Almería: Fundación Cajamar.

Picas, J. (1999). La construcción social del subdesarrollo y el discurso del desarrollo. En Los límites del desarrollo. Barcelona: Icaria.

Pichardo Muñiz, A. (1991). Evaluación del impacto social: Una metodología alternativa para la evaluación de proyectos (No. INVES-ET E50 P591). Costa Rica: Ed. Universidad de Costa Rica.

Podestá, E. (1999). Estudio de la gestión ambiental en la microregión del Rosario. Programa Desarrollo Local del Centro Latinoamericano de Economía Humana (CLAEH), Serie Desarrollo local en América Latina $\mathrm{N}^{\circ} 4$, Montevideo.

Porter, M. (2007). La ventaja competitiva de las Naciones. Harvard Business Review, 85(11), 69-95.

Ruiz, E., \& Cantero, P. (2011). Entre Darwin, la baronesa y el cucuve. El desarrollo del turismo de base local en Floreana (Galápagos). Pasos. Revista de Turismo y Patrimonio Cultural, 5, 63-77.

Ruiz, E., \& Solis, D. (2007). Turismo Comunitario en Ecuador. Desarrollo y sostenibilidad social. Quito: Abya-Yala.

Ruiz, E., Hernández, M., Coca, A., Cantero, P., \& Campo, A. D. (2008). Turismo comunitario en Ecuador. Comprendiendo el community-based tourism desde la comunidad. Pasos. Revista de turismo y patrimonio cultural, 6(3), 399-418.

Sancho, A. (2004). Turismo y desarrollo. Universidad de Valencia. Jornadas Internacionales de Turismo Justo: un reto para el desarrollo. Ob- tenido de: https://www.uv.es/ sancho/Turismo\%20y\%20desarrollo.pdf

Sancho, A. (2005). La sostenibilidad turística en la Comunidad Valenciana: Oportunidades, barreras y perspectivas de futuro. Hacia la sostenibilidad del sector turístico valenciano. Conselleria de Territori i Habitatge. Fundación Entorno.

Sancho, A.; García, G.; Pedro, A., \& Yagüe, R. (2001). Auditoria de sostenibilidad en los destinos turísticos. Valencia: Editorial ENE.

Santana Turégano, M. Á. (2003). Formas de desarrollo turístico, redes y situación de empleo. El caso de Maspalomas (Gran Canaria). Universitat Autònoma de Barcelona.

Savino, A. (2008). Estrategia de turismo sustentable en reservas de biosfera y sitios RAMSAR de Argentina. Buenos Aires, Argentina: Programa Naciones Unidas para el Desarrollo.

SECTUR, Secretaría de Turismo de México. (2007). Elementos para evaluar el impacto económico, social y ambiental del turismo de naturaleza en México. México: SECTUR

Sociedad Internacional de Viajeros en Ferrocarril. (2015). Sociedad Internacional de Viajeros en Ferrocarril. Los 25 trenes del mundo. Obtenido en: http://www.irtsociety.com/trains.php.

Temple, D. (2003). Las estructuras elementales de la reciprocidad. La Paz: TARI/Plural Editores.

Unda, M. (2005). Experiencias en gestión y desarrollo local. Quito-Ecuador: EDD/EZE.

Valarezo, G.R., \& Torres, V.H. (2004). El desarrollo local en el Ecuador. Historia, actores y métodos. Quito-Ecuador: Ediciones Abya-Yala.

Varisco, C. (2008). Desarrollo turístico y desarrollo local. La competitividad de los destinos turísticos de sol y playa. Universidad Nacional de Mar del Plata.

Vázquez, A. (2009). Desarrollo local, una estrategia para los tiempos de crisis. Conceptos críticos. Apuntes del Cenes, XXVIII (47), 117-132.

Villaruel, P. (2015). Tren Crucero recibe en Madrid premio a la excelencia en Fitur. El Universo, 
Obtenido de: :http://www.eluniverso.com/noticias/2015/01/27/nota/4489186/tren-crucero-recibira-madrid-premio- excelencias-fitur

White, S., \& Gasser, M. (2001). Local economic development: a tool for supporting locally owned and managed development processes that foster the global promotion of decent work. Gi- nebra: Departamento de Creación de Empleo y Desarrollo Empresarial de la OIT.

Wilmott, P. (1986). Social Networks, Informal Care and Public Policy. London: Policy Studies Institute.

Zamorano, F. (2002). Turismo alternativo. México: Editorial Trillas. 